UNIVERSIDAD DE GRANADA

MÁSTER UNIVERSITARIO EN TUTELA DEL PATRIMONIO HISTÓRICO-ARTÍSTICO. EL LEGADO DE AL-ÁNDALUS

\author{
TRABAJO FIN DE MÁSTER
}

\title{
Cultura y mitología vikinga en los medios de masas contemporáneos: cómic, series de TV y videojuegos.
}

Presentado por:

D./Da . José Ángel Passolas Liébanas 
UNIVERSIDAD DE GRANADA

MASTER UNIVERSITARIO EN TUTELA DEL PATRIMONIO HISTORICO- ARTISTICO. EL LEGADO DE AL-ANDALUS

TRABAJO FIN DE MASTER

\section{Cultura y mitología vikinga en los medios de masas contemporáneos: cómic, series de TV y videojuegos.}

Tutor: Ricardo Anguita Cantero

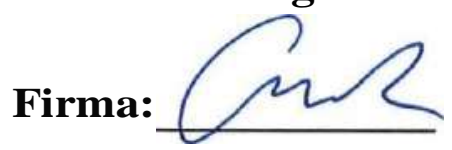




\section{Índice}

1. JUSTIFICACIÓN DEL TFM.

1

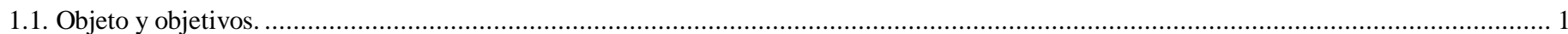

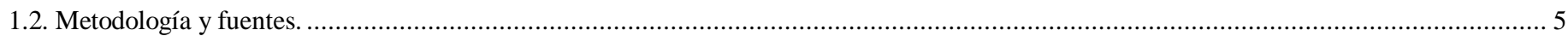

2. LA LITERATURA MEDIEVAL ESCANDINAVA: CREACIÓN DE UNA MITOLOGÍA....................................................................... 8

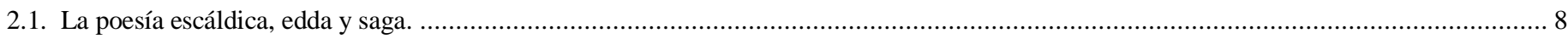

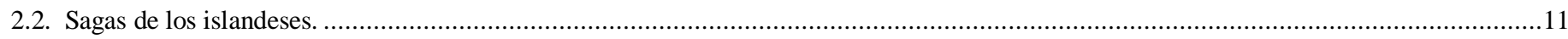

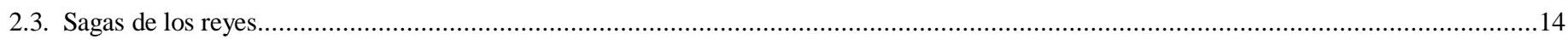

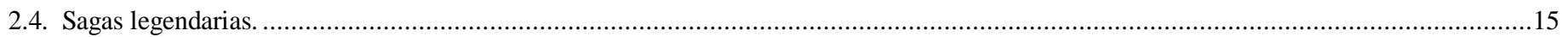

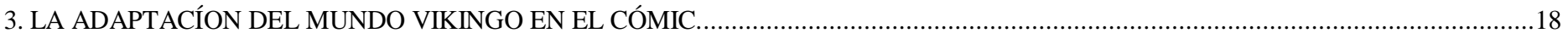

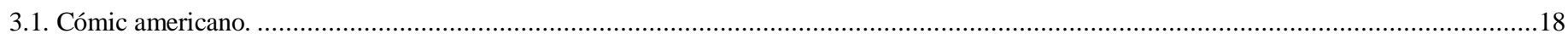

3.1.1. Un cómic fundacional: Príncipe Valiente de Harold Foster (1937) .......................................................................................19

3.1.2. Adaptación de la mitología nórdica en el universo de Marvel: Thor de Stan Lee y Jack Kirby (1962). ..........................................25

3.1.3. La representación de la cultura vikinga en el cómic americano contemporáneo: Northlanders de Brian Wood (2007)...........................35

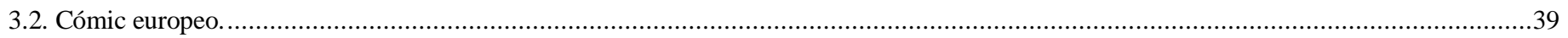

3.2.1. Primer contacto del mundo vikingo en el cómic europeo. Hans G. Kresse, el talento neerlandés: Eric de Noorman (1946).................39

3.2.2. Ragnar le Viking de Eduardo Teixeira Coelho y Jean Ollivier (1955) . ......................................................................................43

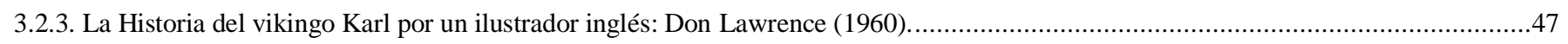

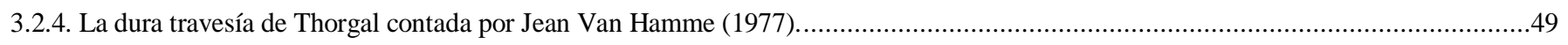

3.2.5. La versión más terrorífica del vikingo: Crónicas Bárbaras de Jean-Yves Mitton (1994).................................................................54

3.2.6. La reinvención del mito de Wagner en el cómic: Siegfried de Alex Alice (2007). ...................................................................59

3.2.7. El mundo vikingo en el cómic español: Beowulf de Santiago García y David Rubín (2013). ......................................................62

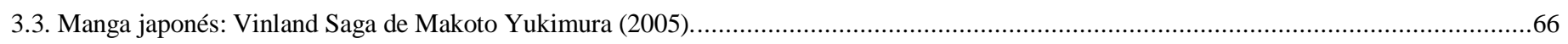

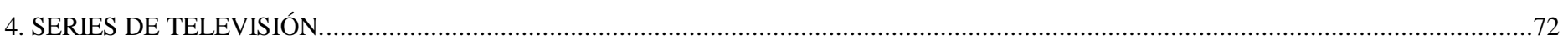

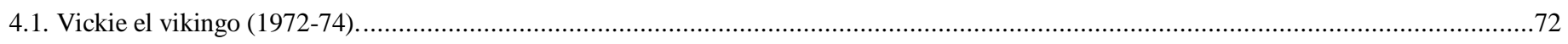

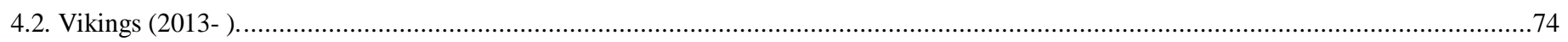

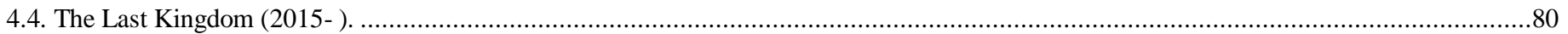

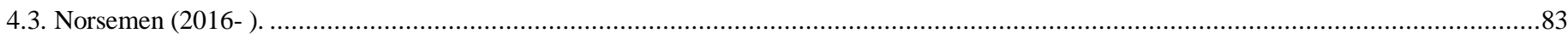

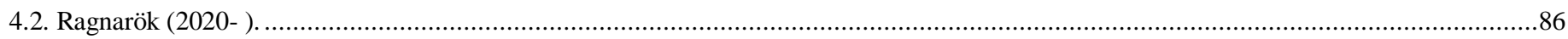

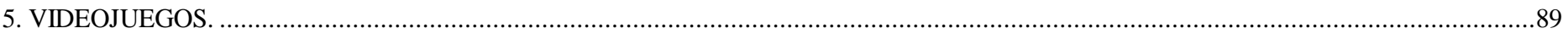

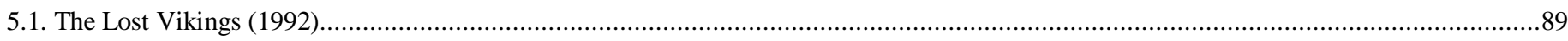

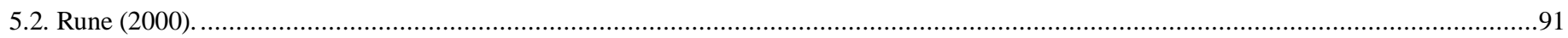

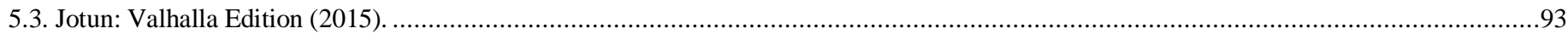

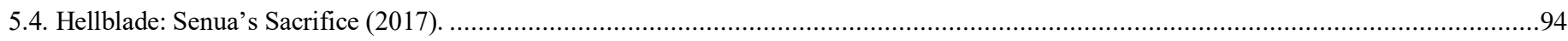

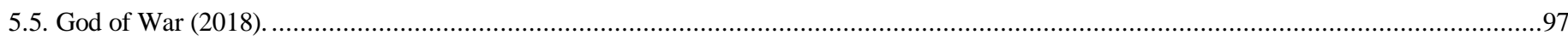

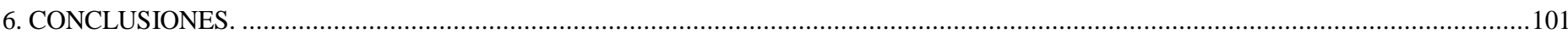

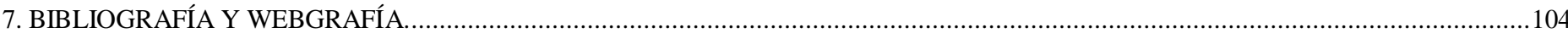

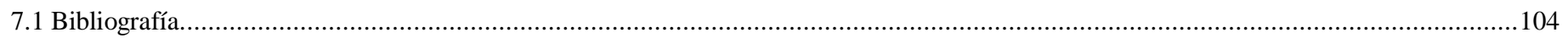

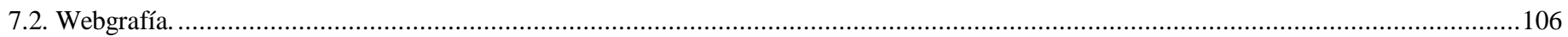




\section{Resumen}

Los medios de masas contemporáneos han dedicado a lo largo de los siglos XX y XXI cada vez mayor atención a la cultura vikinga y su mitología. Este creciente número de obras de ficción surgidas en torno a este pueblo, nos muestra una amplia y diversa visión sobre su historia, costumbres y mitos, generalmente matizados por su presentación en creaciones vinculadas al género de aventuras.

En referencia al cómic, Harold Foster será el pionero en introducir la cultura vikinga a través de su obra Principe Valiente (1937), en la que su protagonista, Val, es un vikingo que aspira a ser caballero de la Mesa Redonda sirviendo al Rey Arturo. A partir de esta obra fundacional, surgirá un número elevado de obras ambientadas en el mundo vikingo en las diversas escuelas internacionales del cómic, especialmente en la bande dessinée francobelga, donde destacan títulos como Thorgal (1977) de Jean Van Hamme y Grzegorz Rosinski, o Siegfried (2007), de Alex Alice. Por otra parte, el manga japonés desarrolló en el año 2005 una de las series que más éxito han obtenido en las últimas décadas, como lo es Vinland Saga (2005), de Makoto Yukimura. Volviendo al panorama americano, tanto las editoriales Marvel y DC, han desarrollado la mitología nórdica en sus respectivas obras, destacando en el caso de Marvel, la aparición del superhéroe Thor, inspirado en el dios asgardiano nórdico, hijo de Odín, o la popular serie de Northlanders (2009), de Brian Wood, perteneciente a Vertigo Comics, sello de DC Comics.

Siguiendo la estela del cómic, las series de TV han sido las que coincidiendo con la llegada del digital, más producciones están generando en la última década en lo relativo a la cultura vikinga, destacando la serie Vikings (2013- ), del héroe vikingo Ragnar Lothbrok, que es citado en las sagas medievales. Respecto al último medio de masas contemporáneo, los videojuegos, estos han ido generando un proceso evolutivo claro, desde prácticamente introducir la estética del vikingo sin referenciar otros aspectos desde un estudio más profundo, como es el caso del videojuego de plataformas The Lost Vikings (1992), de la compañía Silicon \& Synapse, a completar un desarrollo íntegro de la cultura vikinga y su mitología, con una saga tan destacada como lo es God of War, que en su último título (2018), decidió sumergirse en la mitología nórdica, sustituyendo la griega con la que fue concebida.

Palabras clave: Cultura vikinga, mitología vikinga, Edad Media, medios de masas, cómic. 


\section{JUSTIFICACIÓN DEL TFM.}

\subsection{Objeto y objetivos.}

La cultura nórdica, en general, ha sido una gran olvidada a lo largo de la historia. Sus estudios, sin embargo, han ido en aumento durante los últimos años, sobre todo en referencia a la figura del famoso pueblo que irrumpió en Europa a finales del siglo VIII con el ataque al monasterio de Lindisfarne, en costas inglesas, y que prácticamente sobrevivió durante un periodo de casi trescientos años. Entre ellos se encuentran los primeros trabajos sobre la historia del mundo vikingo y su arte por parte del arqueólogo danés Ole Klindt-Jensen, ocupando una investigación que corresponde a la década de los sesenta y setenta; siguiendo con los del arqueólogo británico y profesor emérito, James Graham-Campbell; los dedicados por parte del fotógrafo y escritor español, Manuel Velasco Laguna, con obras notables como Breve Historia de los Vikingos: Cultura y hazañas de los "demonios del norte", los mejores aventureros, navegantes, exploradores y mercaderes de su tiempo (2005) y Territorio Vikingo (2012); la contribución del historiador británico, John Haywood, de la mano de su libro titulado Los hombres del Norte: La saga vikinga 793-1241 (2016); la publicación del pasado año del historiador noruego, Kim Hjardar, Vikingos en guerra; o la más reciente, Eso no estaba en mi libro de historia de los vikingos (2020) de la doctora en estudios escandinavos, Irene García Losquiño.

Pero el modo en que se desarrollaron como sociedad, es imposible separarla de sus creencias y leyendas, que tuvieron su origen en los primitivos pueblos germanos, generando un corpus mitológico. Estas surgieron de forma oral, por medio de relatos que iban transmitiéndose de generación en generación. Los primeros especialistas en transmitir estas historias eran los escaldos, que eran poetas y guerreros que se encontraban al servicio de los monarcas y cuyo mayor florecimiento se halló durante los siglos IX y XII. Otras manifestaciones en el ámbito medieval, pero más de carácter popular y fundamentalmente relacionado con lo mitológico y heroico, se encontraron en los textos de la Eddas y Sagas, generalmente escritas por autores anónimos y ya adentrados en el marco cultural cristiano. 
Dos obras fundamentales que gestan la mitología nórdica aportando una visión completa sobre el proceso cosmogónico de la misma, son el Völuspá o profecía de la adivina, correspondiente al primer poema de la Edda poética, de autor anónimo, y el Gylfaginning, escrita por el escaldo islandés, Snorri Sturluson, autor de la Edda prosaica.

Esta base ha servido para configurarla dentro de la cultura popular, que por otro lado, ha encontrado en ella una indudable admiración por parte de sus consumidores, creciendo por momentos, y llegando incluso al denominado fenómeno fan. Se puede considerar como primera obra que recoge la mitología nórdica, la referente al poema épico medieval anglosajón ambientado en la Escandinavia medieval, Beowulf, estimada como una de las grandes epopeyas medievales europeas. Otra obra fundamental del siglo XIII, es la del poema épico escrito por un autor anónimo de origen austriaco titulado El cantar de los Nibelungos, historia que recoge como principal protagonista al héroe legendario Sigfrido, y que servirá para que en el siglo XIX, Richard Wagner componga Der Ring des Nibelungen (El anillo del nibelungo), un ciclo de cuatro óperas.

Asimismo, la literatura contemporánea se ha servido de la mitología nórdica y el mundo vikingo con títulos como: The Broken Sword de Poul Anderson (1954), The Weirdstone of Brisingamen: A Tale of Alderley de Alan Garner (1960); las referencias a los dioses mitológicos escandinavos en las novelas de Neil Gaiman, autor de The Sandman; o las novelas que integran la colección The Saxon Stories, del británico Bernard Cornwell. De todas ellas, la más influyente dentro de la literatura fantástica de los siglos XX-XXI, es la escrita por J.R.R. Tolkien, cuyas obras: El Hobbit (1937), El Señor de los Anillos (1955), y El Silmarillion (1977), incluyen seres propios de la mitología como son los elfos, enanos y gigantes de hielo; el nombre de Gandalf el mago, está prestado de uno de los personajes de las eddas; o el continente donde se desarrolla la acción, conocido como La Tierra Media, cuya influencia está en Midgard, el mundo de los humanos unido junto a los ocho restantes por medio de las raíces del árbol Yggdrasil.

Aunque dentro de los medios de comunicación de masas, los denominados mass media, especialmente, el cómic, cine, series de televisión y videojuegos, son los que últimamente han apostado más en este terreno. Todos ellos, han sido capaces de contar nuevas historias y dar, en muchos casos, un giro de tuerca a la mitología nórdica. El cómic 
como medio de masas que más antigüedad alberga, junto al cinematográfico, en comparación a las series o videojuegos, ha tenido la oportunidad de reflejar todo este mundo que comprende de un modo mucho más extenso, deteniéndose particularmente en la figura del vikingo, explorando en este aspectos cotidianos de su vida, motivaciones, comportamientos tanto éticos como morales, etc.

Por lo tanto, partiendo del mundo vikingo y su mitología, el presente trabajo se ocupará en analizar la visión que el creador que está detrás de la obra ha reflejado en la misma, puesto que son varias las que se han desarrollado a lo largo de las décadas, habiendo en ellas una mente creativa distinta que las expone dentro de un marco contextual, que viene dado por cuestiones tan diversas relacionadas con su autor, como la formación recibida, el ámbito socio-político en el que enmarca, intereses, etc., haciendo en cada una de ellas una obra de arte singular en sí misma. Ese sello identificativo, no solo estará en manos del creador, en el caso del cómic, sino que también gran parte de culpa lo tendrá el encargado de darle dibujo y color (en ocasiones siendo el mismo), el cual le otorgará de una expresividad y calidad distintiva, labor de la que también se le reconocerá durante dicha investigación.

Entre los citados mass media se destacarán, durante el curso de la investigación, el cómic, series de televisión y videojuegos. La atención, en primer lugar, irá dedicada a uno de los subgéneros más prolíficos del cómic histórico, los denominados cómics de "fantasía vikinga", ambientados en el mundo medieval y llenos de tintes mitológicos y leyendas nórdicas. Una vez sentadas las bases de la leyenda y mito escandinavo, se hará un repaso a través de los autores y obras más relevantes respecto al citado género, con mención especial a la obra fundacional de Harold Foster, "Príncipe Valiente", cuyo estilo será decisivo para los trabajos posteriores.

Las obras que beben directamente del estilo del autor canadiense, son: el cómic neerlandés, Eric de Noorman, de Hans G. Kresse (1946); Karl the Viking, de Don Lawrence (1960), de producción británica; los incluidos dentro de la bande dessinée franco-belga, como Ragnar le Viking (1955) de Jean Ollivier y Eduardo Teixeira Coelho, o Thorgal (1977) de Jean Van Hamme y Grzegorz Rosinski. 
Las demás que formarán parte del análisis serán las restantes del panorama americano: Thor, de Stan Lee y Jack Kirby (1962), dentro del Mundo Marvel, y Northlanders (2009), de Brian Wood, perteneciente a Vertigo Comics, sello de DC Comics; junto a las europeas: Chroniques Barbares (1997), de Jean-Yves Mitton, y Siegfried (2007), de Alex Alice; y la obra española, Beowulf (2013), de Santiago García y David Rubín. Por último se mencionará uno de los mangas más exitosos de las últimas décadas, el título de Vinland Saga (2005), de Makoto Yukimura.

En siguiente término, se tratará sobre las series de TV que han incorporado el mundo vikingo y su mitología. Dentro de este apartado, la producción por parte canal History, Vikings (2013), es la más relevante de totas las que serán objeto del TFM. Otras series que han incluido esta temática son: la producción británica, The Last Kingdom (2015- ); la noruega e hilarante, Norsemen (2016- ); y la más actual emitida por Netflix, Ragnarök (2020), de coproducción noruega-danesa, sin olvidar la entrañable serie de dibujos animados, Vickie el vikingo (1972-1974).

Por último, como objeto de estudio, se integrará una serie de videojuegos que han trasladado dicha temática en su mundo. Dentro de este aspecto, se han seleccionado los títulos: The Lost Vikings (1992), de la compañía Silicon \& Synapse, actual Blizzard; Rune (2000), de Human Head Studios; Jotun: Valhalla Edition (2015), diseñado por Thunder Lotus Games; Hellblade: Senua's Sacrifice (2017), de la compañía británica, Ninja Theory; y la prestigiosa saga God of War, que recientemente en el año 2018, se adentró en la mitología nórdica tras su origen, que se encuentra en la griega.

Para concluir, he decidido no incluir al cine dentro del análisis del tratamiento de la mitología nórdica y costumbres en los mass media, debido a que ya existen trabajos dedicados en este aspecto, tales como: el artículo del antropólogo Maximiliano E. Korstanje, "El culto a los muertos: la mitología nórdica antigua en el cine moderno", para Revista Chilena de Antropología Visual; "Cine e historia. Una aproximación desde una perspectiva docente: la Edad Media”, de Juan Antonio Barrio Barrio, publicado en la Universidad de Alicante; o "Historias de cine: Thor y el enigma de la IX Legión romana", escrito por Fausto Fernández, para Clío: Revista de historia, y por lo tanto me he centrado en un análisis más original de los citados medios de masas que han formado parte del TFM. 
A continuación se desarrollan los objetivos del TFM:

1. Describir la representación de la cultura vikinga en la cultura contemporánea de medios de masas y, más concretamente, en el cómic, las series de TV y los videojuegos. Indagar en la mitología nórdica y en la figura del vikingo.

2. Estudiar las principales obras de ficción vikinga en cada uno de estos medios de masas, dando la posibilidad de establecer la comparación que existe en el modo de tratar el mundo vikingo y su mitología, de unos respecto a otros.

3. Analizar la técnica artística de sus autores.

4. Explorar las narrativas desarrolladas en torno a la cultura vikinga, sus costumbres y mitología en los medios de masas contemporáneos analizados, a través de las referencias de los títulos que se han considerado más transcendentales del subgénero de fantasía vikinga.

5. Valorar la presencia y el interés creciente por la cultura vikinga en los medios de masas durante las últimas décadas, aumentando las narrativas derivadas de ellas.

\subsection{Metodología y fuentes.}

Para la realización del TFM, en primer lugar se han seleccionado las obras que integran el mismo, tanto a lo referido al cómic, series de televisión y videojuegos. A continuación se ha seguido el método heurístico, consistente en la búsqueda intensiva de bibliografía, cuyo propósito ha sido el de contrastar la información obtenida a través de ella, sirviendo a su vez de apoyo para la elaboración del mismo. Por otra parte, la fuente fundamental para el análisis de las obras, se ha encontrado en las propias fuentes primarias, es decir, mediante la visualización de los cómics, en su caso en formato físico, y de las series de televisión. Por último, a través las revistas digitales especializadas en análisis de medios de cultura de masas, 
se ha extraído tanto información relativa a las tres artes desarrolladas en el trabajo, como recogido las entrevistas de sus autores relatando su proceso creativo y motivacional a la hora de su concepción.

En primer lugar, para la introducción a la mitología escandinava y referencias del mundo vikingo, se ha tenido en cuenta los siguientes trabajos: Santiago Barreiro y Renan Birro (2017) El mundo nórdico medieval: una introducción, para Sociedad Argentina de Estudios Medievales; obras del académico español Enrique Bernárdez; José Luis Borges y María Vázquez (1966) Literaturas germánicas medievales, en su edición argentina, Falbo; Santiago Ibáñez (1995) La saga de los Ynglingos, para la editorial valenciana, Tilde; Luis Lerate (1984) Edda menor (Edda prosaica o de Snorri), en Alianza Editorial; Francis Logan (2014) Los vikingos en la historia, Fondo de Cultura Económica; Alexander Murray y Crisitna Borrego (2013) Quién es quién en la mitología, Edimat Libros; y Heinrich Niedner (1997) Mitología nórdica, Edicomunicación.

El apartado referente al cómic, se ha seguido su análisis por escuelas, en primer lugar la relativa a la americana, con la obra de Hal Foster; siguiendo por la europea, en especial atención a las que se integran en la bande dessinée, y para finalizar la japonesa. Las publicaciones que se han consultado para su estudio, son: Foster, Hal. (2011) Príncipe Valiente, de Planeta DeAgostini; Coipel, Olliver. (2015) Thor: Tales of Asgard by Stan Lee and Jack Kirby. Limited Edition, de la editorial Giclee; Wood, Brian. (2007) Northlanders, de Vertigo (DC Comics); Van Hamme, Jean. (2019) Thorgal, Norma Editorial; Mitton, JeanYves. (2015) Crónicas Bárbaras, Yermo Ediciones; Alice, Alex. (2008) Siegfried, Norma Editorial; García, Santiago y Rubín, David. (2013) Beowulf, Astiberri; y Yukimura, Makoto. (2005) Vinland Saga, de la revista japonesa Kōdansha (Magazine Afternoon). Por otro lado, las referencias que se han recogido por parte de webs especializadas en el análisis de los mismos y autores, han sido: Tebeosfera, Zonanegativa, Eslahoradelastortas, Lambiek, Excelsior.universomarvel y Kirbymuseum.org, como destacadas. Apuntar, por último, la monografía dedicada al mundo del cómic: Historia de los Comics, de Javier Coma, publicada Toutain Editor.

En relación a las series de televisión, Vikings, es la única serie que por su éxito, ha generado artículos como "Análisis histórico de la serie Vikingos de History Channel”, para la revista Los Vikingos en la Historia (2015), de la de la historiadora especializada en cultura 
vikinga, Laia San José Beltrán, autora de la monografía: Vikingos. Una guía histórica de la serie de History Channel (2014), y el de la investigadora Mayte Donstrup, titulado: "Vikings: poder e identidades culturales en la serie de History Channel, publicada en Revista de comunicación (2017). Por su parte, las páginas webs especializadas en el análisis de ellas, y que se han tenido como referencia, son: Serielizados, Fueradeseries, Filo.news, Hipertextual, Minigranada, Rirca, Serielistas.lasexta, Revistalainterferencia y Archivoshistoria.

Para concluir, en el capítulo de videojuegos, se han tenido como alusivas las siguientes páginas webs que tienen por objeto su tratamiento: Vandal.elespanol, Gamespot, Alfabetajuega, Inexistente.org, Ign y su vertiente en español Es.ign, Vidaextra y Cineverso. 


\section{LA LITERATURA MEDIEVAL ESCANDINAVA: CREACIÓN DE UNA MITOLOGÍA.}

Escandinavia como pueblo germánico perteneciente a la familia lingüística indoeuropea, desarrolló una lengua conocida como "antiguo nórdico", base fundamental con la que se concebiría su literatura en la Edad Media. Su conocimiento se debió a la llegada del alfabeto latino, pero desde el siglo I de nuestra era, estos pueblos y especialmente los países nórdicos utilizaron un sistema de escritura conocida como rúnica o futhark antiguo, del que se creé que pudo surgir del alfabeto griego o latino (Serna, 2017, pp. 31-37). La mayoría de las inscripciones se encuentran en los países nórdicos, pero también se hallaron en Norteamérica y muchas de ellas proceden del periodo vikingo, razón de su existencia en islas del Atlántico Norte (Islandia, Feroe, Groenlandia, etc.). Su número variaría a lo largo del tiempo, desde su origen protonórdico de unas 24 runas hasta su reducción a 16 en época vikinga hacia el año $800^{1}$.

\subsection{La poesía escáldica, edda y saga.}

A lo largo de los siglos IX al XII, en Islandia, surge y se desarrolla la poesía escáldica. Su etimología es compleja, ya que puede procerder del islandés skáld "poeta", o del alemán e inglés (schelten-scold) en referencia al sentido de reprender o regañar, aunque el escaldo podía ser a su vez guerrero, comerciante o granjero. Se trataban de poemas recitados, bien usados para calumniar a un enemigo o para conmemorar por medio de poemas "drapur", hazañas de reyes y señores que acompañaban en las cortes (Porter, 2017, pp. 53-54). La mayoría de los escaldos eran islandeses, aunque en un primer momento predominaban los noruegos y a pesar de la rivalidad que mantenía con la poesía europea continental, supo mantenerse en el tiempo. El escaldo y vikingo más reconocido fue Egill Skalla-Grímsson (S. $\mathrm{X}$ ), que aparecerá en la saga que da su nombre atribuida al erudito islandés Snorri Sturluson (1179-1241) hacia el siglo XIII. La poesía escáldica a su vez se incorporó a modo de

\footnotetext{
${ }^{1}$ Sobre el antiguo nórdico y escritura rúnica, Inmaculada Senra Silva realiza un análisis exhaustivo en la publicación de 2018, El mundo nórdico medieval: Una introducción (Eds. Santiago Barreiro y Renan Birro). Buenos Aires: Sociedad Argentina de Estudios Medievales, dentro del apartado "Lengua y sistemas de escritura".
} 
preservación en obras manuscritas como en el caso de las sagas, cuya labor también funcional respecto a estas últimas era la de apoyar su argumentación dentro de un lenguaje más directo, gracias al metro que utilizaba, el "dróttkvaett", totalmente opuesto al empleado en la saga.

Este género compartió antigüedad con la poesía éddica, un conjunto compilado de poemas anónimos recogidos en el manuscrito medieval islandés Codex Regius, cuya fecha se enmarca en torno al año 1275 y que fue descubierto por el obispo islandés, Brynjólfur Sveinsson en el año 1643. Estos poemas datan entre los siglos IX y XIII y tratan temas de la mitología nórdica y leyendas germánicas del pasado dentro de un carácter heróico. Comparte material mitológico de la Edda prosaica o menor de Snorri Sturluson (c.1220), un manual escáldico escrito por este autor, y es por ello que se renombró como "Edda" o Edda de Saemundr, puesto que el obispo atribuyó este compilado a Sæmundur fróði (apodado el Sabio, 1056-1133), aunque se conoce coloquialmente, y para distinguir la de Snorri Sturluson, como Edda poética o Edda mayor (Poilvez, 2017, pp. 84-85).

Dentro de las compilaciones mitológicas, y que según Poilvez (2017, p. 97) sirvió de fuente de inspiración para el poema "Gylfaginning” de Snorri destaca el poema Vọluspá "la profecía de la sibila", obra esencial de la cosmología nórdica, que narra por medio de una völva o vidente, la creación del mundo e inminente final. El poema se narra tanto en primera como en tercera persona, pues la adivina empieza al principio del poema solicitando la atención a un público humano, aunque ésta establece una relación especial con el dios supremo Odín (nórdico antiguo Óđinn). Este presenta una clara estructura, con la aparición de los dioses principales de la mitología nórdica como son los Æsir y cómo estos crearon el mundo y sus habitantes como los elfos, enanos, trolls, gnomos, kobolds, nibelungos, elfos oscuros y a los personajes de donde nacería la estirpe humana, Ask y Embla, y la aparición de otros dioses como Kvasir o las Valquirias ${ }^{2}$; la descripción de los nueve mundos, en los que de forma metafórica cuelgan de un arbol conocido como Yggdrasil; la lucha entre los Æsir y Vanir, dioses de la naturaleza asociados a la fertilidad, el mar y la prosperidad, destacando entre ellos los dioses Njörðr, Skaði, Frey y Freyja; la lucha del orden y el caos a través del relato del apocalipsis o Ragnarök, con protagonistas como los gigantes, el propio Odín, Baldr,

\footnotetext{
${ }^{2}$ En la mitología nórdica, son las encargadas de trasladar los cuerpos de los guerreros que han muerto en guerra (einherjar) para luchar en la batalla final del Ragnarök acompañando a los dioses.
} 
Thor o Loki y su hijo Fenrir, y cómo finalmente del resultado de este enfrentamiento volvería a renacer el mundo ${ }^{3}$.

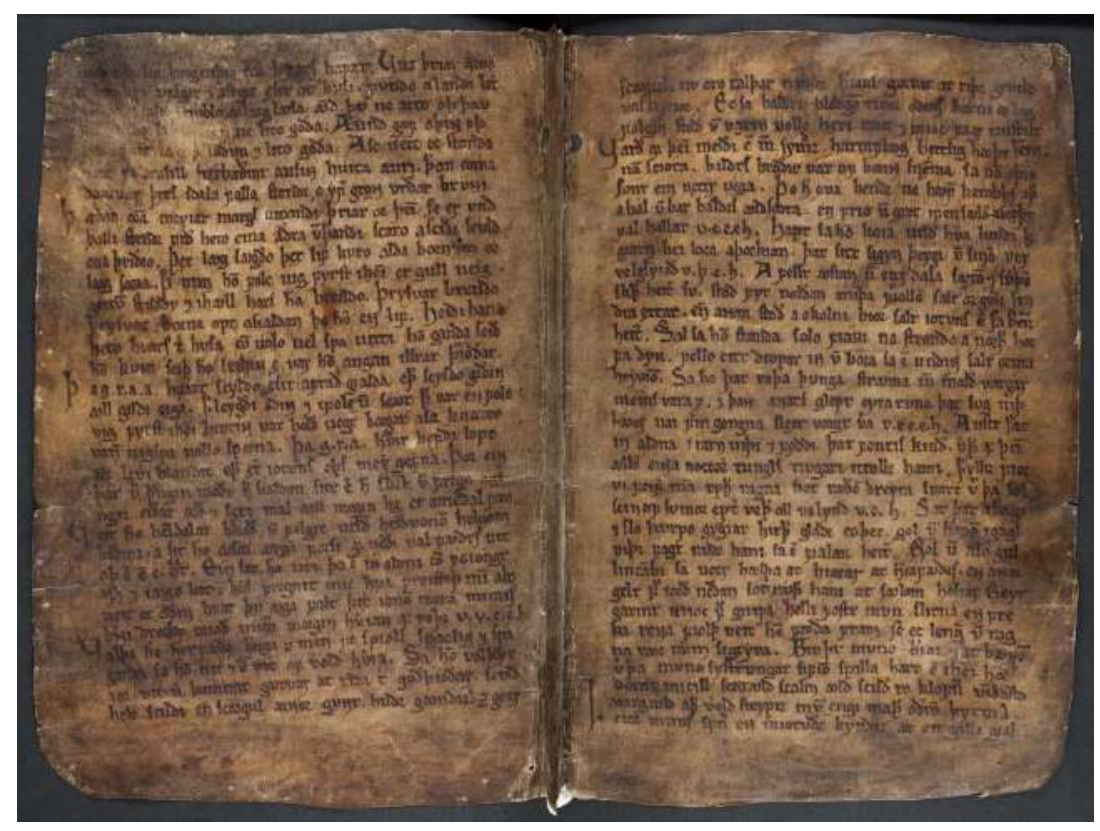

Páginas del Codex Regius GKS 2365 4to con el contenido del poema Völuspá. Fuente:

https://handrit.is/is/manuscript/view/GKSO4-2365

Junto a las compilaciones mitológicas, el Codex Regius contiene inmediatamente a estos, cantos y poemas de héroes semilegendarios y personajes históricos como reyes ostrogodos, burgundios o el propio Atila de los Hunos, ya dentro de un contexto literario propiamente europeo y no sólo exclusivamente escandinavo. En él aparecen obras como en primer lugar, la de un conjunto de poemas dedicados al héroe noruego Helgi (Helgakviða Hundingsbana I, Helgakviða Hundingsbana II y Helgakviða Hjörvarðssonar), o la presentación en la obra Grípisspá del Ciclo Nibelungo, de Sigurd o Sigfrido del poéma épico del Cantar de los Nibelungos, héroe legendario germánico que tendrá aparición también en la Saga Volsunga. Este funciona a modo de introducción dando paso al desarrollo de los acontecimientos del personaje desde su juventud hasta la muerte del dragón Fáfnir, narrados en los poemas de Reginsmál (Dichos de Regin), Fáfnismál (Dichos de Fáfnir) y Sigrdrífumál o Canción de Sigrdrífa. Los siguientes eventos van enfocados a la esposa de Sigurd, Guðrún o Krimilda, que una vez tras el fallecimiento del héroe, se casa con Atli (Atila).

\footnotetext{
${ }^{3}$ Para más información acerca del contenido del poema y su relación con el Gylfaginning de Snorri Sturluson, es recomendable el trabajo de Hermann Pálsson en El más grande poema del norte pagano Volüspá, "La profecía de la Sibila”, publicado en Acta poética, vol. 16, n 1-2 (1995), pp. 37-54.
} 
La saga por su parte es un término complejo de definir, puesto que integra un género muy amplio, y a su vez en algunos casos, se produce una mezcla de hechos históricos con pura ficción ${ }^{4}$. Son obras que se enmarcan entre los siglos XIII y XIV, escritas en prosa, y en ellas por lo general relatan la vida de un personaje islandés, centrando la acción en el periodo de colonización de la isla, centro de notable creación de las mismas, hasta su proceso de cristianización en el siglo XI (Bernárdez, 1984, p. 6). Dentro de su producción destacan las denominadas Sagas de los Islandeses, de autores anónimos que se inspiraron a través de las fuentes orales que se transmitían de generación en generación, y de las literarias, que los propios islandeses iban generando en el tiempo a raíz de una serie de factores de distinta índole. A pesar de su anonimato, una de las sagas más destacadas por extensión y calidad es la de Egil Skallagrímson, poeta y guerrero, a la que le es atribuida a Snorri Sturluson. Junto a estas, dentro de las denominadas sagas nórdicas se encuentran las dedicadas a obispos y vidas de santos o reyes, predominando la obra considerada como el summun de la literatura nórdica, escrita por el citado autor y conocida como Heimskringla ("El orbe del mundo"), un compilado sobre los orígenes míticos de los reyes noruegos a partir de una sólida documentación (Lerate, 1984, p. 23). Otra saga a destacar es la llamada Sturlunga saga (c. 1300), compilación perteneciente al grupo de sagas contemporáneas de materia secular y escritas en su mayoría por autores anónimos. Por último, mencionar una saga propiamente de temática mitológica como es la saga Völsunga, dentro de la categoría de las sagas legendarias o "Sagas de los Tiempos Antiguos", centrada sobre la leyenda de Sigurd.

\subsection{Sagas de los islandeses.}

"Este arte empezó siendo oral; oír cuentos era uno de los pasatiempos de las largas veladas de Islandia. Se creó así, en el siglo X, una epopeya en prosa: la saga. La palabra es afín a los verbos sagen y say (decir y referir) en alemán e inglés. En los banquetes, un rapsoda repetía las sagas”. (Borges, 1966, pp. 32).

\footnotetext{
${ }^{4}$ La discusión del origen de las sagas y fiabilidad desde el punto de vista histórico para el estudio de la sociedad escandinava medieval, surge desde el siglo XVII. Op. Cit. pp. $146-159$.
} 
Las sagas de los islandeses, también denominadas Islendingasögur, son un conjunto de obras que ponen en contexto la colonización de la isla entorno al año 870 y que constituyen el cénit de la literatura en lengua vernácula, propia de la literatura escandinava de la Edad Media. Estas están formadas por un total de treinta y siete sagas anónimas que no siguen una estructura individual, puesto que las motivaciones de cada autor no eran las mismas, por ello como bien dice Manrique Antón (2017, p. 148). "cada saga en particular es una obra de arte única", capaz de albergar temáticas tan variadas como los conflictos de poder entre familias, costumbres precristianas y la asimilación del cristianismo, o el ensalzar al colonizador.

Entre las más destacadas nos encontramos con la Egils saga, la única que sale del anonimato, puesto que es atribuida a Snorri Sturluson (c. 1240), correspondido al manuscrito de primera mitad del siglo XIV, Moðruvallabók, que contiene once sagas. El poema se centra en la figura del vikingo y skaldo Egill Skalla-Grímsson, según Borges (1966, p. 35) "el más ilustre de los poetas de la época precristiana". La historia se ambienta en Fjordane, Noruega, con Kveld-Úlf (Lobo nocturno), que es capaz de predecir las desgracias de su familia. Úlf, tiene dos hijos: Grim, que más tarde pasará a llamarse Skallagrim y Thorolf, el mayor de los hermanos. Thorolf se encuentra al servicio del rey Harald I de Noruega, a pesar de que su padre, Kveld-Úlf, siempre renegara de la corona:

"Kveld-Úlf dijo que el rey mandó decirle que Kveld-Úlf debería ponerse a su servicio, o en su lugar uno de sus hijos.

-¿Qué respondiste?», dijo Thórólf

-Dije que pensaba que nunca podría someterme al rey Harald, y eso mismo deberíais hacer vosotros dos si aceptarais mi consejo; creo que todo apunta a que nuestro destino es que el rey nos cause la muerte." (Bernárdez, 1984, p. 54)

Tras distintos enfrentamientos con el rey Harald e instigaciones contra Thorolf por parte de los hermanos gemelos Harek y Hrærek, el monarca decide matarlo durante una emboscada. Ante este suceso, Olvir Hnufa, tío de Thorolf y Skallagrim, marchan a la corte para reclamar justicia, donde reciben la reprobación del rey. Ketill hængur, primo de Thorolf, ante un ataque de ira reúne hasta sesenta guerreros, matando a los conspiradores. Skallagrim 
conoce a Bera, hija de un rico y acaudalado, llamado Yngvar, los cuales se casan, teniendo dos hijos, uno de ellos era Thórólf, en honor al hermano fallecido de Skallagrim y el otro Egill.

Egill era un niño muy parecido a su padre, no muy atractivo y moreno, pero desde muy pronto, con tan solo tres años, desarrolla habilidades impropias de una persona de su edad, adquiriendo una fuerza descomunal, llegando incluso en un episodio a matar a un chico de once años, llamado Grím Heggsson, durante la disputa de un juego y por medio de un hachazo, lo que hizo que tanto Egill como Thórd, amigo de Egill y el responsable de darle el hacha a este, huyeran. Al encuentro con su padre, a este no le agradó nada lo sucedido, pero al contrario, su madre vio en ello a Egill como un prometedor vikingo y expresó su deseo de que cuando se hiciera mayor, habría que darle un barco de guerra, lo que motivó el primer poema de Egill:

\footnotetext{
"Así dijo mi madre, que me habría de comprar nave, y bellos remos, para ir a vikingo, firme, en pie en la proa, y mandar bella nave, lanzarme así a la mar, matar a más de uno”. (Bernárdez, 1984, p. 101)
}

Ya con diecisiete años de edad, Egill emprende un viaje junto a su hermano, en la que se convierte en su primera expedición vikinga. Durante una dura incursión junto a Olvir, que trabajaba para su jefe Thórir aterrizan en la isla de Atley, donde se encontraba la hacienda del rey Eirík de Noruega y que era administrada por Bárd de Atley. Esa misma noche, en la que llega el rey junto con su esposa Gunnhild, se celebra un banquete en el que se invitan a los acompañantes de la expedición y a Egill. Bárd conspira junto a la reina contra Egill, decidiendo envenenar su bebida, pero el vikingo al descubrir ello, acaba con la vida de Bárd.

Más tarde Egill, comienza la conquista de Inglaterra junto a Thórólf, pero este muere durante la misma y en su vuelta a Noruega se casa con la mujer viuda de su hermano. De nuevo su vida se cruza con la del rey Eirík y en un episodio mata a uno de sus hijos. Tras dar 
sepultura a su padre, y estando en una situación delicada, decide marchar de nuevo a Inglaterra, parando en Northumbria, encontrándose con el rey y Gunnhild, que se habían exiliado tras el anterior suceso que llevaba consigo una maldición. Egill, por consejo de un amigo suyo se entrega, pero el monarca ordena su ejecución. El vikingo logra escapar y sus próximos destinos serán Noruega y Suecia. A su vuelta a Islandia, dos de sus hijos mueren y abatido, intenta acabar con su vida, pero su hija Thorgerd le anima escribir el poema Sonatorrek. Al final de su vida, con un Egill padecido de sordera y ceguera, muere sin apenas disfrutar de la riqueza obtenida a lo largo de sus incursiones.

\subsection{Sagas de los reyes.}

Conocidas como konungasögur, son tal como indica su título, sagas que relatan los hechos y vidas de los reyes, generalmente en su mayoría de Noruega y a menor escala de Dinamarca (Barreiro, 2017, p. 161).

Las grandes monarquías, se alzaron durante el periodo de la era vikinga, produciéndose en primer lugar en Noruega seguida de Dinamarca y Suecia. Islandia, por su parte, Islandia carecía de ella, aunque durante los siglos XIII-XIV concentraría toda su autoridad.

Dentro de su producción, la obra más temprana es Hryggjarstykki, compuesta por el escaldo, Eirik Oddsson, sobre la vida del monarca Harald Gille y sus dos hijos, Magnús el Ciego y a Sigurth Gadabout-Deacon, basadas en impresiones propias y relatos de testigos oculares de personas (Sveaas, 2012), y que se encuentra en paradero desconocido.

Sin embargo, algunas de sus partes se encuentran recogidas por la obra, en la que según Borges es "la más importante de la literatura de Islandia", la Heimskringla (Esfera del Mundo). Es una obra a la que generalmente se le atribuye a Snorri Sturluson, datada entre los años 1230-1235, por la que el autor usaría como referencia tres obras: la biografía de Óláfs 
Tryggvasonar, escrita por el monje benedictino del siglo XII Oddr Snorrason; la Fagrskinna (Piel Hermosa), apodada así debido a su elegante encuadernación; la Morkinskinna (Piel Enmohecida), donde incluya la biografía de Magnus I de Noruega; y Helgisaga, una biografía del siglo XIII sobre el rey Olaf II el Santo de Noruega (Barreiro, 2017, p. 170).

La saga consta de un total de dieciséis biografías de reyes, la cual narra los concursos de los reyes en un periodo de cuatrocientos años. La primera en orden, corresponde a la denominada saga de los Ynglingos, fundamental para el título de la saga, Heimskringla, puesto que toma las dos primeras palabras de ella: kringla heimsins (Ibáñez, 1997, p. 15). La saga sirve para establecer una rama dinástica iniciada por el dios Odín, hasta llegar a Rognvald el Sabio, rey de Noruega. En la saga se asocia la fundación de la dinastía sueca de Upsala por parte del dios nórdico de la fertilidad, Frey, y sigue la línea dinástica referida, siendo ellos los antepasados directos del rey noruego Harald. Odín es el jefe de Asgard, desde donde envía expediciones militares a todas las partes del mundo y sus hermanos Vili y Vé, gobiernan Ásaland, que se encuentra en la frontera de Suecia. Odín jamás pierde una guerra.

Esta es una montaña que va de noreste a suroeste del país sueco. Odín tiene posesiones en Asia, concretamente en tierra de turcos y al norte se encuentran las colinas inhabitables, asociado al país de la "tundra". La mirada de Odín no estaba dirigida a Troya, de hecho su autor ni la menciona, sino que los dioses Aesir estaban más apegados a las actividades militares de los romanos, aunque Troya se ubicaba cerca del entonces la Constantinopla, capital Imperio Bizantino. Odín, por lo tanto va en busca de nuevas tierras que habitar, desde Rusia, pasando por Alemania y tierras escandinavas. Odín es un gran manipulador, un brujo capaz de cambiar de forma y hechizar a través de sus palabras versadas, y en su muerte lo incineran junto con todas sus posesiones para ascender al Valhalla.

\subsection{Sagas legendarias.}

También conocidas como Fornaldarsögur (Sagas de los tiempos antiguos), nombre recogido por los trabajos de Carl Christian Rafn y Peter Erasmus Müller, son historias sobre 
los reyes y vikingos de Noruega, Dinamarca y Suecia, antes de tomar la forma que hoy día conocemos (Lavender, 2017, p. 181). Esta, a su vez, sería dividida por sagas de héroes, sagas de vikingos y sagas de aventuras/cuentos de hadas.

Dentro de la categoría, sagas de héroes, con un enfoque más trágico que las dos restantes y lleno de tintes mitológicos y fantásticos, se encuentra por antonomasia la denominada Saga de los Saga de los volsungos (Saga völsunga). Esta, por su contenido, está relacionada con el poema épico medieval del siglo XIII y de autor anónimo, conocido como el Cantar de los nibelungos (Murray, 2013, p. 181).

Rerir, caudillo vikingo e hijo de Sigi y este de Odín, no podía tener hijos, llegando a oídos de la diosa Frigg. El dominio de Rerir era el reino de Hunaland. Frigg, le ayudó dándole una manzana mágica, y gracias a ella nació Volsung, el cual tuvo once hijos, de los cuales dos de ellos eran gemelos: Sigmund y Signy. Signy, estaba celebrando un banquete con motivo de su casamiento con Siggeir, rey de Gotaland, cuando un anciano clavó una espada en un árbol que se encontraba en el salón, acto seguido comentando que quien la sacara de él, sería de su propiedad, el anciano se trataba de Odín. El único capaz de sacarla fue el hijo de Volsung, Sigmund, muriendo el padre de este posteriormente durante el enfrentamiento con el rey sueco por la posesión de la espada, que colgaría a todos sus de un árbol, sobreviviendo únicamente Sigmund.

Sigmund, tuvo tres hijos: el primero, Sinfjotli, fue fruto de un incesto con su hermana, y los otros dos, Helgi y Hamund, de su relación con Borghild. Tras distintos conflictos familiares, Sigmund viaja a Dinamarca casándose con la princesa Hjordis, con la que tendría su hijo Sigurd. Tras la muerte de su padre, Sigurd sería criado en la corte del rey danés Hjalprek, que se había casado con Hjordis. Este fue educado por las artes y ciencias de Reginn, cuyo padre sería asesinado por su hermano Fafnir al no compartir con él el tesoro otorgado por los dioses y que acabaría convirtiéndose en dragón, quedándose con el tesoro.

Reginn, vio en el joven Sigurd óptimas capacidades para matar al dragón, y forjó para él una espada logrando matar al dragón, que al tocar su sangre le volvería invulnerable, salvo en una parte de su espalda. El plan de Reginn era traicionar a Sigurd, por lo que este acabaría matándole, quedándose con todo el tesoro que resultaba estar maldito. Ante esta nueva 
situación, Sigurd se casa con Gudrun, hija del rey Gjuki y de la hechicera Grimhild. El hermano de Grimhild, Gunnar, estaba enamorado de la Valkiria Brynhild, que se encontraba dormida por Odín y estaba custodiada por un castillo de fuego, y pidió ayuda a Sigurd para que la rescatase disfrazándose de Gunnar y tras la hazaña se casaría con él. Llena de ira y sabiendo la verdad, Gudrun le revela a la valkiria este hecho y ella reta a Gunnar que mate a Sigurd, decidiendo el primero que se encargue de ello su hermano Guttorm, resultando heridos de muerte ambos, y suicidándose Brynhild. 


\section{LA ADAPTACÍON DEL MUNDO VIKINGO EN EL CÓMIC.}

La irrupción del pueblo escandinavo y sus costumbres ha sido objeto de fascinación por parte de las grandes escuelas de la historieta. El gran impulso que se produjo fue a través del cómic estadounidense, con la obra Príncipe Valiente de Harold Foster (1937), dando inicio a la iconografía estereotipada del vikingo rudo y no históricamente precisa, y pocas décadas más tarde con la irrupción de Stan Lee y Jack Kirby, de la mano del héroe nórdico, Thor, dentro del universo Marvel (1962), junto al más recientemente con el título de Brian Wood, Northlanders (2009). A Foster le seguirán durante varias generaciones una gran cantidad de autores cautivados por la autenticidad y frescura del maestro canadiense, así surgirán cómics coincidiendo con el desarrollo de este, tales como Eric de Noorman, de Hans G. Kresse (1946) dentro de la producción neerlandesa, o la británica, con Karl the Viking, de Don Lawrence (1960).

Pero sin duda alguna el gran centro de producción de temática vikinga está relacionado dentro del panorama europeo de la bande dessinée franco-belga, desde primeros títulos como Ragnar le Viking (1955) o Biorn le Viking (1962), de Jean Ollivier y Eduardo Teixeira Coelho, a títulos más recientes como Thorgal (1977), de Jean Van Hamme y Grzegorz Rosinski; Chroniques Barbares (1997), de Jean-Yves Mitton, y Siegfried (2007), de Alex Alice, además de otros, que son dignos de mención como Aslak (2011), de "Hub" y Asgard (2012), de Xavier Dorison. Por último destacar la original adaptación al manga japonés, a través de la serie Vinland Saga (2005), del mangaka Makoto Yukimura, y la española Beowulf (2013), de Santiago García y David Rubín.

\subsection{Cómic americano.}

En primer lugar, hay que contextualizar según la época de cada obra, y su momento histórico, la era o edad correspondiente por la cual se encuentra establecida la división de la historieta americana. Así, Príncipe Valiente pertenece a la Edad del Oro del Cómic; Thor, a la Edad de Plata; y Northlanders, al Cómic contemporáneo. Del mismo modo que cada uno de ellos se concibió a través de un formato distinto, puesto que la obra de Hal Foster nació como tira de 
prensa: el sunday/página dominical, diferenciándose de la obra del cómic de Lee y Kirby, y la de Brian Wood, siendo ambos creados en formato comic book ${ }^{5}$ editados por las grandes editoriales mainstring: Marvel y DC, tratándose del sello Vertigo de DC la serie de Wood.

\subsubsection{Un cómic fundacional: Príncipe Valiente de Harold Foster (1937).}

Príncipe Valiente, es la obra más influyente y longeva publicada en prensa más, puesto que lleva haciéndolo ininterrumpidamente desde hace 83 años, desde 1937 hasta la actualidad.

El canadiense Harold Rudolph Foster (1892-1982) es uno de los grandes maestros del arte del cómic, cuyo título Príncipe Valiente es considerado como la obra cumbre del género de aventuras históricas. Su formación como dibujante atrajo a Joseph H. Neebe, director de la agencia Campbell-Ewald, quién le propone adaptar a tira de prensa diaria la popular novela Tarzán de los monos de Edgar Rice Burroughs, tras el rechazo por parte de J. Allen St. John, un magnífico ilustrador que se ocupaba en la realización de sus portadas literarias. De este modo, Foster publica desde el 7 de enero de 1929 hasta el 16 de marzo de 1929 una tira diaria hasta llegar a las sesenta, de cinco viñetas cada una, formando un total de trescientas viñetas ${ }^{6}$.

Tras un primer rechazo de Foster para seguir adaptando la que sería la segunda novela de Burroughs, Rex Maxon sería el encargado de suplirle y de también realizar la versión dominical, fracasando en esta última estrepitosamente debido a su mediocridad (Gutiérrez, 1994, p. 25), lo que daría a lugar la incorporación de Foster en el año 1931 al ahora llamado sindicato United Features (Syndicate), para dibujar las páginas dominicales desde el 27 de septiembre de 1931 hasta el 2 de mayo de 1937. Los guiones por otra parte les eran suministrados por parte del syndicate, hecho que acabó por colmar la paciencia del autor que deseaba tener el control de su propia obra, a la vez que tiene en mente crear un relato épico en tiempos del Rey Arturo. Tras su propuesta al syndicate y su consiguiente rechazo, contactaría

\footnotetext{
${ }^{5}$ Este, en términos generales, se trata de un formato de revista o cuadernillo con grapa, de periodicidad mensual, cuyo tamaño oscila unos 17 x $26 \mathrm{~cm}$, y su contenido alberga entre 24 y 32 páginas en color o monocromo, en los que se incluye cubiertas, publicidad, textos autorreferenciales de modo intercalado, y la historia, sobre todo en los últimos años, se divide por entregas.

${ }^{6}$ Ya en esta serie, Foster introduce a los vikingos a pesar de que la acción se desarrolle en un entorno exótico.
} 
con su empresa rival, el King Features Syndicate, propiedad de William Randolph Hearst, cuyo director general Joe Connelly aceptaría su idea con la condición de que el título en vez de ser "Príncipe Arn", ideado por el propio Foster, fuera el de "El Príncipe Valiente en los días del Rey Arturo", título con el que finalmente vería su publicación en el año 1937.

La acción transcurre en el siglo $\mathrm{V}$, cuyo protagonista es Valiente también conocido como Val, un príncipe vikingo e hijo del rey de Thule que por motivos de usurpación tiene que abandonar el reino junto con su familia y un minúsculo ejército de leales a la corona. El territorio al que acapara está formado por unos terrenos pantanosos de la costa inglesa, un lugar en el que albergan criaturas tales como dragones, monstruos, ogros y hechiceras. Una de estas últimas, la bruja Horrit le predice futuros malos augurios y mientras tanto se prepara para ser caballero combatiendo todos los peligros que le acechan. Una vez que se siente preparado, inicia un periplo lleno de heroicidades ganándose una fama que se verá recompensada cuando cumpla su sueño de ser caballero de la Mesa Redonda sirviendo al Rey Arturo.

La maestría técnica con la que Foster trata su obra y los elementos que los integra, y en especial la naturaleza, son fruto tanto de las aventuras vividas durante su infancia como la de su vocación por el arte del dibujo. En ella emplea un estilo naturalista absolutamente innovador a través de una técnica preciosista y minuciosa, que une junto a la narrativa. Sus viñetas se componen dentro de una visión panorámica donde todos los elementos entran en escena sin perder ningún detalle, así los acontecimientos secundarios son detallados con tal grado de realismo que acaparan la atención como si de una escena principal se tratase (Martínez-Pinna, 2003). A este tono documental que emplea en la naturaleza, hay que sumarse al profundo estudio en el que se basa para reflejar una Edad Media bastante inusual recreada a su manera, puesto que combina elementos que abarcan durante siglos. Esta anacronía hace que tome licencias respecto a los hechos históricos, o refleje costumbres modernas asociadas con la sociedad americana del siglo XX. Su realismo manifiesto es reflejo de la evolución que sufren sus personajes, hasta tal punto que estos llegan a envejecer a la par que lo hace su lector o propio autor, encontrando explicación en el deseo de Foster de que su personaje no fuera el arquetipo de héroe imbatible, al contrario, lo humaniza y hace que disfrute o sufra a través de sus experiencias personales, muchas en común con las vividas por el creador, que por otra parte se identifica con el espíritu norteamericano del hombre que madura y se hace así mismo. 
Foster, aparte de su formación como dibujante, supo aunar todo lo aprendido para llegar a crear tal conjunto armonioso, siendo decisivos para su formación los grandes paisajistas ingleses del siglo XIX, e ilustradores ingleses y estadounidenses tales como Arthur Rackham, JC Leyendecker, Edwin Austin Abbey, Joseph Clement Coll y en especial Howard Pyle, autor de numerosas novelas relacionadas con la leyenda artúrica, cuyas ilustraciones fueron tan influyentes hasta tal punto que algunas de sus viñetas pasarían a ser directamente un calco de las de Pyle.
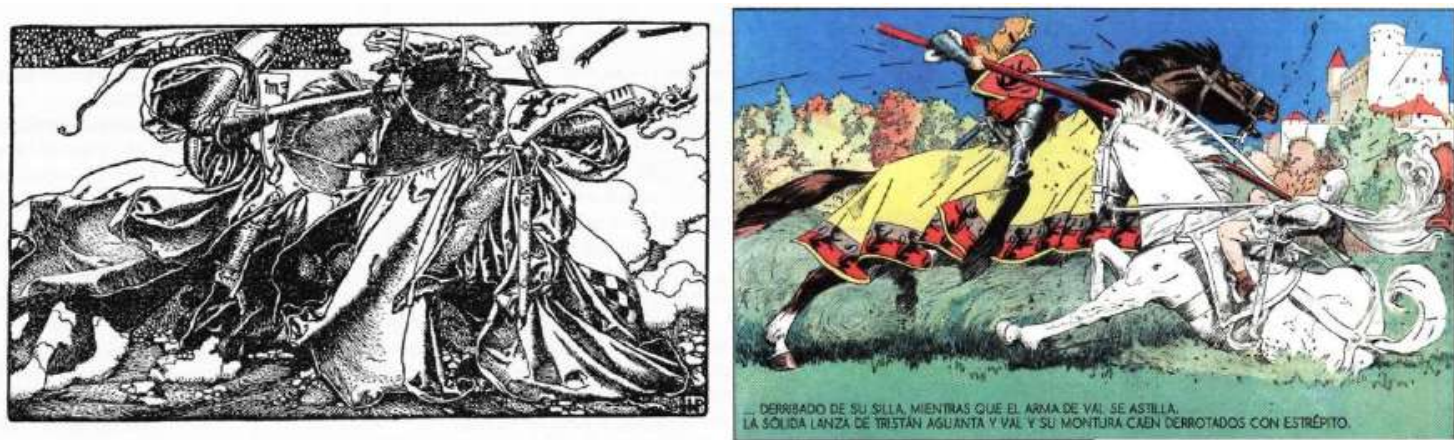

A la izquierda, ilustración de H. Pyle, a la derecha, de Hal Foster. Fuente: https://opuszine.us/posts/howardpyles-vision-king-arthur-his-knights y FOSTER, Hal. (2011) Príncipe Valiente. Barcelona, Planeta DeAgostini.

Más allá de su técnica como dibujante, se ha de destacar el empleo de una narrativa nunca vista hasta antes, produciendo una ruptura con la propia identidad del cómic en cuanto a sus modos tradicionales de redacción se refiere. La más manifiesta es la de la sustitución de los globos de texto, comúnmente conocidos como bocadillos, por textos al pie de la ilustración; la presencia de un narrador externo a la acción, que junto a las de los personajes que participan logra centrar la atención del relato en detrimento de una narrativa artificiosa; o el entrecomillado en ocasiones para el estilo directo. Pero a pesar de ello, esta nueva técnica estaba fundamentada y principalmente diseñada para que no acabara siendo una interferencia que perjudicara la calidad de su obra, a la vez que conseguía crear una mayor conexión con sus lectores ${ }^{7}$.

Tras cuarenta años dedicándose Foster a la serie, siendo el único responsable tanto de los guiones como de la realización gráfica de la obra y dedicando una labor diaría de cincuentas horas por plancha, vería la necesidad de buscar nuevos colaboradores. En 1971, tras barajar su candidato ideal, en el que estuvo como posible Wally Wood, finalmente

\footnotetext{
${ }^{7}$ Marina Segarra García, expone mediante ejemplos ilustrativos la cualidad narrativa de Foster en: La narrativa de Harold Foster: más allá de la grandeza del ilustrador. Cuco, cuadernos de cómic, nº 4, 2015.
} 
colaboraría con él John Cullen Murphy, autor del cómic Big Ben Bolt que distribuía también el King Features Syndicate. Su colaboración en el dibujo con Foster se llevaría a cabo hasta 1978, año que quedaría exclusivo a Murphy, aunque compartía guión con Foster hasta su retiro en 1980, quedando Murphy y sus hijos como responsables contando con la ayuda del dibujante Gary Gianni, que finalmente quedaría como encargado del dibujo en 2004 bajo la dirección de Mark Schultz, siendo Gianni finalmente reemplanzado por Thomas Yeates en 2012.

Foster retrata al vikingo desde un prisma convencional del pirata que va acompañado en grupo y surca los mares a través de su drakkar con la intención de obtener un ansiado botín mediante la práctica del pillaje, e incluso incendiando los lugares en los que paran. Cuando Val decide enfrentarse al príncipe Arn por el amor de Ilene, emprendiendo su viaje hacia el reino de Ord, muestra su naturaleza al dibujar un poblado de la costa inglesa que se encuentra arrasado tras el paso de estos ${ }^{8}$.
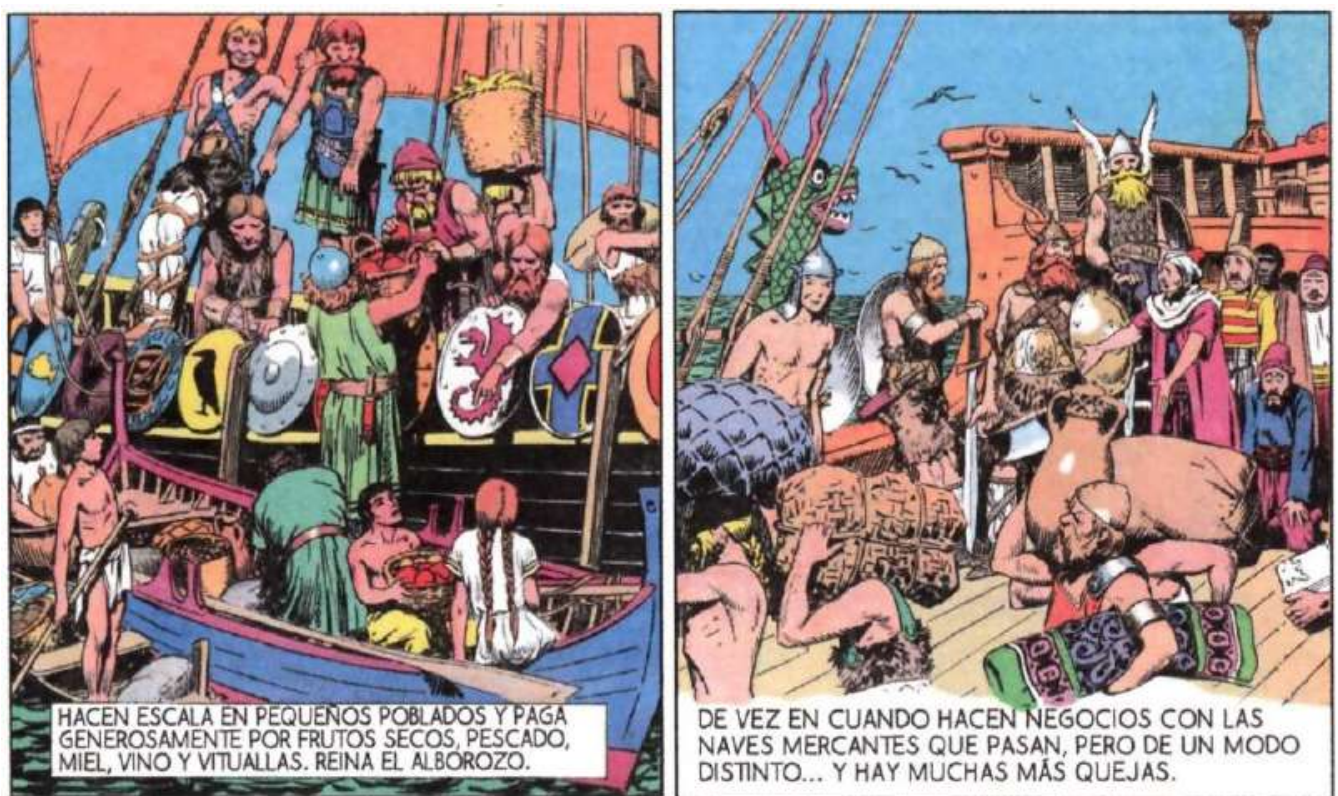

Vikingos en Príncipe Valiente. Fuente: FOSTER, Hal. (2011) Príncipe Valiente.

Barcelona, Planeta DeAgostini.

\footnotetext{
${ }^{8}$ La viñeta a la que se hace referencia se encuentra en la página 30 del tomo 2 (correspondiente al año 1938) de la edición Planeta DeAgostini, que reedita las tiras dominicales originales del cómic desde su inicio en 1937 hasta 2012, en un total de 75 tomos ordenados, con motivo del 75 aniversario de la obra: FOSTER, Hal. Príncipe Valiente. Barcelona, Planeta DeAgostini, n², 2011, p. 30.
} 
A pesar de lo que pueda parecer de simple y previsible la actitud y el modo de proceder de los hombres del norte, el autor les aplica un carácter a ciertos personajes que aparecen a lo largo de la trama. El vikingo tiene palabra, como es el caso de uno de los primeros vikingos de la serie, Thagnar, un líder pirata que promete y acaba cumpliendo la libertad de Val después de enfrentarse en una lucha en la que queda como ganador. La decadencia se muestra en Sligon, el tirano que arrebata el trono de Thule a su padre, que evoluciona moralmente conforme se hace mayor y de ser ese guerrero ambicioso, decidido a conquistar todo un reino por la fuerza y lograrlo, reflexiona y se da cuenta que esa ambición ya se ha perdido, ahora Val es aquel joven vikingo lleno de vigor dispuesto a asumirse en cualquier peligro por recuperar a su amada Ilene, y este acaba cediendo el trono de nuevo a su padre, harto por una parte de la violencia descontrolada y por otra de la falsedad de su corte. El vikingo a su vez es vanidoso y carismático, como el pirata Boltar, que hace llamarse asimismo honrado y que muestra su desaprobación cuando se le retrata y se le pone precio a su cabeza, que el estima bajo, pero que a su vez es astuto porque reconoce cuando hay un peligro de por medio. La superación también se ve reflejada en Gundar Harl, un vikingo tullido, que a pesar de las dificultades es un magnífico constructor de naves.

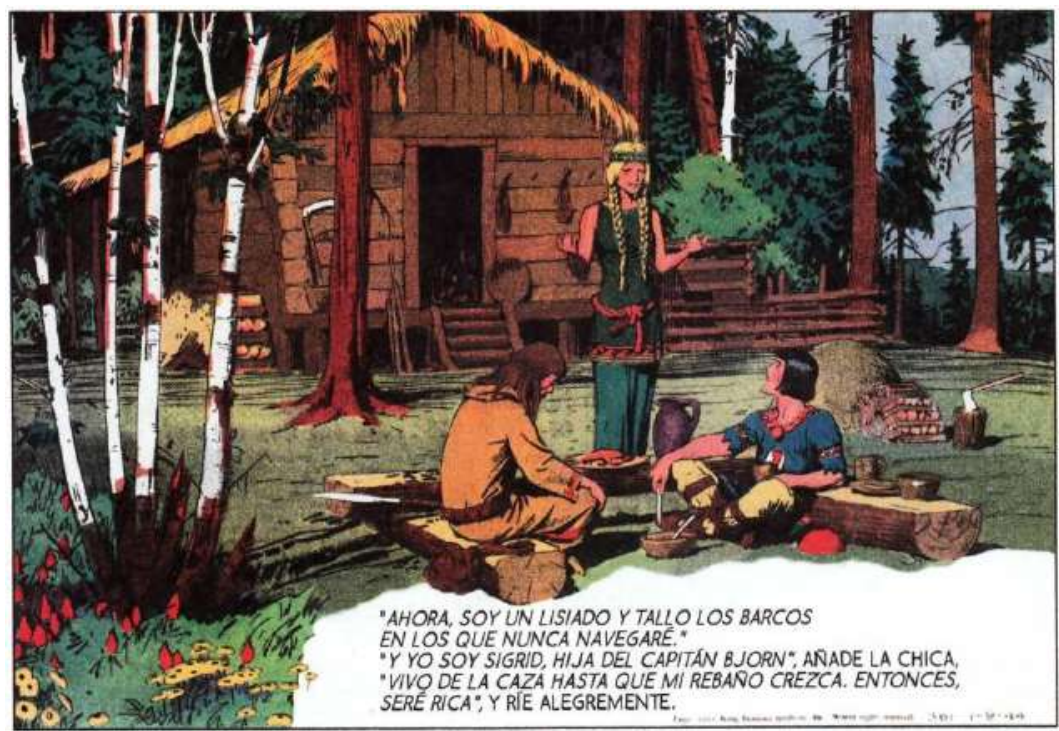

Hogar vikingo. Fuente: FOSTER, Hal. (2011) Príncipe Valiente. Barcelona, Planeta DeAgostini.

Interesante es el lugar natural de Valiente, el reino de Thule cuya capital es Vikingsholm. Foster, a medida que la historia avanza, lo ubica en medio de un entorno exótico por medio de cascadas y bosques frondosos que rodean la fortaleza. El reino a su vez se proclama pacífico y justo, donde los habitantes se entrenan, eruditos y extranjeros se 
reúnen para debatir, o se montan banquetes en el gran salón para celebraciones de distinta índole. Por otra parte, los conflictos se rigen conforme a las reglas de la caballería mediante el duelo a muerte, un acto que es indefendible, puesto que los mismos protagonistas se dan cuenta de que la manera más pura de poner en riesgo una vida debería ser por asuntos de fuerza mayor como la de defender su país y rey.

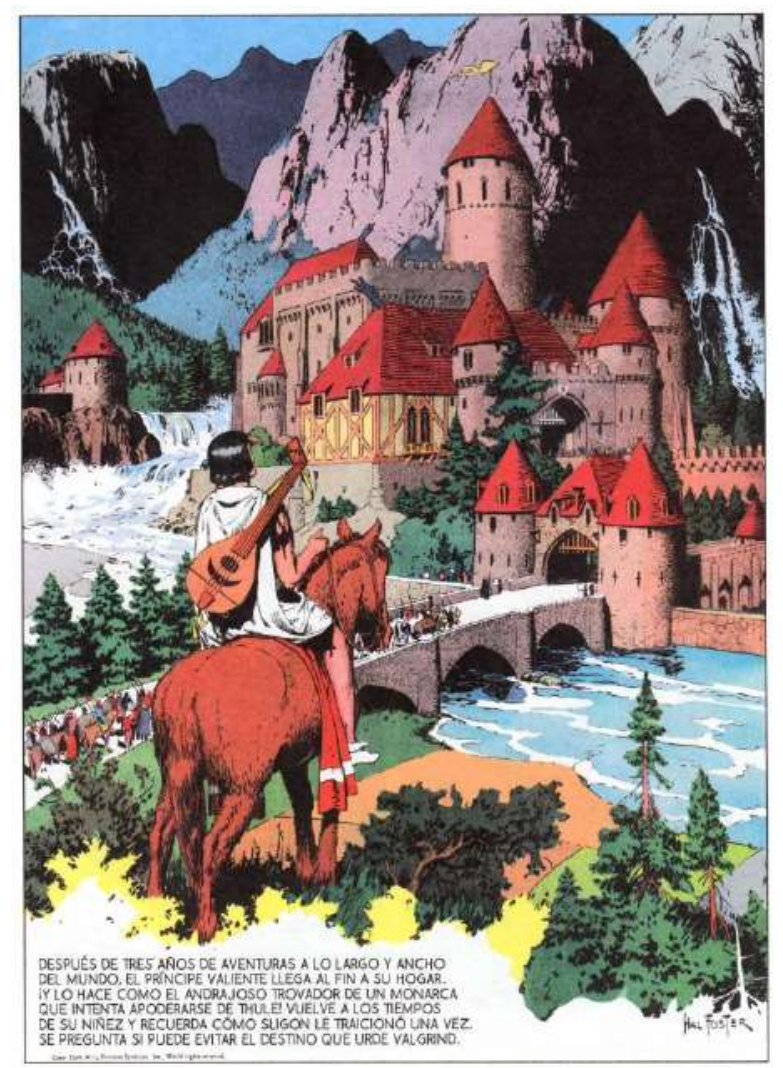

El reino de Thule. Fuente: FOSTER, Hal. (2011) Príncipe Valiente. Barcelona, Planeta DeAgostini.

En el aspecto religioso, aunque este es un capítulo donde de nuevo se produce un salto temporal, puesto que el cristianismo en el siglo en el que se ubica la acción no había llegado a Escandinavia, existe un claro conflicto entre creencias cristianas y nórdicas. El rey en un episodio manda a Val a Roma para conseguir misioneros, que con la palabra del Credo, consiga erradicar las costumbres bárbaras del pueblo. Los clérigos cuando llegan a la ciudad fundan una iglesia que servirá para el bautizo de sus hijas, nacidas en la misma capital. El cristianismo se deja caer, a través de una referencia en una de sus láminas, que es impuesto por el rey, trayéndole graves consecuencias a aquellos que osen desobedecerle, aunque 
muchos de los vikingos se resisten a la nueva religión, temerosos en parte debido a que puedan destapar la ira de sus dioses ${ }^{9}$.
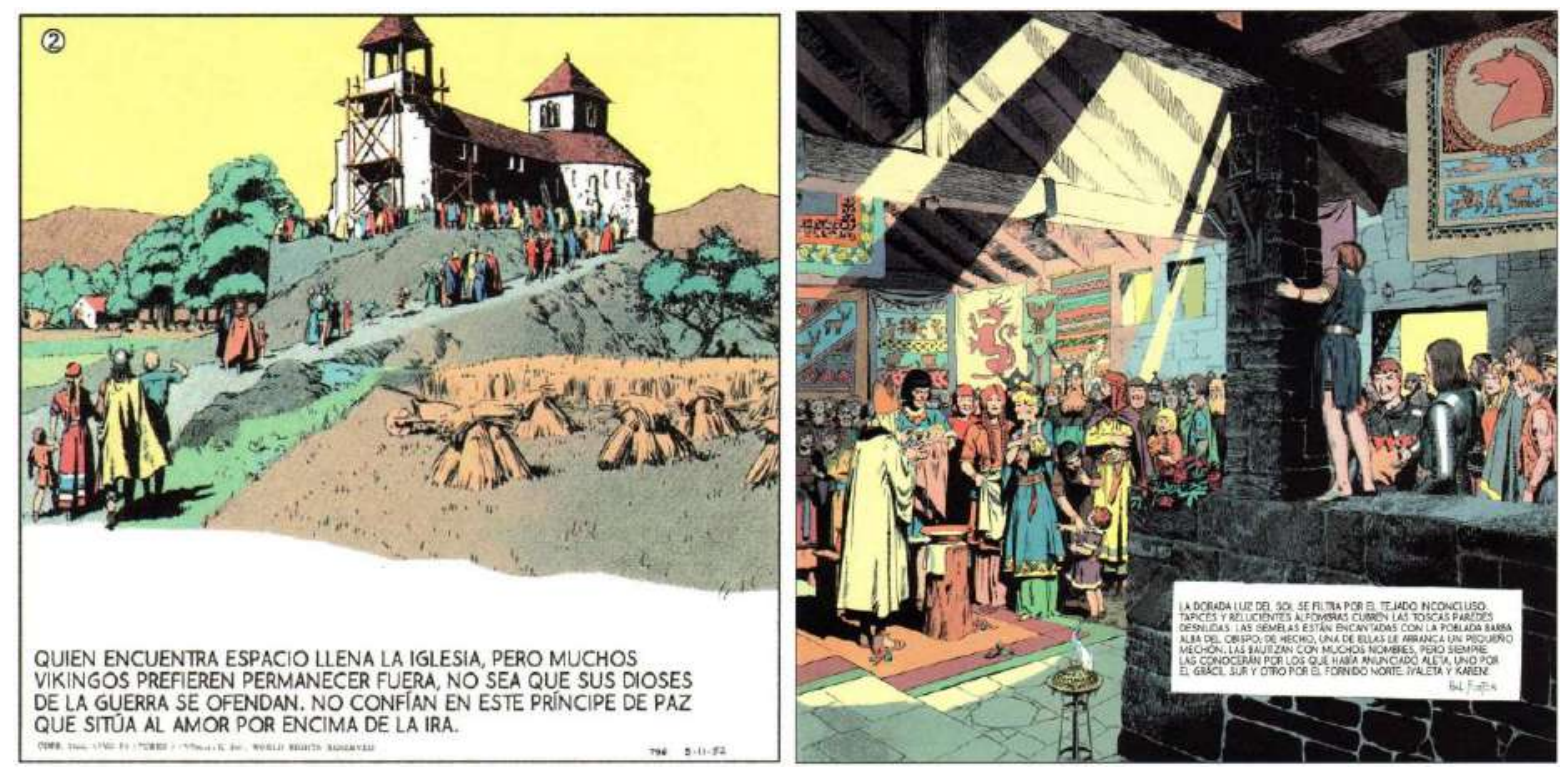

FOSTER, Hal. (2011) Príncipe Valiente. Barcelona, Planeta DeAgostini.

\subsubsection{Adaptación de la mitología nórdica en el universo de Marvel: Thor de} Stan Lee y Jack Kirby (1962).

\section{El dios asgardiano en el cómic americano: Thor de Stan Lee y Jack Kirby.}

La primera aparición en el cómic del dios mitológico nórdico, se produce en el año 1940 cuando Darm Gormley, bajo el alias "Wright Lincoln" crea Thor: God of Thunder para "Weird Comics" de "Fox", en el que un simple humano llamado Grant Farrel adquiría los poderes del hijo de Odín para combatir contra el mal (Bishop, 2016). El personaje aparece identificado tal como las eddas describen al dios del trueno, con capa y su martillo mágico "Mjolnir", pero con un atípico casco alado. El personaje duraría hasta la quinta publicación,

\footnotetext{
${ }^{9}$ FOSTER, Hal. Príncipe Valiente. Barcelona, Planeta DeAgostini, nº15, 2011, pp. 28-29.
} 
transformándose a continuación en Dynamite Thor, pero su tratamiento era tan nulo que se cancelaría pronto.

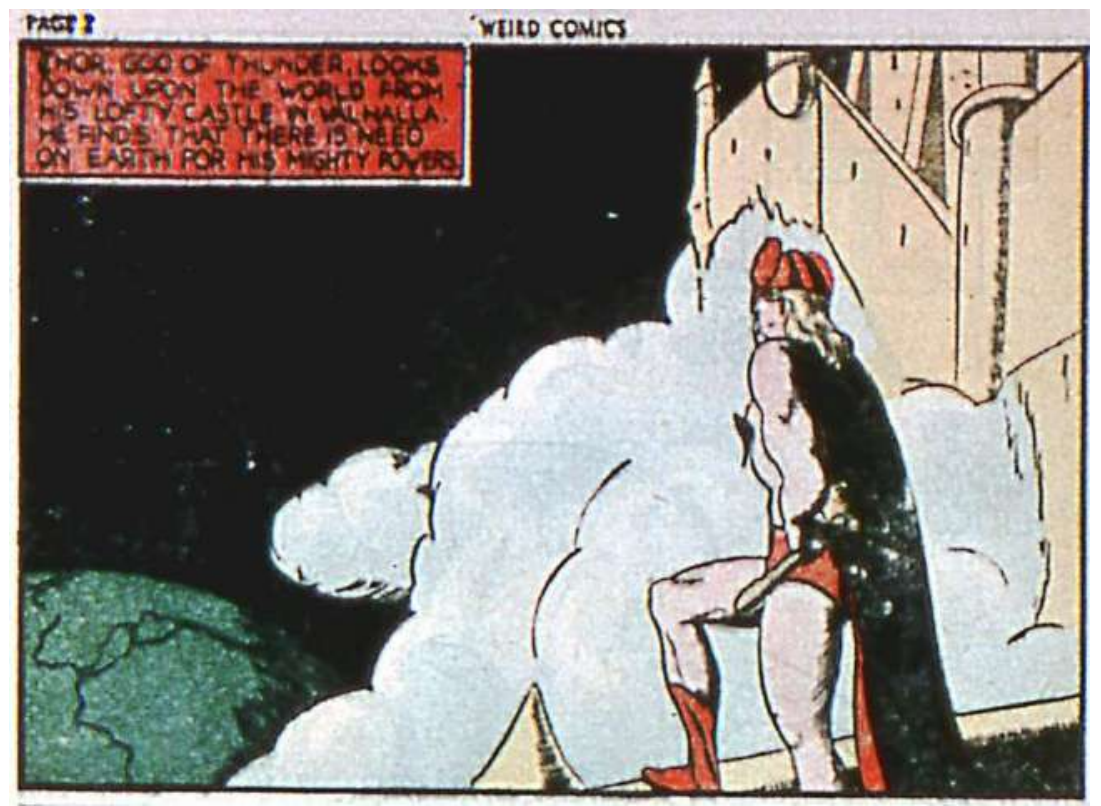

Viñeta de Thor: God of Thunder, para "Weird Comics" de "Fox" del año 1940. Fuente:

http://www.germanicmythology.com/works/FoxComicsArt.html

En el año 1942, Jack Kirby y Joe Simon recogen la leyenda nórdica para una de las historias Sandman, con el título The villain from Valhalla, publicándose en el número 75 de la serie de cómics estadounidense Adventure Comics de DC. En esta ocasión aparece como un bárbaro supervillano y pelirrojo de nombre "Fairy Tales Fenton", cuyo objetivo era el de introducir hábilmente por parte de sus creadores un personaje que aparentemente tuviera superpoderes, puesto que en realidad se descubriría que solo era un experto de la metalurgia que manejaba su característico martillo y hacía resistente su armadura gracias a sus habilidades (Mendryk, 2007). Kirby en 1957 recupera el personaje para el número 16 de la colección "Tales of the Unexpected" de DC/National, con el título The Magic Hammer, e introduciendo al público la primera versión de Loki. 


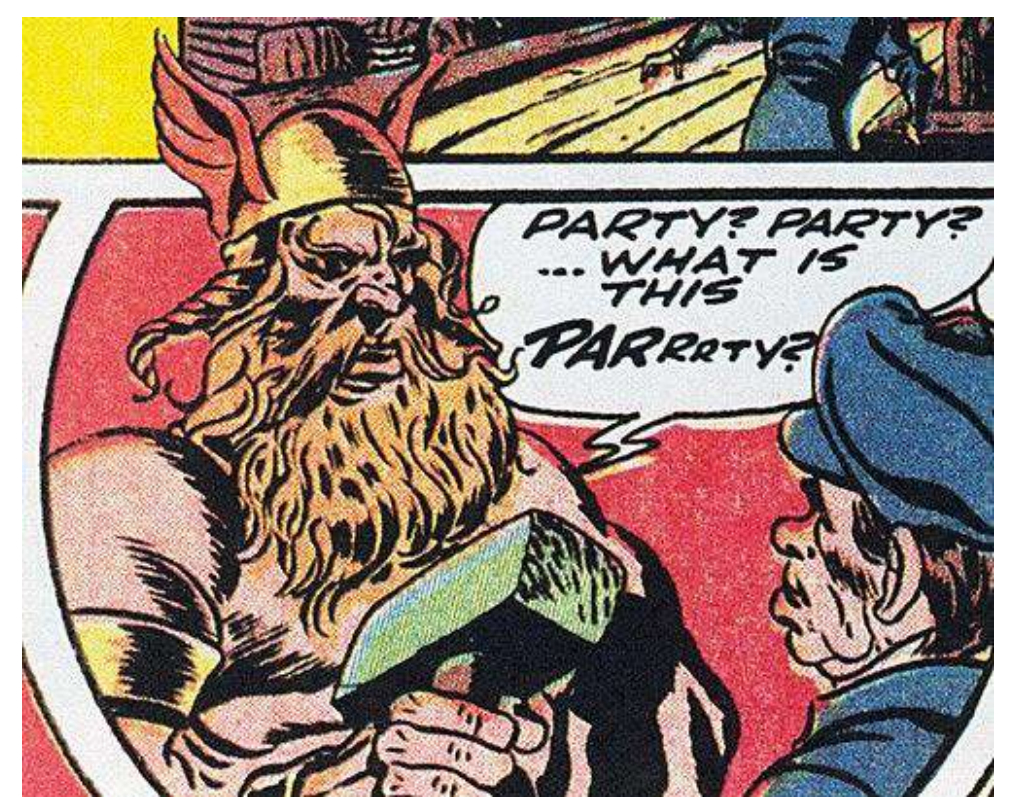

The villain from Valhalla (1942). Fuente:

https://web.archive.org/web/20120525110035/http://kirbymuseum.org/KirbysThreeThors

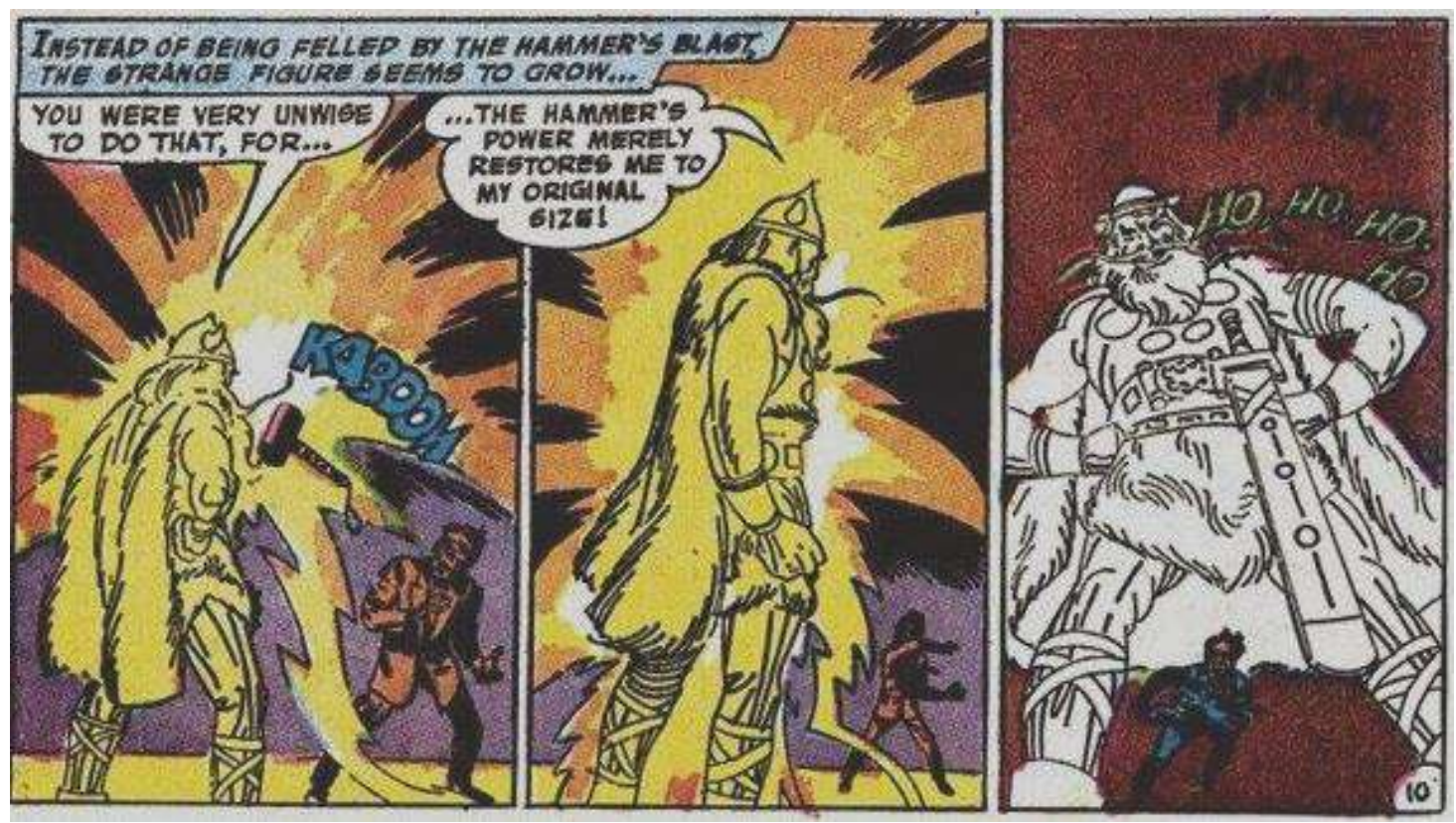

The Magic Hammer (1957). Fuente: https://www.bitfeed.co/page/jack-kirby-drew-the-first-version-ofthor-for-dc-comics

En 1959 vuelve a aparecer en varias ocasiones, una de ellas mediante el dibujo de Steve Ditko, co-creador de Spiderman y el Doctor Extraño, para la desaparecida editorial estadounidense "Charlton Comics" en el número 11 de Out of This World, donde Thor aparece con barba y pelo amarillo, de nuevo mostrando una distinta apariencia del dios. La 
otra versión aparece ese mismo año a través del número 127 del Caballero Oscuro de DC, en una historia del dibujante Sheldon Moldoff, en el que un coleccionista de objetos mitológicos, Henry Meke, le es transferido los poderes del dios, que reproduce fielmente en cuanto al color de pelo rojo y barba, aunque se toma la libertad del casco alado.

Será en 1962 cuando Jack Kirby, Stan Lee y su hermano Larry Lieber, autor de los guiones, presenten a Thor bajo el seudónimo de Donald Blake, quién adquiere su poder, y se publica para la revista de Marvel, Journey Into Mystery en el número 83. La trama aglutinaba entre lo más puramente mitológico, remontándose tanto a lo celta con el mito del rey Arturo, como lo germano-escandinavo; la ciencia ficción, con la aparición de alienígenas y el propio concepto del superhéroe, que vivía su edad dorada durante este periodo. En una biografía del propio Lee, explica el origen y motivo de su aparición una vez es creado un ser tan fuerte como Hulk:

\begin{abstract}
"But how do you make someone stronger than the stronger human? It finally came to me; don't make him human-make him a god. That notion intrigued me. I certainly had enough gods to choose from. I decided readers were already pretty familiar with the Greek and Roman gods. It might be more fun to delve into the old Norse legends... besides, I pictured the Norse gods looking like Vikings of old, with the flowing beards, horned helmets, and battle clubs. After writing an outline depicting the story and the characters I had in mind, I asked my brother, Larry, to write the script because I didn't have time... and it was only natural for me to assign the penciling to Jack Kirby, who drew it as though he has spent his whole life in Asgard, the home of the gods". (Mair y Lee, 2002, pp. 157-158).
\end{abstract}

Loki, uno de los personajes claves dentro del universo Marvel será presentado en el Journey Into Mystery \#85 (1962) como el hermanastro enemigo de Thor, distanciándose de la mitología, apresado en el interior de un árbol de Asgard, y que tras lograr escapar busca vengarse de Thor, que se en ese momento está en la tierra bajo el aspecto de Don Blake, transformándose en el dios mitológico para enfrentarse con Loki (Rosa, 2001). 

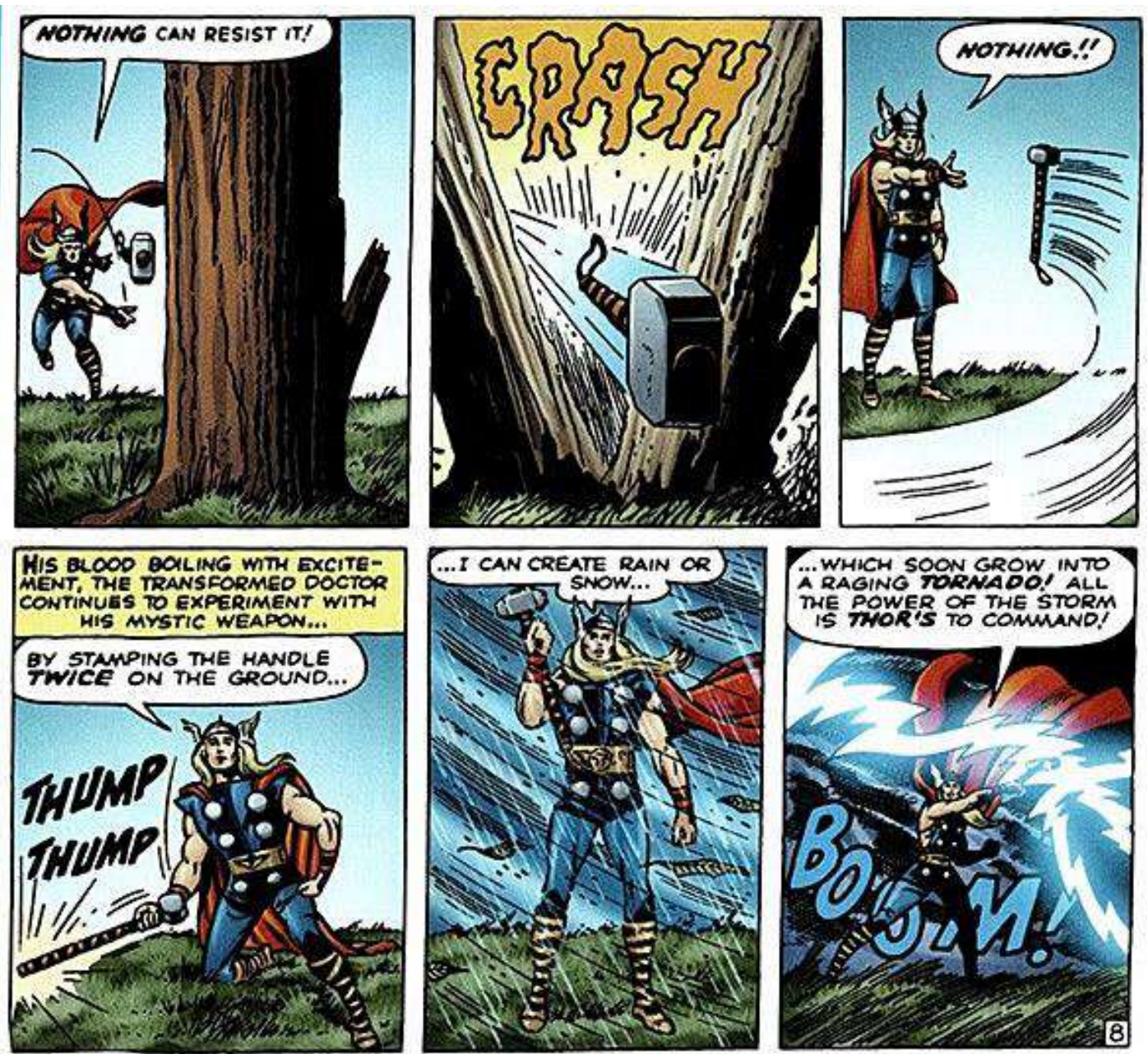

Journey Into Mystery \# 85 de Kirby y Stan Lee, 1962. Fuente: http://kirbymuseum.org/KirbysThreeThors

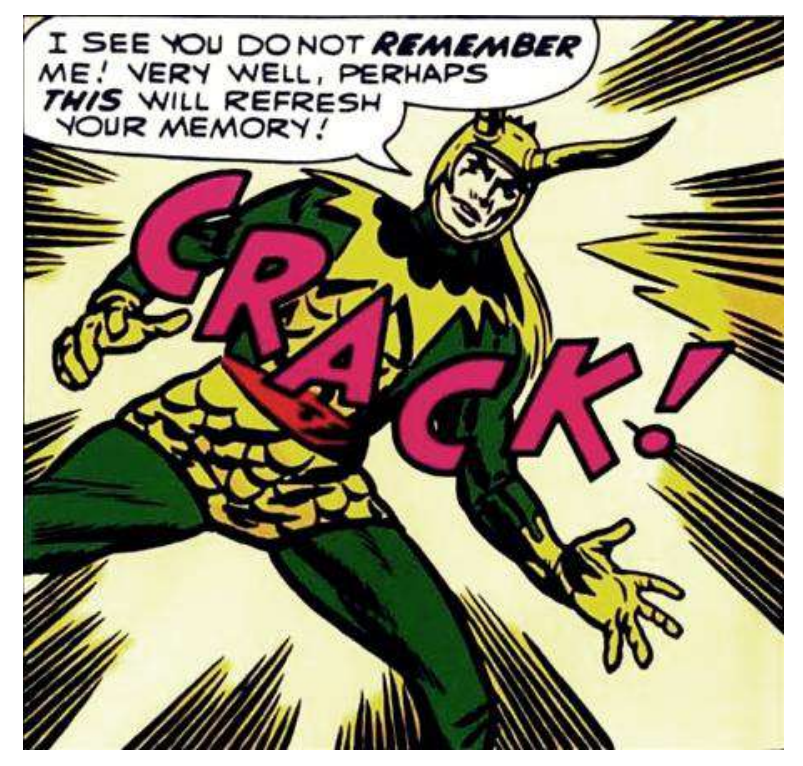

Aparición de Loki en el Journey Into Mystery \# 85. Fuente:

https://excelsior.universomarvel.com/era marvel/era_jim1085.html 


\section{El mundo de los dioses nórdicos Æsir en el imaginario de Lee y Kirby: Asgard.}

Desde la creación de Thor en 1962, prácticamente no existía cualquier referencia a la mitología nórdica a pesar de la integración en la historia de personajes como Loki, Heimdall, Balder, Odín o Tyr, lo que hacía al personaje principal "tremendamente plano" (Acebes, 2018). Es cuando llega en octubre de 1963 y a través del número 97 de Journey Into Mystery, la descripción de la mitología del dios del trueno en una historia de solo cinco páginas y con el título: Tales of Asgard! Home of the Mighty Norse Gods y que tendría su continuidad durante los 49 números siguientes, configurándola al universo Marvel.

El relato arranca con la presentación del pueblo vikingo, quien a través de las leyendas contadas a través de ellos sobre los dioses, son los principales causantes de darles vida a estos. Los Aesir eran los dioses bondadosos, que constantemente se encontraban en lucha con los malvados Gigantes de Hielo. Estos dioses vivían rodeados por la tierra del fuego al sur y la tierra de las nieblas al norte. Surtur, que reinaba en el sur, era el demonio de fuego poseedor de una espada llameante con la que aguarda el fin del mundo y la destrucción tanto de dioses como de hombres. Bajo todos ellos yacía el mágico manantial de la vida donde fluyen los ríos, que se congelarían debido al fuerte frío del norte.

Pasados unos siglos más tarde, esos bloques de hielo que se formaban en los ríos servirían para dar vida a un gigante enorme llamado Ymir, el más grande de todos ellos, y a una vaca mágica, también de enormes proporciones, que le nutriría de leche al gigante ${ }^{10}$. Tras varios años recorriendo las tierras heladas, en un instante brotaría del hielo Bur el primero de los dioses Aesir. De su matrimonio nació Borr que tendría tres hijos, siendo uno de ellos Odín, al que apodaron como "el padre de todos" y encargado de aniquilar a los Gigantes de Hielo. Dirigido junto a sus hermanos por el esplendor de la Tierra, deciden finalmente crear un anillo mágico en torno a esta y al árbol Yggdrasill, cuya misión era la de proteger a la Tierra mientras espera a la llegada del hombre ${ }^{11}$.

\footnotetext{
${ }^{10}$ En la Edda, el origen de la creación tanto del gigante de hielo Ymir como de la vaca mágica, cuyo nombre es Audhumla y principal causante del nacimiento de Bor, surge de la unión entre el hielo del norte y el fuego del sur: Velasco, M. Op. Cit., p. 101.

${ }^{11}$ El árbol Yggdrasil, era el enorme fresno del cual sus ramas sostenían los nueve mundos del universo mitológico nórdico donde concentraba a dioses, gigantes, enanos, elfos y humanos: Ibídem. p. 103.
} 


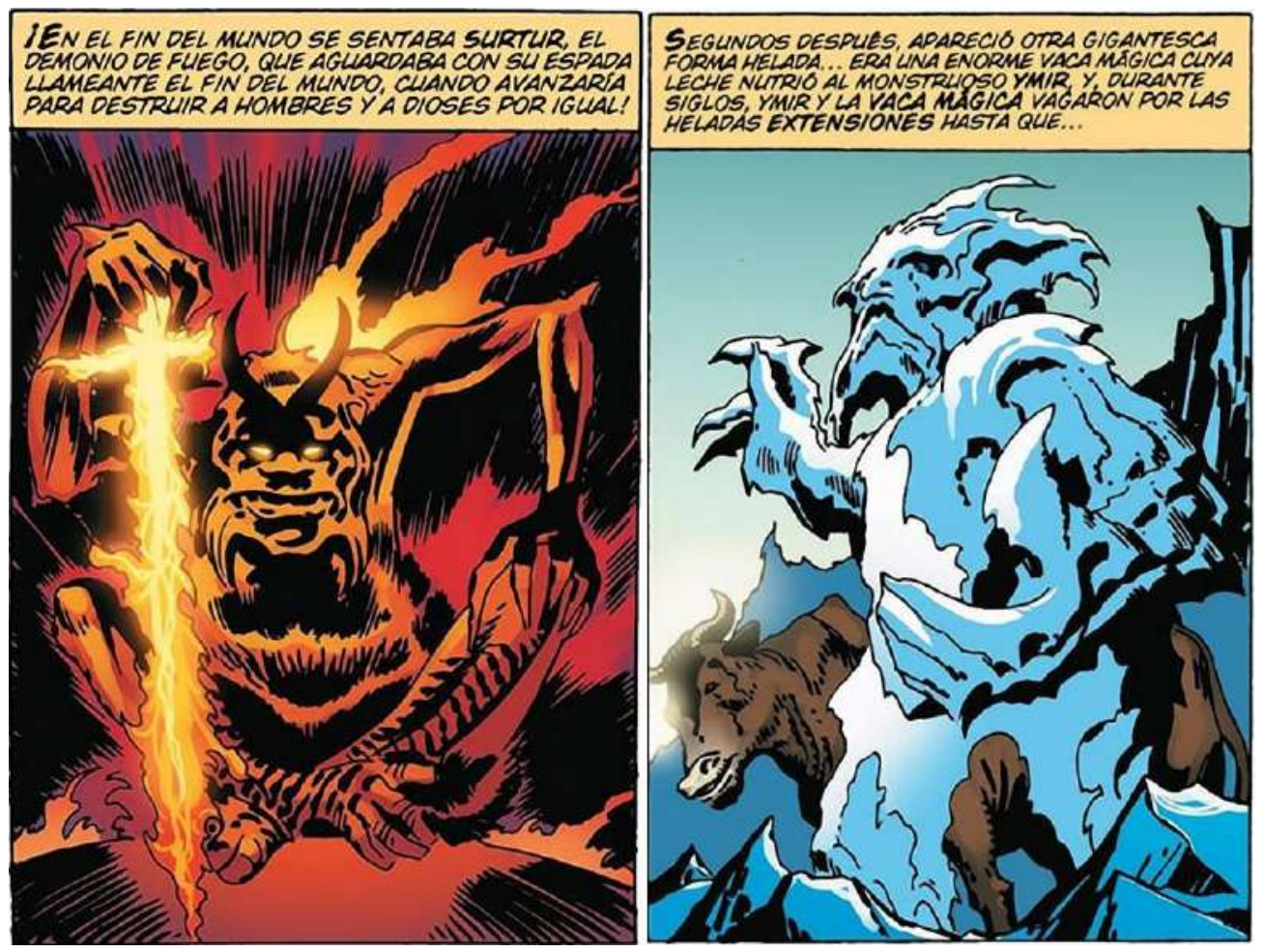

Suntur e Ymir: Relatos de Asgard, arte de Olivier Coipel, reimpresión del original Journey Into Mystery. \#97. Fuente: Coipel, OLLIVER. (2015) Thor: Tales of Asgard by Stan Lee and Jack Kirby. Limited Edition. Giclee.

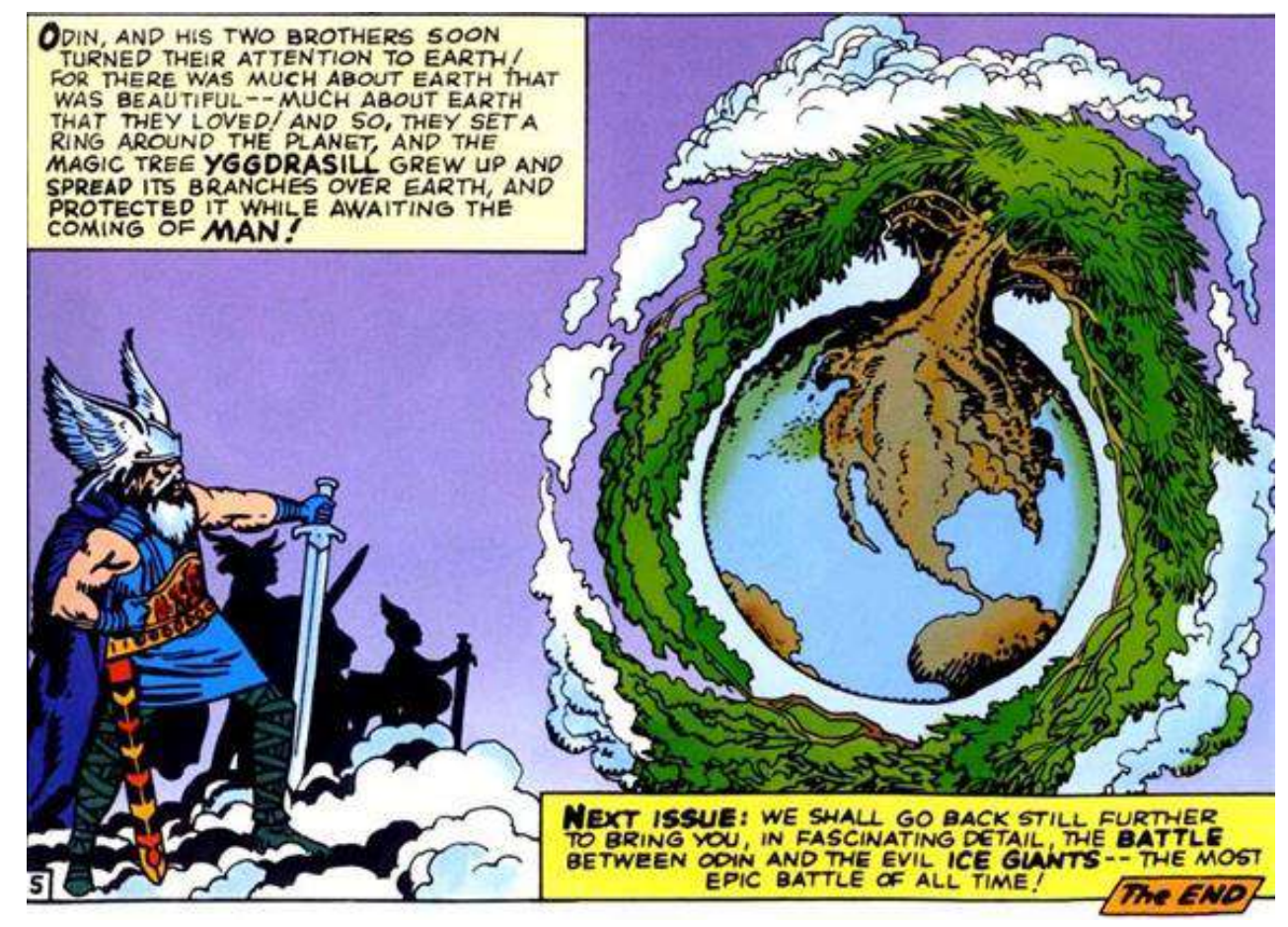

El árbol Yggdrasil protegiendo la Tierra del Journey Into Mystery. \#97 (1963). Fuente:

https://excelsior.universomarvel.com/era marvel/era_jim1097.html 
Este interés por darle un sentido mitológico al universo de Thor, situando a Asgard en el mapa, siempre fue desde un principio concebido por Jack Kirby, declarado entusiasta e investigador de la mitología nórdica. El propio Lee durante una entrevista en el año 1967 realizada por Mike Hodel para WBAI radio, New York reconocería la labor de Kirby:

"Well, you've got the right guy here, because I always say that Jack is the greatest mythological creator in the world. When we kicked Thor around, and we came out with him, and I thought he would just be another book. And I think that Jack has turned him into one of the greatest fictional characters there are. In fact, I should let Jack say this, but just on the chance that he won't, somebody was asking him how he gets his authenticity in the costumes and everything, and I think a priceless answer, Jack said that they're not authentic. If they were authentic, they wouldn't be authentic enough. But he draws them the way they should be, not the way they were". (Thomas y Fingeroth, 2011, p. 164).

Asgard es la morada de los dioses asgardianos, que a diferencia de la forma esférica de la tierra o la luna, está constituida por una masa de tierra relativamente plana, parecida a la de un asteroide, suspendida en el espacio y con una superficie que es aproximadamente el mismo que el territorio continental de los Estados Unidos, cuya naturaleza y física son diferentes de la de los cuerpos planetarios de la dimensión terrenal. Asgard no rota sobre su eje ni gira en torno al sol, pero sí tiene intervalos de día y de noche, de duración desconocida, por lo que un objeto funciona como un sol o incluso algún tipo de fuerza. Tampoco es seguro que haya estaciones, aunque siempre hay una parte en la que permanentemente es invierno y en otra que es verano.

La gravedad también es distinta a la de la Tierra, ya que en vez de ejercerse desde el centro de la tierra, lo hace desde algún punto por debajo de ella, por lo que un ser o un objeto puede caer al vacío una vez se traspasen los límites de su superficie, pero una fuerza hace mantener los bordes ante su desintegración y evita que la atmósfera se escape. Asgard es considerado como un "Mar del Espacio", la cual tiene una superficie que permite la navegación de los buques de Asgard similares a los barcos vikingos, pero la naturaleza exacta del espacio en la dimensión de Asgard se desconoce, aunque su gravedad se asemeja bastante a la de la Tierra, con una mayor densidad, peso y resistencia en comparación a esta última. 
Su dimensión consta de otras áreas, los habitantes asgardianos se refieren a suma de los nueve mundos y cuatro de ellos comparten espacio, siendo Asgard, la especie más poderosa y lugar donde habitan los dioses; Vanaheim, raza hermana de los asgardianos, conocidos como los Vanir y de aspecto humano; Nidavellir hogar de los Enanos, vecinos de Asgard y que les une una fuerte relación con ellos, y Alfheim, donde habitan los elfos luminosos.

Asgard tiene un laberinto complejo de portales que da a otras partes de los nueve mundos, y que a salvo la Tierra, que mediante el Bifrost está en contacto permanente con la tierra y protegido por Heimdal, el resto se encuentran en un plano contiguo designado por parte de los cartógrafos de Asgard. Otro pasaje especial de Asgard es el reino extradimensional del Olimpo, que es la morada de los dioses griegos, que por otra parte se cree de este artificioso y antinatural por el hecho de no pertenecer a la cosmología asgardiana. También se halla un fenómeno natural como es la "Cueva del Tiempo", por el que el paso a otros tiempos es posible.

Midgard, que es la tierra y quinto planeta, no le es influenciada ningún tipo de alteración física aunque constantemente los elementos de la cosmología asgardiana se encuentren en movimiento y a pesar de que el eje de la tierra se halle alineado con una de las raices el árbol cósmico de Asgard conocido como Yggdrasil. En la Tierra o Midgard habita la serpiente Jormungand, que es la hija de Loki, con forma de dragón enorme se sitúa rodeando las montañas de Jotunheim, lugar donde habitan los gigantes y sitio más cercano a Midgard, con forma de anillo plano y situado en un plano dimensional propio.

Los asgardianos creen en la otra vida una vez mueren y pueden ir o al Valhalla si han muerto con honor, o por el contrario si no lo hacen acaban en Niffleheim, lugar donde habita otra criatura que es el dragón alado Nidhogg y el gigante de hielo Ymir, y que es hermano del octavo reino, el de los muertos de $\mathrm{Hel}$, donde acaban los muertos ordinarios. En Varinheim habita Fenris, hijo de Loki y la gigante Angrboda, lugar en el que se encuentra prisionero, dejó sin una de sus manos a Tyr, hijo mayor de Odín, por su mordedura. Los reinos faltantes son Svartalfheim, hogar de los elfos de la oscuridad y séptimo de los reinos, de forma parecida a Asgard pero de menor tamaño, tiene múltiples portales para conectarse al reino principal lo que hace que pueda ser un submundo de este, y el noveno Muspelheim, perteneciente a los demonios de fuego, tiene su propio plano dimensional y fue gobernada por 
una de las criaturas más temibles, Suntur, quién la profecía le adjudica el principal causante de los dioses adgardianos, al desatar el Ragnarök ${ }^{12}$.

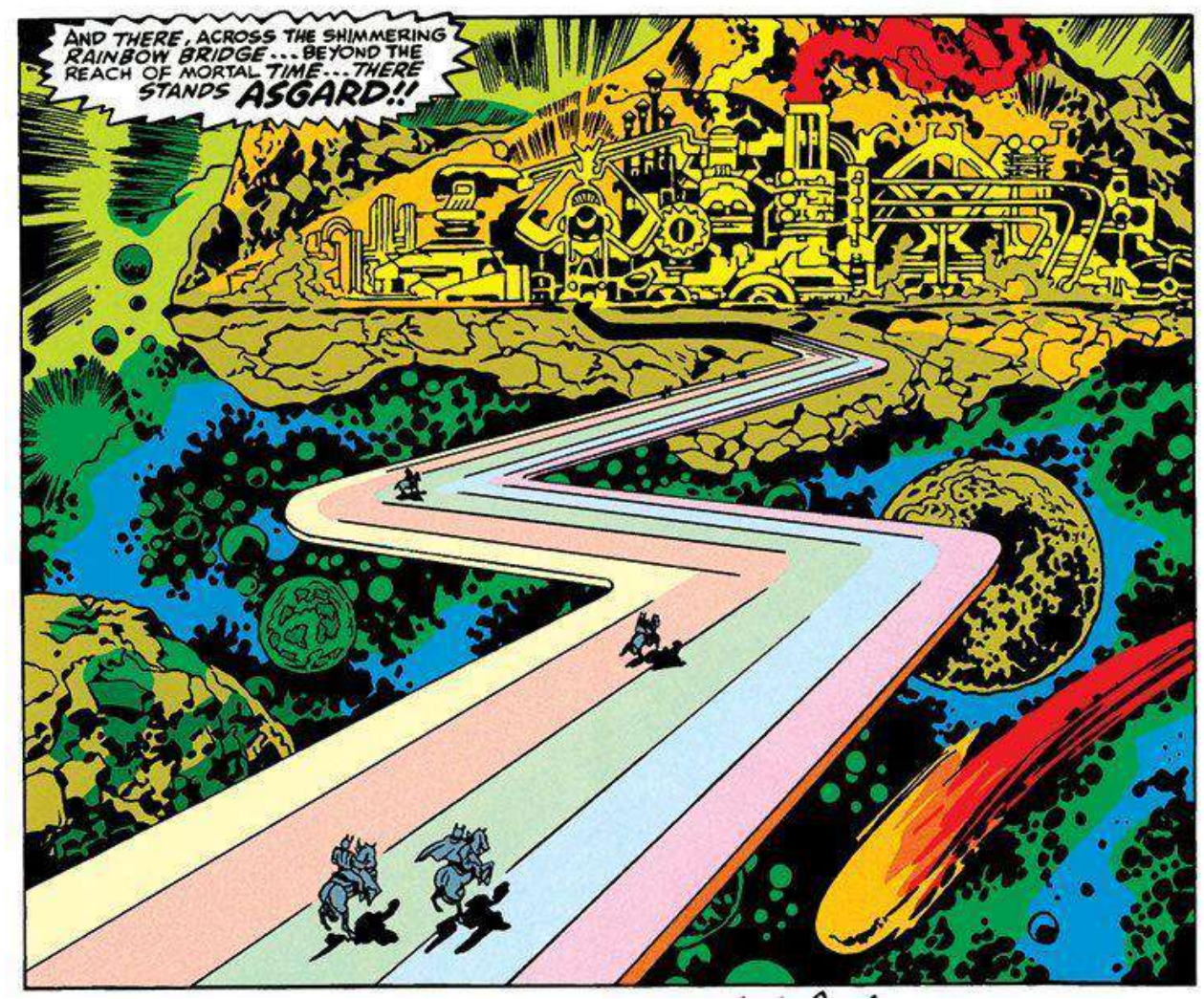

Asgard, Marvel Comics. Fuente: https://hwcol.com/2020/04/13/el-infierno-el-cielo-y-jesus-existen-en-dc-y-loscomics-de-marvel-de-una-manera-extranal

${ }^{12}$ En el apartado cinematográfico, han sido destacables las producciones entorno al héroe mitológico coincidiendo con la llegada del digital a lo largo del siglo XXI. Destacar la primera de ellas adaptada de Marvel Comics, titulada Thor (2011), del director Kenneth Branagh, asumiendo el papel del dios nórdico el actor Chris Hemsworth, que participará en las siguientes entregas: Thor: El mundo oscuro (2013), dirigida por Alan Taylor; Thor: Ragnarok (2017), bajo la dirección de Taika Waititi; y la más reciente (2018), Vengadores: Infinity War, cuyos encargados de dirigirla fueron los directores Anthony y Joe Russo. 


\subsubsection{La representación de la cultura vikinga en el cómic americano contemporáneo: Northlanders de Brian Wood (2007).}

Bajo el guión del estadounidense Brian Wood (1972) tras la propuesta de Will Dennis, editor de Vertigo (DC Comics), nace en el año 2007 Northlanders, concluyéndose en el año 2012, con un total de 50 ediciones. La idea de Dennis era la de darle forma a un clásico como era The Viking Prince (1955) de Robert Kanigher y Joe Kubert, de la serie de cómics publicada por DC Comics titulada The Brave and the Bold. En una entrevista para la página web de cómics $C B R$, Wood dijo que el origen de su idea argumental estuvo relacionada mediante el visionado del DVD The Yakuza Papers, una serie de películas violentas y fantásticamente bien ambientadas sobre gángsters de la posguerra en Japón, y como a partir de ello indica que "The very first thing I wrote about Northlanders was: "A nihilistic crime saga set in A.D. 870, when much of England was under Viking rule" (Callaham, 2009).

La idea original de Wood, era la de no realizar una serie convencional con un protagonista principal, sino que quería un conjunto de historias independientes de gran arco argumental, y tal como indica Jiménez (2015) que estas fueran "auto-conclusivas, de seis o siete episodios, con protagonistas diferentes" dando la posibilidad de poder ambientar las distintas épocas de la historia y así recorrer toda la etapa vikinga, además de introducir interludios de hasta dos números que reflejase aspectos de la vida cotidiana de la civilización vikinga. Por otra parte, cada arco sería dibujado no siempre por el mismo artista para así remarcar mejor la independencia señalada.

La primera saga con la que nace la serie bajo el título de El regreso de Sven, nos sitúa en el 980 d. C., Sven es un componente de la guardia varega del Imperio Bizantino. Por aquel momento Constantinopla era un gran centro cultural y de una civilización muy desarrollada, en la que nada apenas podía compararse a la del pueblo vikingo del que procedía y del que tuvo que huir desde muy pronta edad. En el mar recibe la noticia, por parte de un grupo de vikingos que quería su muerte, de que su padre Olaf, caudillo de la comunidad, ha sido asesinado por su propio hermano Gorm, por lo que Sven decide volver a su hogar, las islas Orcadas (Orkney Islands) para vengarlo y reclamar la herencia de la cual es legítima (Torralba y Marín, 2009). 


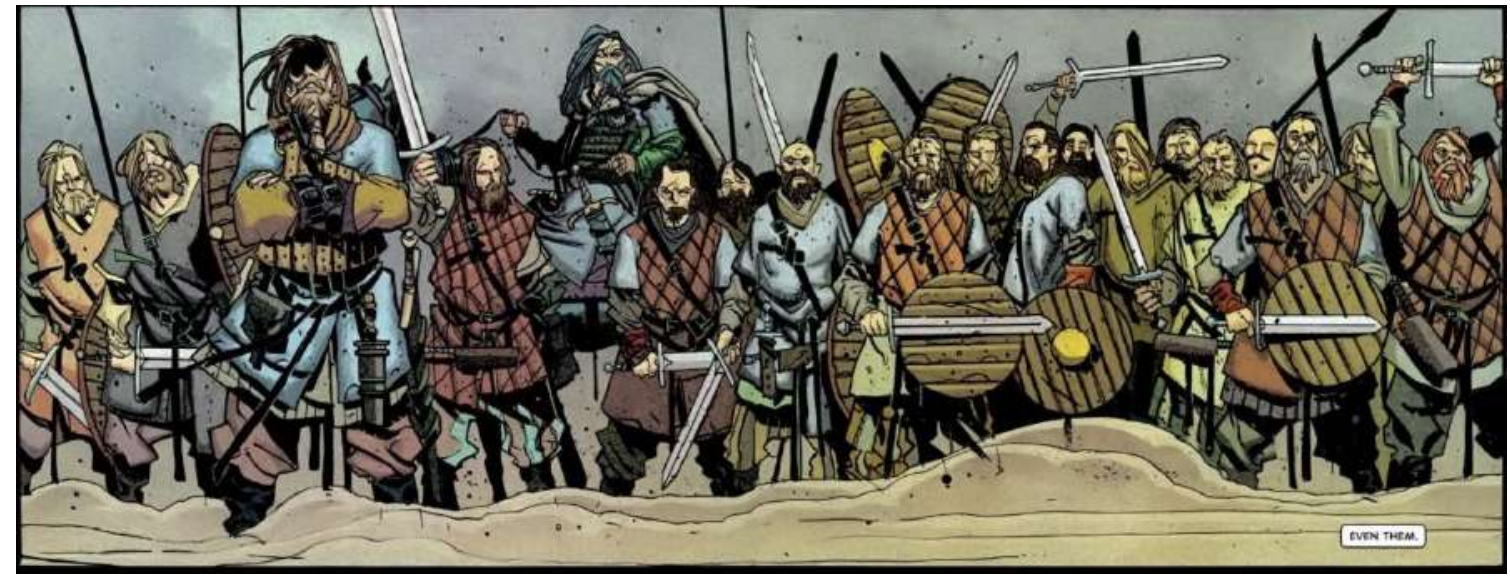

Vikingos en la historia del Regreso de Sven, arte de Davide Gianfelice. Fuente: Wood, BRIAN. (2007) Northlanders. Vertigo (DC Comics).

La labor de documentación por parte de Wood para adentrarse en el mundo vikingo fue descomunal tal y como refrenda el propio guionista con sus propias palabras, de las que José Torralba y Raul Marín se ocuparon de la traducción para su artículo en la página web de análisis de videojuegos, Zonanegativa:

"Me llevó un año y medio de serio trabajo. Compraba cualquier libro que hiciera referencia al tema. La colección de obras sobre esta materia que he acumulado en este tiempo sería la envidia de cualquier biblioteca universitaria... He viajado a las islas Orcadas y por el norte de Escocia, donde transcurre el primer arco argumental. . También por Islandia, que es un lugar muy, muy rico en historia vikinga. Pasamos tres semanas allí, y el aficionado que llevo dentro se emocionó al seguir los pasos de la gente sobre la cual había leído en las Sagas”. (Torralba y Marín, 2009).

Esa independencia narrativa anteriormente indicada a través de varias historias contadas a lo largo de la serie, permite a Wood reflexionar sobre varios puntos de vista que directamente asociados a la sociedad y mentalidad vikinga. En la historia de Sven, retrata los motivos del ocaso de su existencia, provocado no por factores externos, sino por la propia incapacidad de avanzar como cultura al encontrarse anclados bajo el dictado de unas tradiciones obsoletas y no edificar sobre los territorios que iban arrasando, que es todo lo contrario a lo que llegó hacer un territorio multicultural como Constantinopla (Miklagård para los vikingos). Esta idea se resume en las palabras que pronuncia Sven: “esa es la única cultura que merece conocer, la que viene de conquistar y asimilar a otras gentes para adaptarse de lo que es extraño y aprender de lo que es diferente". 
Respecto al tema de las creencias, cristiana y pagana, en este aspecto quiere hacernos ver que una no es tan distinta de la otra en el sentido del destino de las personas. En ambas mentalidades, se trata como acto de cobardía el esconderse ante las adversidades porque habrá merecido la pena agarrar una espada y dar tu vida por ello. Los dioses, tanto el cristiano como los paganos, son los que deciden si habrá gloria o no el día de la batalla y sus fieles están convencidos de que los guían y protegen ante ella, y en caso de caer será también porque ellos lo han decidido así y no habrá sido en vano, puesto que como recompensa, serán recibidos respectivamente en sus reinos, unos abrazados a Dios y los otros disfrutando con los dioses en la "Sala de Odín".

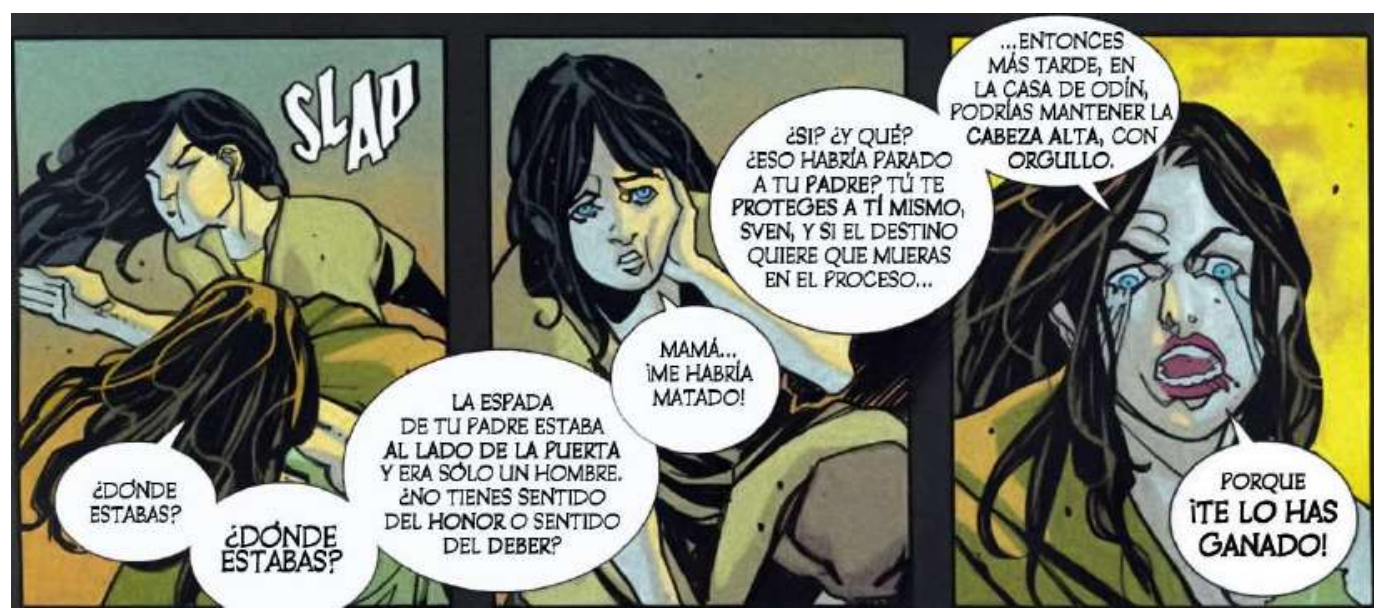

Filosofía desde el punto de vista de la creencia vikinga. Fuente: Wood, BRIAN. (2007) Northlanders. Vertigo (DC Comics).
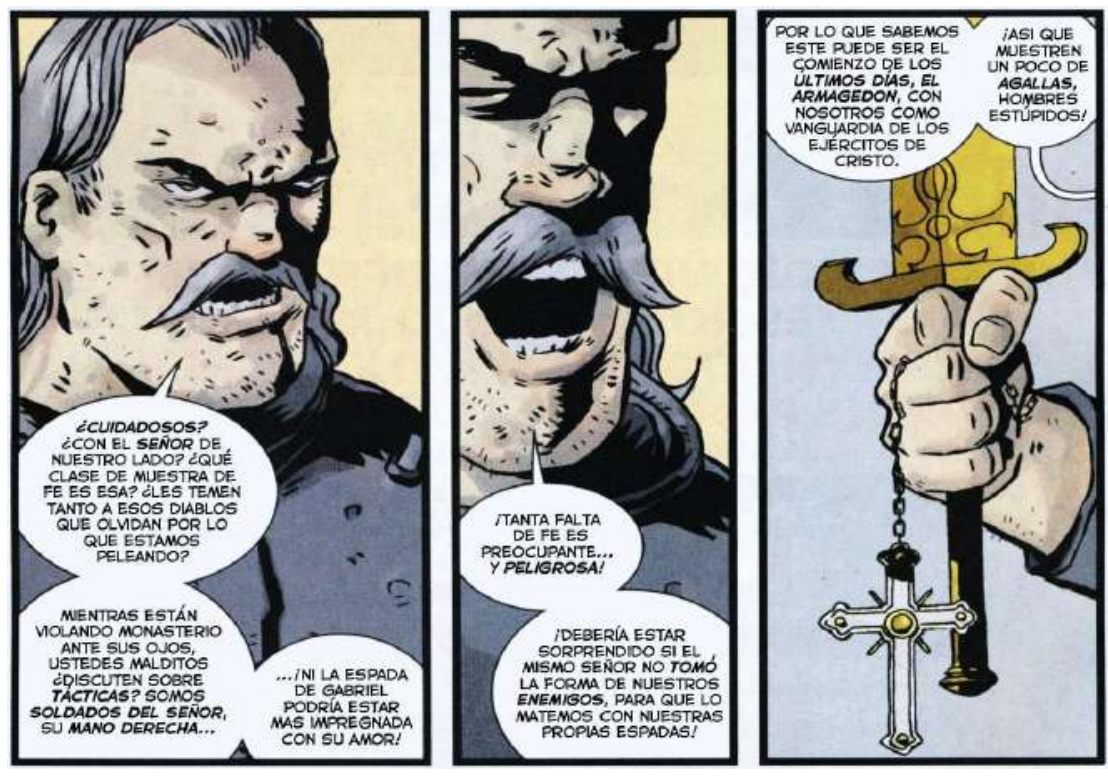

Filosofía desde el punto de vista de la creencia vikinga, arte de Dean Ormston. Fuente: Wood, BRIAN. (2007) Northlanders. Vertigo (DC Comics). 
En una de estas historias autoconclusivas de un solo número y titulada El arte vikingo del combate singular, no solo hace referencia a las normas y estrategias las cuales se mueve el guerrero durante una batalla, sino que utiliza esa trama para profundizar sobre lo que internamente procesa la persona que está en ese instante luchando. Una vida que se asume corta, que podría ser tranquila como la de un granjero que cosecha su tierra, pero que sabe que tiene todas las papeletas de ser llamado a una batalla de la cual posiblemente no vaya a ver de nuevo nunca más a esposa e hijos, y que para que esto no ocurra deba arrebatar la vida de un semejante. El vikingo adora lo que hace, el arte de sus barcos, sus incursiones, sus guerreros más fieros, o su capacidad intimidadora, pero sobretodo sobrevive, quiere lo mejor para su familia y si tiene que abandonar su tierra para hacer otra vida en ella lo hará, a pesar de que se la arrebate a otra, pues después de todo aceptan con resignación que los dioses disfruten verlos luchar contra todo constantemente para labrarse un lugar.

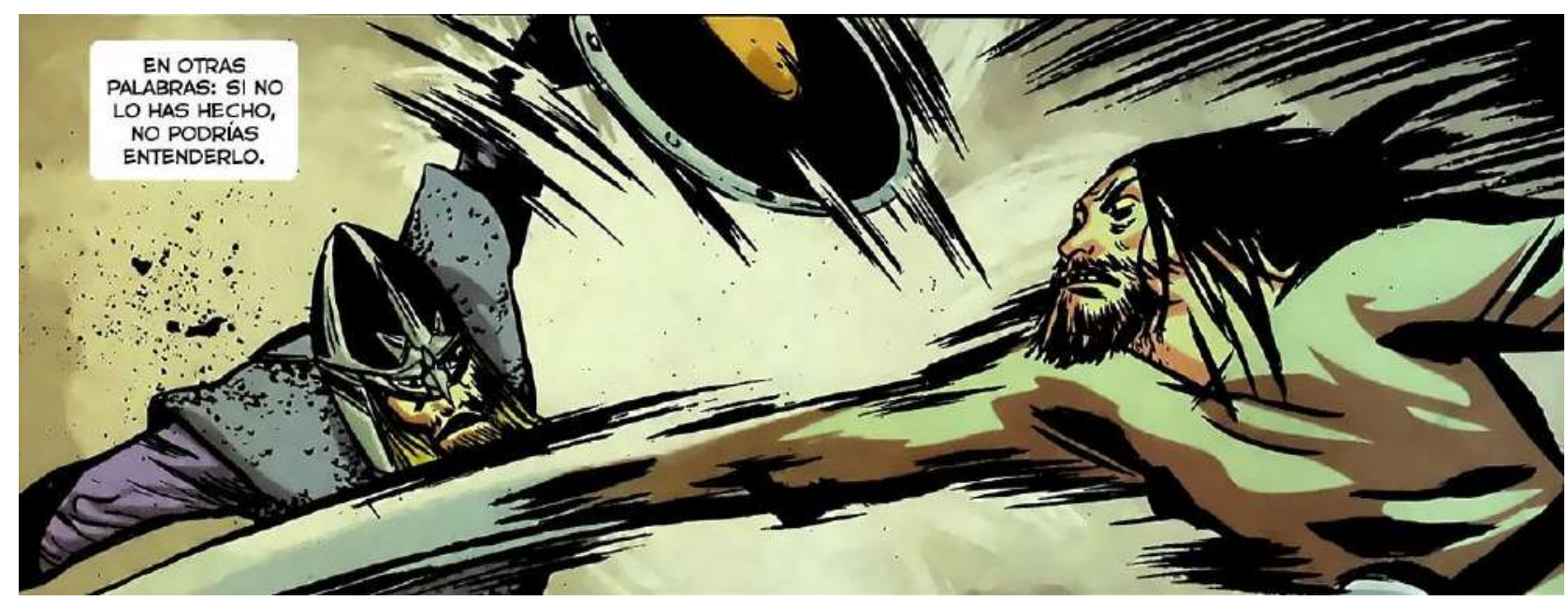

Duelo entre vikingos, en la historia de El arte vikingo del combate singular, arte de Vasilis Lolos. Fuente: Fuente: Wood, BRIAN. (2007) Northlanders. Vertigo (DC Comics). 


\subsection{Cómic europeo.}

\subsubsection{Primer contacto del mundo vikingo en el cómic europeo. Hans G. Kresse, el talento neerlandés: Eric de Noorman (1946).}

La serie Eric de Noorman (1946), fue una de las principales obras populares de los Países Bajos, bajo autoría de Hans G. Kresse.

Hans Georg Kresse (1921-1992) fue uno de los ilustradores más relevantes del panorama neerlandés gracias a la reputación que le dio su obra Eric de Noorman. Desde pronta edad tenía un don para el dibujo, a pesar de que comenzó haciendo trabajos de carpintería. Su interés por esculpir, el cual recibió formación, lo compaginaba con la de la lectura de cómics, fascinándole la técnica realista del Tarzán y Príncipe Valiente de Hal Foster, así como la que empleó Alex Raymond para su "Flash Gordon". Es cuando en 1938 decide, sin ninguna formación previa en el dibujo, crear su primer cómic en la revista de boy scouts, De Verkenner, un fan-fiction dedicado al famoso héroe de la selva con el título de Tarzán de los monos (Huygens ING, 2013). A partir de 1940 también dibuja un cómic basado en un western y llamado Tom Texan, pero la Alemania nazi obliga su cierre. Al mismo tiempo se dedica a hacer una guía de exploración, Lassowerpen en Touwdraaien, para aprender a utilizar lazos y cuerdas por medio de ilustraciones y basado en el libro americano How to spin a rope.

En torno a los años 40, Kresse solicita trabajar en el estudio del también creador de cómics neerlandés, Marten Toonder. Por entonces Toonder había sido el pionero del país en introducir el mundo de la historieta trabajando para varias revista locales, pero decidió crear su propio estudio en un momento perfecto, puesto que la guerra cortaba la entrada de cómics foráneos y la demanda se hacía notar (Lambiek, 2020). Tras mostrar su obra a Toonder, este quedaría impresionado, pero decidió esperar para que éste acrecentara su formación y Kresse se dedicó a crear portadas de libros para la editorial "Boekenbedrijf Arena" en Haarlem.

Tras recibir una carta del centro de reclutamiento de Alemania para servir al ejército, ya que la ley le consideraba como tal al estar su madre casada con un alemán, este simuló 
tener una enfermedad nerviosa de una manera tan convincente que lograría su baja del servicio por ser considerado "mentalmente loco" en el año 1942. A su regreso a Haarlem, encontró trabajo en un curso de animación cinematográfico estando bajo la dirección del dibujante y arquitecto Henk Kannegieter. El estudio estaba ligado a una compañía de cine nacionalsocialista conocida como "Nederland-Film", más tarde cambiando su nombre por "Bavaria Film", aunque Kresse renegaba absolutamente de esa ideología. Al cerrar la compañía, se uniría finalmente al estudio de Toonder donde trabajó con otros compañeros de la Nederland-Film, y tras pasar por distintos departamentos fue designado finalmente al de cómics e ilustración, donde desarrollaría trabajos como la novela pictórica "Pinneke Proost" (1943). Entre otros proyectos realizados durante estos años, destaca el del cómic basado en la leyenda germana Siegfried bajo el seudónimo de "Henk Zwart", e inspirado en la obra histórico-realista del Príncipe Valiente de Hal Foster, publicada por la revista quincenal infantil Jeugd, también controlada por los nazis, o el de ilustraciones para una revista de la resistencia, "Metro". Tras la liberación de los Países Bajos, Kresse pasó un tiempo en cautiverio tras ser culpado por colaborar para la causa alemana, pero Dick van Veen, un amigo suyo y empleado de Toonder se ocuparía de que este fuera liberado de todos los cargos, logrando sacarle de prisión. El periodo de la posguerra fue una etapa intensa para Kresse, ya que era muy valorado por Toonder y éste se dedicaba a crear numeros cómics de distinta naturaleza, desde lo cómico a la fantasía, incluyendo el apartado nativo americano y lo detestivesco.

Esta saturación parecía no afectarle, pero quería cambiar de rumbo hacia un género más dramático y fue cuando propuso a Toonder diseñar un cómic sobre la historia de un héroe vikingo llamado Leif, y por lo tanto ambientada en la Edad Media. Por entonces ya se estaban popularizando series de aventuras vinculadas con la navegación y que era del agrado neerlandés debido a su larga tradición, destacando cómics como "Kapitein Rob" de Pieter J. Kuhn (1945-1966) o "Kappie" (1945-1972) del estudio de Toonder. A Toonder le gustó la idea, porque la encontraba interesante desde el punto de vista comercial y creía que era más conveniente que la historia se desarrollara en un ambiente más mitológico, cuya representación ideal fuera el continente perdido de la Atlántida con la presencia de seres monstruosos y criaturas místicas, llegando finalmente a un acuerdo entre ambos en el que se incluía el cambio de nombre del personaje principal, dándose a conocer como Eric. Sin embargo no llamó la atención de ninguna revista o periódico neerlandés porque en los Países 
Bajos se preferían historietas de corte cómico para niños, por lo que tuvieron que contactar con periódico belga "Het Laatste Nieuws" que quiso darle una oportunidad a la serie, debutando finalmente el 6 de junio de 1946 y siendo distribuido a los distintos países escandinavos.

Eric es un joven rey vikingo de buen corazón y gran fortaleza de cuya relación con Winonah nace su hijo Erwin, un chico cuyo mal genio le acabará trayendo graves problemas. Los personajes que le acompañan durante sus aventuras son entre otros: Pum Pum, un criado enano; el navegante pesimista Orm; Svein, un bravo guérrero; el veterano constructor de barcos, Cendrach y su hija Branwen. El cómic sufrirá una evolución debido al enfoque que querían darle tanto Toonder como Kreese, el primero más interesado en un sentido mitológico, en el que se idealizaba la Edad Media mediante la presencia de magos, dragones o duendes, pero Kreese quería más rigurosidad histórica para una mayor credibilidad y a partir de 1951 toma las riendas y el mismo se ocupa de "destruir la Atlántida" para ubicar la acción en la Roma antigua, teniendo como protagonista al emperador Cómodo, o del mismo modo enfrentar a su personaje en batallas contra diferentes pueblos, donde aparecen personajes históricos como Atila. Para ello el artista se vería obligado a obtener una extensa documentación a través de largos viajes por el mundo, que serviría para ubicar escenarios, construcciones, objetos, etc.

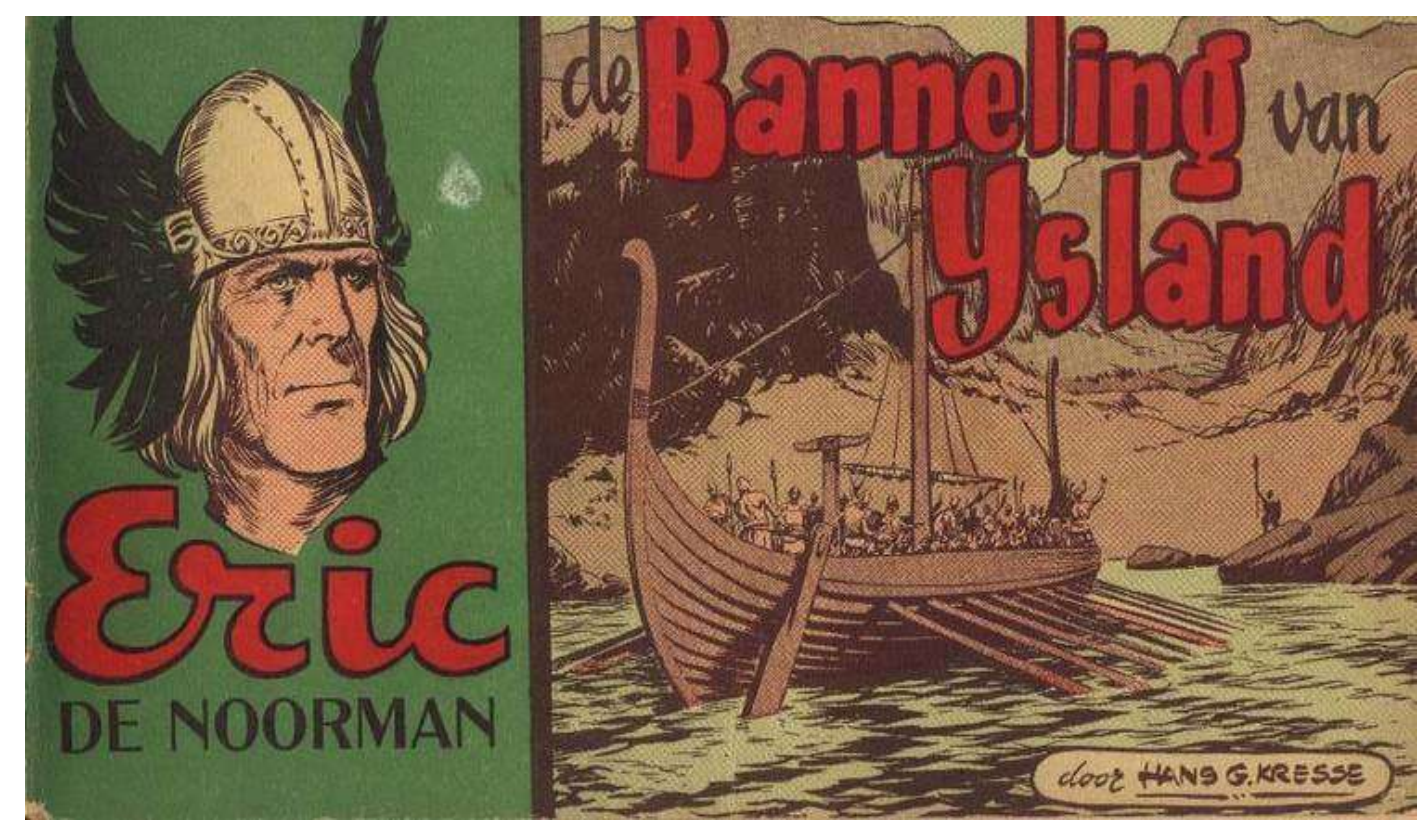

Portada del $n^{\circ}$ 37, El exilio de Islandia (1958). Fuente: http://www.digistrip.nl/HTML/Eric\%20De\%20Noorman\%2001-52\%20\%28ic\%29.html 
El verdadero éxito que tuvo el cómic se debió en mayor parte al estilo empleado por Kreese, de un realismo muy inigualable en comparación a otras obras del momento. Esa cercanía que sentían los lectores era lograda a través de los efectos que empleaba por medio de la poderosa combinación del blanco y negro y del uso magistral del contraste de luces y sombras, además de llegar a crear escenas de un realismo fotográfico tan cercano que daban la sensación de ser como tal. Al comienzo, sus ilustraciones las realizaba por medio de pluma y tinta, pero ésta sería cambiada posteriormente por el pincel, ganando un mayor naturalismo y elegancia en su dibujo. Asimismo, la serie originalmente nació con el formato de texto debajo de las imágenes, que por otra parte, era lo habitual en los cómics neerlandeses de aquella época (Cepriá, 2008) y era impresa en blanco y negro, aunque posteriormente algunas de las tramas de la serie serían coloreadas con texto adaptado a la forma del bocadillo, hecho que no gustó a sus fans. Tras desgastarse la relación con Toonder y el que era antiguo socio de este, Anton De Zwaan, la serie vería su última publicación el 24 de enero de 1964.

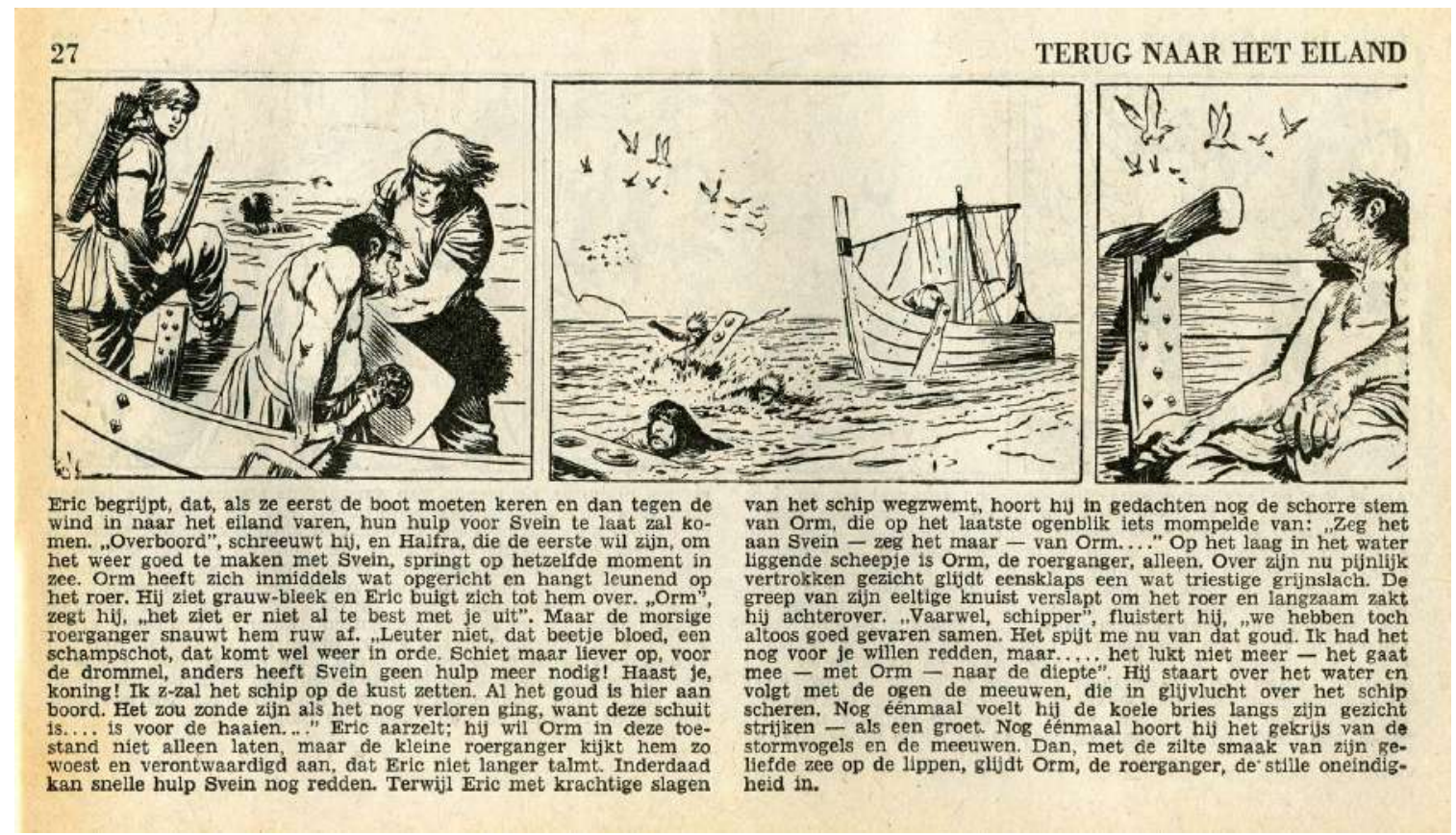

Viñetas con texto acompañado. Fuente: https://www.lambiek.net/artists/k/kresse.htm

En España se reeditó entre los años 1952-53, por medio de la editorial Hispano Americana, en un total de treinta y siete ejemplares más dos variantes, a modo de cuaderno rústica (variantes 1-2) y grapa (1-37) a doce páginas por ejemplar, incluidas sus cubiertas (Humanes y Barrero, 2008). Esta edición contaba de portada a color, a una tinta en su 
contraportada y las páginas y cubiertas de tripa en blanco y negro correspondientes a las caras interiores, además de seguir el modelo del original, con los textos a modo de pie de imagen situado bajo las tiras.

\subsubsection{Ragnar le Viking de Eduardo Teixeira Coelho y Jean Ollivier (1955).}

Ragnar le Viking (1955), es la obra creada por el dibujante portugués, Eduardo Teixeira Coelho y el guionista francés, Jean Ollivier.

Eduardo Teixeira Coelho "ETC" (1919-2005) también conocido bajo el seudónimo de Martin Sièvre, es uno de los grandes referentes en el mundo de la historieta portuguesa. Su pasión por el dibujo le llegó desde muy temprana edad, cuando reflejaba todo lo que le envolvía a su alrededor a través de garabatos que realizaba en su cuaderno. Con diecisiete años comenzó a colaborar en Semper Fixe, un semanario humorístico, publicando una historia bajo el título Há Qualquer Coisa que se Coma?! y también haría trabajos en "O Senhor Doutor", una revista infantil. El inicio de su periplo artístico con el que daría su consagración está en su origen en el momento que conoce a António Cardoso Lopes, director de "Edições O Mosquito", a mediados de 1942. Esta etapa es la considerada como la más dorada del portugués, siendo su primer contacto en la participación de revistas de la editora, como es el caso de la tira cómica Engenhocas e Coisas Práticas, ocupándose, como en otras, de todo el proceso dibujístico. Ganada la reputación de artista reconocido, llegó a la revista O Mosquito, en la cual desarrolló un extenso trabajo con títulos como: Os Guerreiros do Lago Verde (1945), Sigurd o Herói (1946), Falcão Negro (1946-1949) y la serie O Caminho do Oriente $(1946-1948)^{13}$.

También publicaría en otros países, como es el caso de España, lugar donde se llegaría a instalar en 1953. Trabajó para las revistas "El Gran Chicos" entre 1945 y 1948 y "Chicos"

\footnotetext{
${ }^{13}$ Esta última creada bajo la adaptación de Raul Correia, con quién frecuentemente trabajaba durante esta etapa como guionista, aunque también muchas historias serían concebidas exclusivamente por Coelho como las publicadas para el suplemento "A Formiga" de O Mosquito, en la que realizaría una trilogía sobre antiguas leyendas moriscas relacionadas con la tradición oral portuguesa y que estaba compuesta por: A Moura e o Dragão, A Moura e a Fonte y A Moura e o Mar, en: Coma, Javier. Historia de los Cómics. Barcelona, Toutain Editor, 1983, pp. 1209-1210.
} 
gracias a un intercambio que se produjo entre editoriales lusas y españolas, colaborando por ejemplo para O Mosquito el barcelonés Jesús Blasco (1919 - 1995), mientras que Coelho publicaría tres obras: El Hechicero de los Matabeles y Un Jinete del Oeste, ambas en 1944 que posteriormente serían retomadas y traducidas en portugués para O Mosquito, junto a Los Naufragos del Buque sin Nombre que salió para las dos ediciones (Gonçalves y Guimarães, 2018, p. 3) y (Alary, 2002) ${ }^{14}$.

Insatisfecho por no encontrar la verdadera estabilidad que buscaba, terminó instalándose en Francia a partir de 1954 y comenzó a colaborar para la revista "Vaillant" (más tarde "Pif Gadget") hasta los años 70. Esta etapa fue la más profusa, en la que el dibujante empezaría a trabajar con el guionista Jean Ollivier y pasaría a firmar bajo el pseudónimo de Martin Sièvre, realizando entre otros títulos: Davy Crockett (1957), Wango (1957 - 1958), Yves Le loup (1960 - 1962), Robin des Bois (1969 - 1975), Le Furet (1975 - 1976), Érik, le Rouge (1976 - 1977) o Ayak, Loup Le Blanc (1979 - 1984), destacando especialmente su interés por el mundo vikingo. Su fama sin embargo se la dio la serie Ragnar le Viking, creada para la misma revista y que daría inicio en 1955 con textos de Ollivier.

La historia cuenta las aventuras del joven Ragnar, jefe vikingo, que a través del drakkar "Le Coursier des waves" recorre los mares para luchar contra la tiranía y la opresión, rompiendo los prejuicios del vikingo que saquea, mata y esclaviza a los vencidos, e integrando al mismo tiempo elementos propios de la mitología nórdica (Granja, 1984, p. 2010). En su dibujo se atisban ecos de Harold Foster en su amor que procesa por la naturaleza y en su manera de representar el movimiento de los animales de forma precisa y elegante, y además esboza al protagonista fuera de toda convención física a la que se le solía atribuir a estos guerreros, con cuerpos corpulentos. Coelho articula de una manera excepcional el desarrollo de la aventura y la proyección de imágenes que se suceden a un ritmo cinematográfico en los cuales identifica y representa a los personajes ${ }^{15}$. La serie finaliza en 1969 con un total de 40 episodios tras el cierre de la revista en ese año, de la que dará a lugar su sucesora Pif Gadget en la que el portugués realizará una serie de trabajos.

\footnotetext{
${ }^{14}$ En este momento se encontraba instalado en Inglaterra, donde trabajó para la editorial inglesa "Amalgamated Press", colaborando en el pequeño formato mensual "Thriller Picture Library", en la cual realizaría la serie de Robin Hood. También intentó abrirse al mercado brasileño no con mucho éxito, publicando historias reeditadas de la revista O Mosquito para la revista "Aventuras Heróicas", y también para "O Jornalzinho". El trabajo, por otra parte no resolvía sus problemas económicos: Ibídem. p. 2010.

${ }^{15}$ Por otra parte, al igual que en la obra del maestro canadiense, éste prescinde de los globos de diálogo.
} 


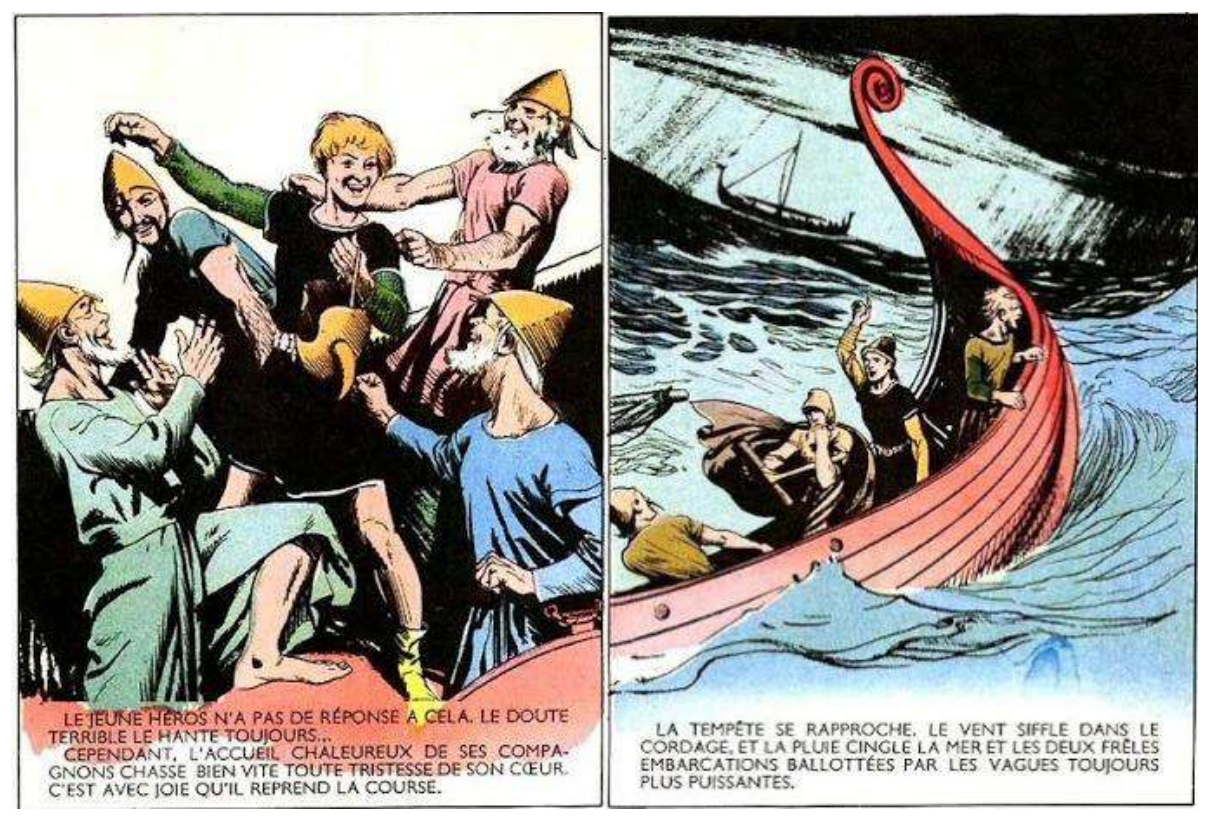

Vikingos junto a Ragnar. En la historia La frontière de l'Enfer, in Vaillant 561 (1955). Fuente: http://johnadcock.blogspot.com/2014/12/the-golden-harp-ragnar-le-viking.html

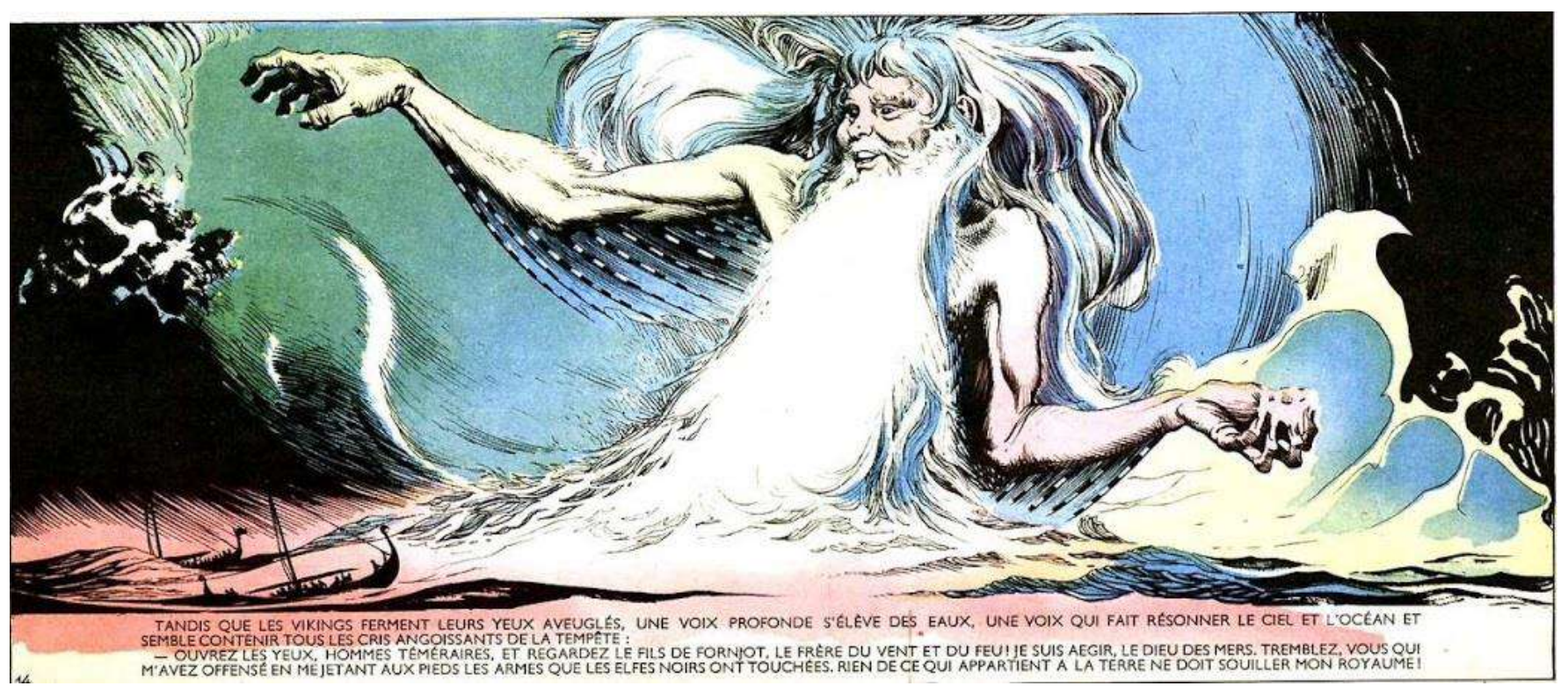

Representación del dios de los mares nórdico, Aegir. En la historia La frontière de l'Enfer, in Vaillant 561 (1955). Fuente: http://john-adcock.blogspot.com/2014/12/the-golden-harp-ragnar-le-viking.html 
El amor que siente tanto el dibujante como el guionista hacia su tema favorito, los vikingos, hace que ambos desarrollen una nueva serie llamada Biorn, le Viking. Esta vez la trama se centra en un jefe vikingo danés llamado Biorn, que es acompañado por su astuto compañero de viaje, Niord y una veintena de hombres de la tripulación del drakkar "Le Harfang", y que será condenado a muerte tras liberar a los prisioneros de unos tiranos en la ciudad noruega Nidaros (actual Trondheim). Anteriormente también tendrá que librar una batalla para recuperar "La espada de Sigurd". Al final del último episodio, como también ocurriría en Ragnar, se encuentra al personaje histórico Erik el Rojo, cuyos hechos son contados en la saga que le da nombre. La serie apareció para una revista de formato pequeño llamada "Brik" en 1962, durando dos años con un total de diecisiete historias, para ser retomada posteriormente en 1966 por la revista trimestral de también pequeño formato, "Pirates", hasta 1968, llegando a nueve historias.

En el año 1976, Larousse crea una colección llamada "Histoire de la France en bandes dessinées", en la que trabajan autores que colaboran con Villant/Pif gadget entre los que se encontraba Coelho, el cual produjo siete historias para la misma con guiones de Ollivier, siendo una de ellas de temática vikinga perteneciente a Jacques Bastian, titulada Les Loups de la $\mathrm{Mer}^{16}$. Tras el éxito de esta colección, ediciones Larousse decide crear una nueva colección de cómics en 1978 llamada "La Découverte du monde en bandes dessinées" que cuenta las aventuras de los grandes exploradores, realizando Coelho cinco relatos con guiones de Ollivier y siendo uno de ellos de nuevo una historia vikinga titulada Des Drakkars à l'Est y que luego sería retomada para España en el Tomo I "La aventura de los vikingos" de la colección "Grandes Heroes de la Historia: el descubrimiento del mundo" de Larousse-Planeta Agostini creada en 1981, bajo el título de Las naves vikingas hacia el este.

\footnotetext{
${ }^{16}$ Tras el éxito de esta colección, ediciones Larousse decide crear una nueva colección de cómics en 1978 llamada "La Découverte du monde en bandes dessinées" que cuenta las aventuras de los grandes exploradores, realizando Coelho cinco relatos con guiones de Ollivier y siendo uno de ellos de nuevo una historia vikinga titulada Des Drakkars à l'Est, que luego sería retomada para España en el Tomo I, titulado La aventura de los vikingos de la colección "Grandes Heroes de la Historia: el descubrimiento del mundo" de Larousse-Planeta Agostini creada en 1981, bajo el título de Las naves vikingas hacia el este.
} 


\subsubsection{La Historia del vikingo Karl por un ilustrador inglés: Don Lawrence (1960).}

Karl el vikingo (1960), es la historia del dibujante inglés Donald Southam Lawrence, uno de los mejores dibujantes dentro del panorama británico.

Donald Southam Lawrence (1928-2003) es reconocido como uno de los mejores artistas británicos de la historia gracias al éxito que obtuvo con títulos como The Rise and Fall of the Trigan Empire (1965) y Storm (1976). Nacido en la ciudad de East Sheen, conocido como "suburbio" del distrito londinense de Richmond upon Thames, sería educado en la Escuela de St. Paul, Hammersmith e ingresaría en el ejército en 1947. Dos años más tarde entró en el Borough Polytechnic (ahora South Bank University) para estudiar arte figurativo, que abandonaría en 1954 (Hansen, 2004, 130). Ese mismo año debutó en el mundo del cómic dibujando un personaje para los estudios Gower Street de Mick Anglo, llamado Marvelman, una imitación británica del Capitán Marvel. Tras su discusión por motivos económicos, puesto que cobraba una libra por plancha, abandona el estudio y encuentra trabajo en sucesivas editoriales como "Amalgamated Press" o "Zip", donde especialmente se dedica a producir westerns, con títulos como Davy Crockett, Daniel Boone, The Wagon Train, Wyatt Earp, Buffalo Bill, Billy the Kid, Wells Fargo, Pony Express, Blackbow the Cheyenne $y$ Cheyenne Veneance.

Por entonces el cómic "Sun" había sido objeto de trabajo para el dibujante a través de la serie Billy the Kid, pero al encontrarse en decadencia decide fusionarse con "Lion", siendo fundada en el año 1952 para competir con la también revista británica de historietas para niños, "Eagle". Esto supone para Lawrence un giro nuevo hacia el género de "capa y espada", creando obras como Olac the Gladiator y Maroc the Mighty, así como de temática vikinga con Karl the Viking, bajo el guión de Henry Kenneth Blumer.

Karl el vikingo, es un sajón de nacimiento que durante su infancia es raptado por los invasores, siendo criado por el jefe del clan, Eingar, para ser un poderoso vikingo. Su nueva familia siempre le considerará como uno de los suyos llegando a convertirse en un guerrero valiente y honorable, que tras ser nombrado jefe, se encargará de conducir a sus hombres a aventuras por todo el mundo, desde lo que algún día se conocería por América hasta Egipto e 
incluso la Atlántida. La trama mezcla el elemento de fantasía y "espada", en donde aparece una amalgama variada de monstruos legendarios con los que tendrá que combatir. La serie debutó con la tira "Sword of Eingar" en 1960, con el jefe Karl que se comprometía junto a su rival Skurl en recuperar el arma, que le da título a la entrega, robada por un señor sajón llamado Earl Gyrth de Eastumbria. Posteriormente, desde finales de los años sesenta hasta principios de los setenta, esta tendría una adaptación para la revista británica "Smash!", cambiando el nombre por el de Eric the Viking y basada probablemente en el líder vikingo de la Alta Edad Media británica, Eric Haraldsson, apodado "Bloodaxe" y conocido a través de las sagas islandesas (internationalhero.co.uk, 2013). Funcionó durante cuatro años, terminando el 29 de septiembre de 1964, con un total de trece aventuras repartidas en 205 episodios, junto cuatro más en los Lion Annuals, uno de los cuales fue escrito por Michael Moorcock.

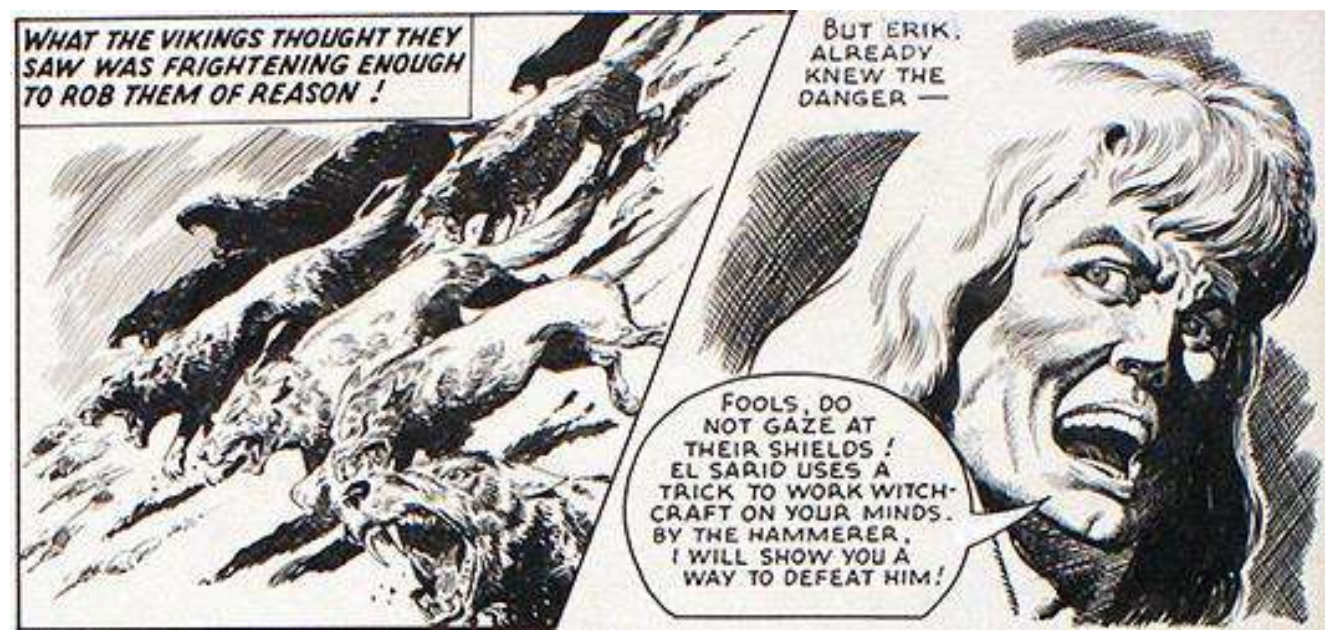

Karl le Viking. Viñeta original del año 1961.Fuente:

https://bookpalace.com/acatalog/info_LawrenceKV001.html
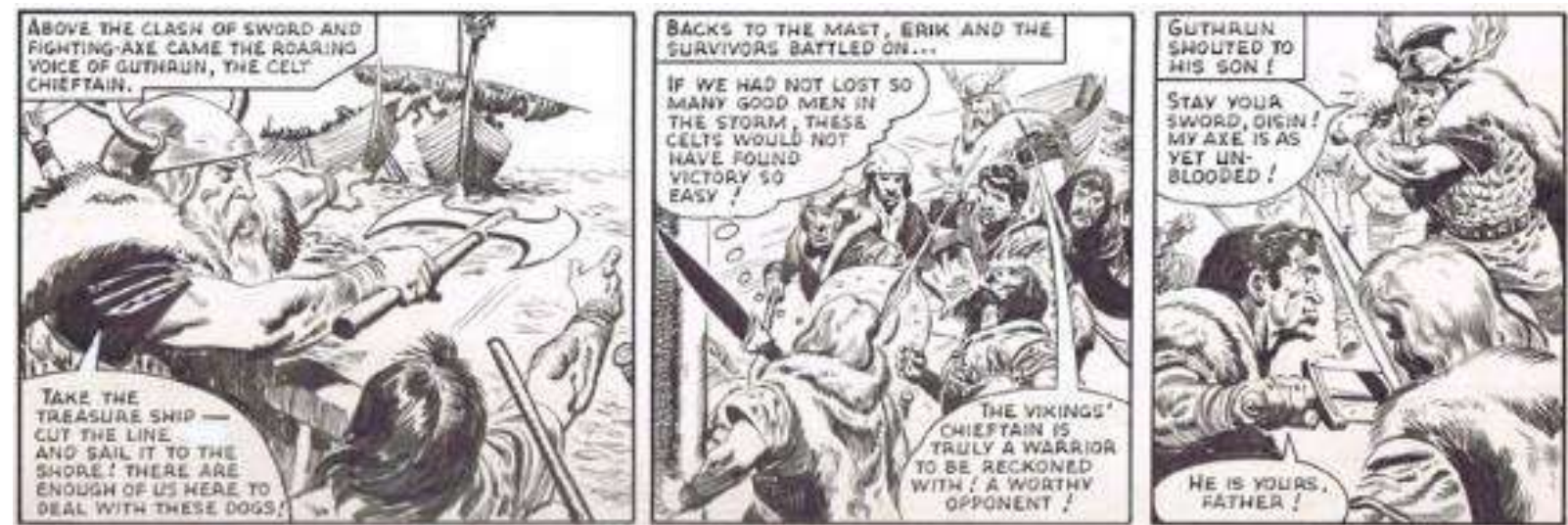

Viñetas de Erik le Viking. Fuente: https://www.comicartfans.com/gallerypiece.asp?piece=729693 
Don Lawrence representa un dominio preciosista demostrando un arte bastante singular, con dibujos de una técnica avanzada y de una calidad soberbia para su tiempo. Un ejemplo de esta, puede percatarse en el dominio de la figura humana combinada con un dibujo alejado de los modos tradicionales, aunque sin emplear aun la página a todo color, una de las señas de identidad del artista, alcanzando su cuota más alta con la serie de ciencia ficción The Rise And Fall Of The Trigan Empire. Sin embargo, y a modo de excepción, realizaría en color directo el "annual" o "almanaque" del año 1965, preludiando lo que estaría por llegar en sus futuras obras.

En España tuvo su edición en la Editorial Maga en el año 1963 para el cuadernillo "El Príncipe de Rodas", con el nombre de Kas-Thor el vikingo ${ }^{17}$. El final de su edición se produjo con el número 62 de la colección, la cual acabaría editándose de nuevo para la revista, también de la Editorial Maga, "Flecha Roja", a partir del número 17 y ya en el formato original sin sufrir alguna modificación, aunque no incluiría tanto su última aventura como la página a todo color del Annual, hecho que no alteraría su éxito en España.

\subsubsection{La dura travesía de Thorgal contada por Jean Van Hamme (1977).}

Thorgal (1977), la popular serie dentro de la bande desinée francobelga, es una obra del guionista belga Jean Van Hamme y del dibujante polaco Grzegorz Ronsinski.

Grzegorz Ronsinski (1941), nacido en la ciudad polaca de Stalowa Wola, es un referente dentro del mundo del cómic contemporáneo. Después de graduarse en el High School of Fine Arts en Varsovia en el año 1967, estudió artes gráficas en la Academia de Bellas Artes de la misma ciudad. Cuando era niño llegó a sus manos los cómics de Vaillant, lo que le llevó a escribir sus primeras tiras con tan solo quince años, dibujando para periódicos como el "Korespondent Wszedobylski" y diseñando portadas de álbums, ilustraciones para libros de texto e historias infantiles. Durante estos años llegó a la revista infantil "Sport i

\footnotetext{
${ }^{17}$ Pero a diferencia de salir en su formato vertical, se creó en formato de cuadernillo apaisado, tal como se editaba en el país, provocando una clara alteración respecto al original, con recortes manipulados; simplificación de las historias; o la adaptación de las viñetas, que eran de distintos tamaños en el editado por Lion.
} 
Turystyka" donde realizaría una serie de trabajos, entre los que destacan una veintena de cómics perteneciente a las series Kapitan Żbik y Pilot śmigłowca y Legendarna historia Polski (komiks.gildia.pl, 2013). En 1976 creó “Relax", la primera revista en idioma polaco dedicada exclusivamente a los cómics, donde también publicaría historias de corte histórico y de ciencia ficción.

Tras su abandono de este pequeño formato de cómics por el motivo de que no quería entrar en cuestiones políticas, decide abrirse al mercado franco-belga y al mundo de la editorial occidental. Al principio no estaba siendo muy fructífera su carrera, aunque realizaba algunos trabajos para las revistas "Trombone illustre" y "Tintin", o para "Spirou", bajo el pseudónimo "Rosek", encargándose de unos cuentos humorísticos cortos titulados Viaje fantástico. Su camino cambiaría definitivamente cuando conoce a André-Paul Duchâteau y especialmente a Jean Van Hamme, creador de series exitosas tales como Histoire sans Héros, Largo Winch y XIII, que quedó impresionado por el talento del joven dibujante al que le propondría crear la serie Thorgal y que se acabaría publicando en 1977 por la revista "Tintin ${ }^{18}$.

Thorgal es un personaje al que le envuelve un halo de misterio que ira revelándose conforme vaya desarrollándose los acontecimientos de la historia. Encontrado y criado por vikingos, será la razón por la que no acabe de lograse la confianza de éstos, entrando en diferentes conflictos. Es un guerrero y arquero formidable pacífico que se encuentra en el corazón de las intrigas entre poderosos, en un mundo donde la magia, los dioses y la brutalidad de los hombres son omnipresentes, y en el que llegará a conocer a Aaricia, hija del rey "Gandalf el loco", con la vivirá una vida llena de aventuras y obstáculos que harán que el personaje demuestre por qué es apodado como "Hijo de las tormentas" (Thorgal, 2020).

\footnotetext{
${ }^{18}$ A su vez sería recopilada en formato álbum por la editorial Lombard, y en España ha sido recientemente publicada la colección integral de la serie mediante la editorial Norma. Lombard, publicó su primer álbum, $L a$ Magicienne traie en el año 1980, constando hasta la actualidad de 37 álbumes. La edición, sin embargo, en España, se recoge en tomos integrales, siendo el primero Thorgal. Integral 1 del año 2019, que incluyó los cuatro primeros álbumes de la serie: La maga traicionada, La isla de los mares helados, Los tres ancianos del país de Arán y La galera negra, publicados originalmente entre 1977 y 1981. La serie, por otra parte, tiene una serie de Spin-off, titulado Los Mundos de Thorgal: danto comienzo en el año 2010 con la serie Thorgal - Kriss of Valnor, ya a los mandos del guión por parte de Yves Sente, dejando el testigo en 2015 a Xavier Dorison y con dibujos de Giulio De Vita, Roman Surzhenko y Fred Vignaux; Yann Le Pennetier con dibujos del propio Surzhenko, con la historia Louve; y La Jeunesse de Thorgal, nuevamente con Yann Le Pennetier y Surzhenko.
} 
La serie creada por Van Hamme y Rosiński, es más que una serie de aventuras ambientadas en el mundo vikingo del siglo X, puesto que integra elementos de ciencia ficción y fantasía, en el que de nuevo aparece el espíritu de Foster en la evolución del personaje que provoca el descubrimiento de una gran cantidad de escenarios y nuevos países con culturas propias, dando a lugar a un continuo cambio de paisajes y constante movimiento que es propiciado por las aventuras que les son destinadas tras sus diferentes encuentros con los dioses; así mismo por la gran amalgama de actores secundarios que aparecen durante el transcurso de la escena, sin olvidar que se trata de un personaje extranjero en territorio vikingo ${ }^{19}$.

La mitología nórdica, presente a lo largo de la saga, sirve tal y como indica Olivera (2010) para crear un corpus que de sentido a la saga y como pretexto al fantástico, puesto que los dioses y seres propios de esta conviven con otras criaturas y seres que son creadas por el autor de la $\operatorname{serie}^{20}$. Es por ello que, aunque históricamente la religión cristiana ya se encontraba extendida en estos países, en opinión de Olivera "cualquier mención al cristianismo habría restado credibilidad y coherencia interna al mundo de Thorgal", ya que todo lo que hace a estos guerreros, su cultura, costumbres, o modo de organización están directamente influidos por su mitología, los dioses que moran en el Asgard, y que se trata de un modo muy convincente, donde los hombres son los que navegan a través de los mares dominado por su dios Aegir, que tendrán o no a su favor; las mujeres salan la carne para que no se pudra durante el viaje; los niños juegan imitando a los mayores; o la manera en la que se ilustra a la perfección el proceso y los rituales que se realizan al vikingo una vez muere para emprender el camino hacia el Valhalla ${ }^{21}$.

\footnotetext{
${ }^{19}$ La serie cuenta con tres historias: Los Ancianos Del País de Aran", La Corona de Ogotai y El Señor de las Montañas, las cuales no tienen relación pero están vinculadas con los viajes en el tiempo, tema favorito de Van Hamme: Belmonte, Fernando F. "Thorgal". En Tebeosfera, Publicación periódica sobre historieta, humor gráfico y otros medios y culturas. Primera época, $\mathrm{n}^{\mathbf{0}} \quad 7 \quad$ (2002). https://www.tebeosfera.com/1/Obra/Tebeo/Norma/Thorgal.htm. Consultado el 06/08/2020.

${ }^{20}$ Del mismo modo ocurre con los diferentes escenarios y ambientaciones históricas que aparecen, conectando con estilo de Hal Foster en Príncipe Valiente: Olivera, Thorgal, un héroe diferente, publicado en la revista "Yellow Kids" y recogido por tebeosfera https://www.tebeosfera.com/documentos/thorgal_un_heroe_diferente.html. Consultado el 07/08/2020.

${ }^{21}$ El gran salón situado en el reino de Asgard gobernado por Odín.
} 


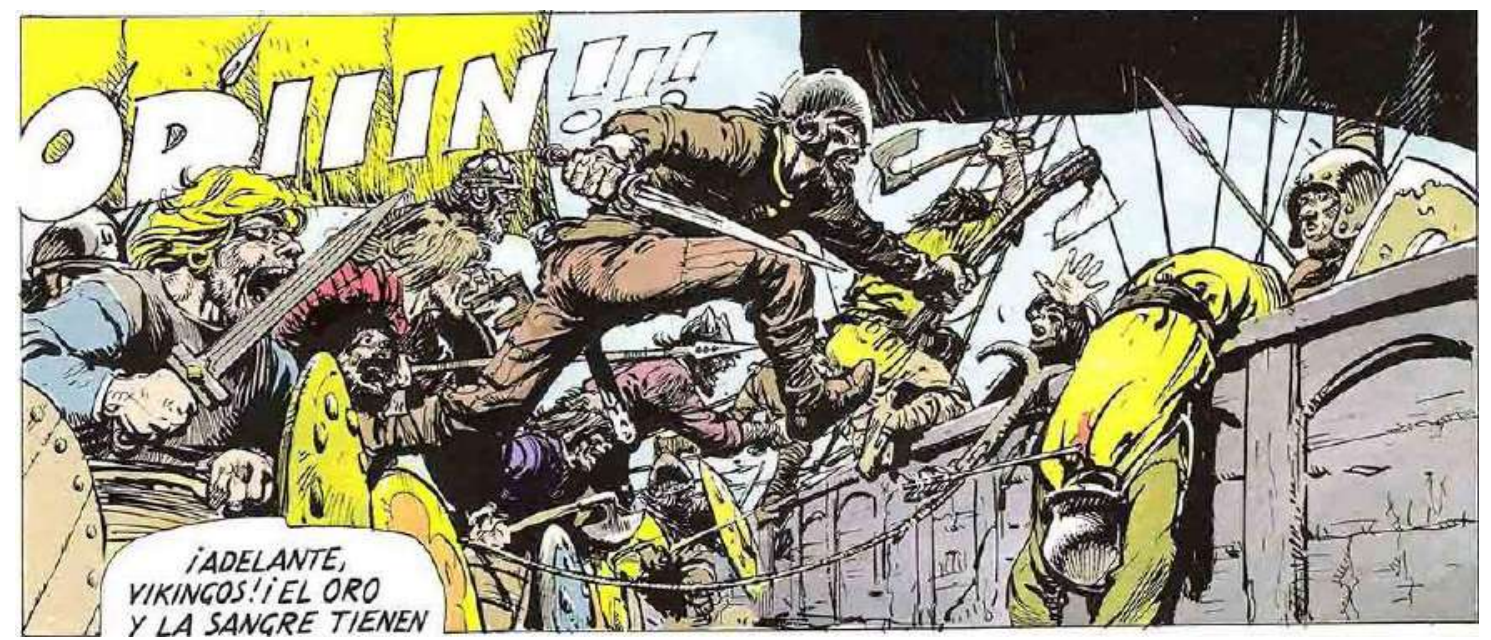

Asalto vikingo. Fuente: Van Hamme, J. (2019) Thorgal. Norma Editorial.

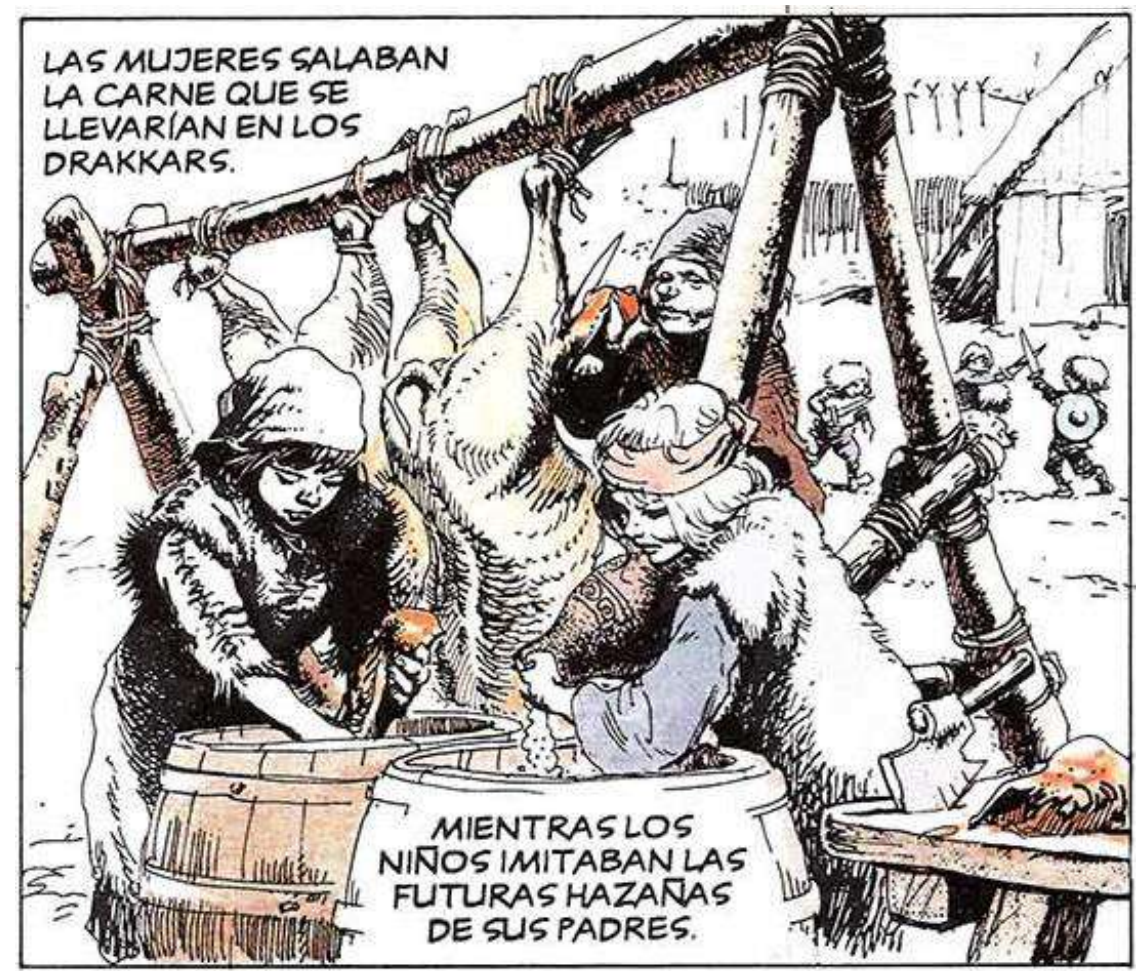

Reflejo de la sociedad vikinga. Fuente: Van Hamme, J. (2019) Thorgal. Norma Editorial. 


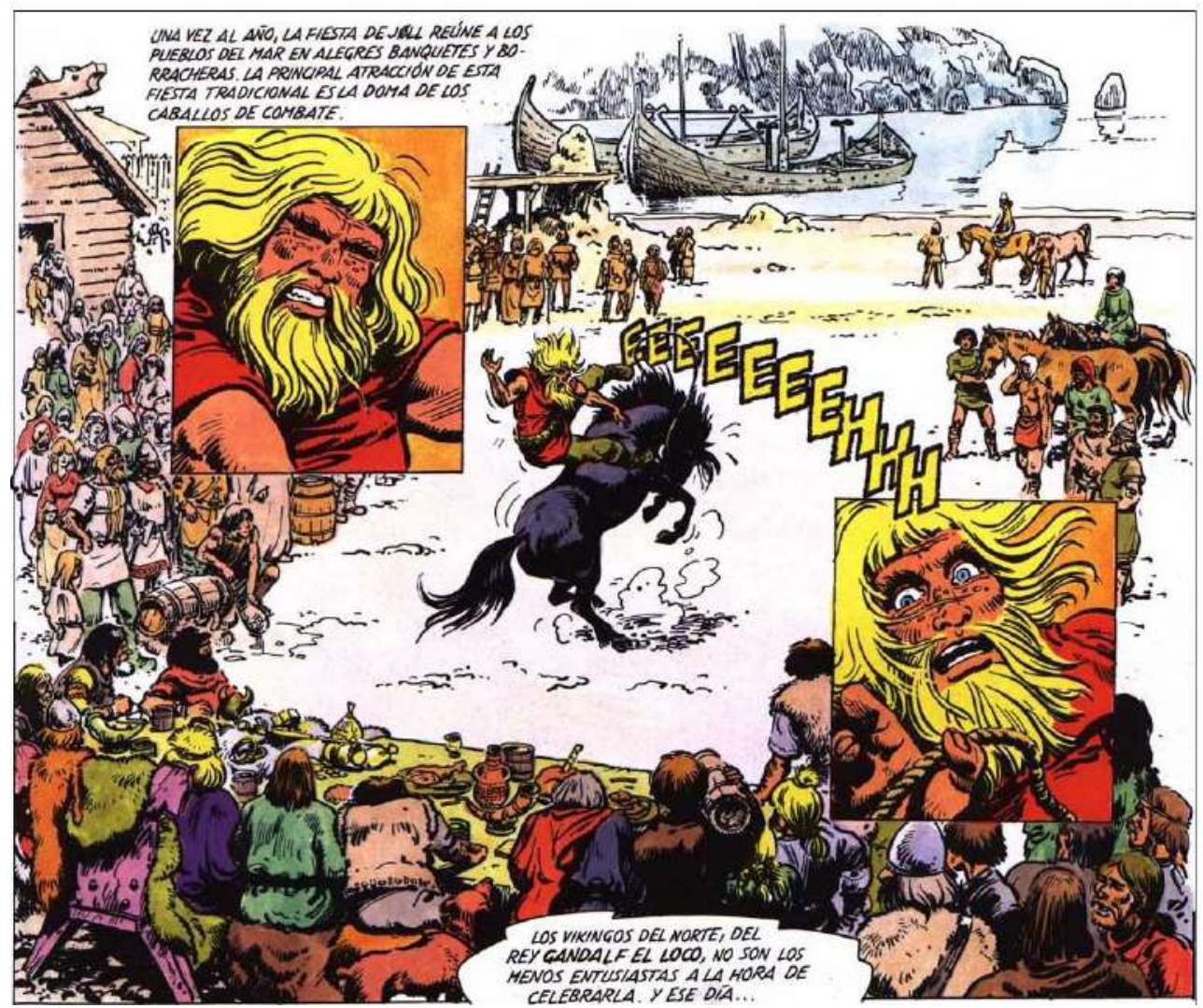

Celebración vikinga. Fuente: Van Hamme, J. (2019) Thorgal. Norma Editorial.

En una entrevista reciente y concebida para la web $2 D G$, Rosiński decía que creó esta serie a partir de la nada, partiendo de la base de que se encontraba inmerso en un país destruido por la guerra y envuelto en ruinas, donde la literatura sería su máxima fuente de inspiración (Blanc, 2017). La serie destaca por una evolución en el aspecto artístico, su naturalismo va acrecentándose poco a poco hasta llegar a su madurez, pero sin perder nunca la originalidad del dibujo. Entre estos aspectos destacan la sustitución de la mancha por el uso de la plumilla que mejora la definición de la línea, o la del blanco y negro por el color en la viñeta, creando ambientes con el propósito de llevar al terreno de la imaginación a su lector y decidir por su propio juicio. Por otra parte, realiza diseños novedosos respecto a la ubicación de las viñetas y los espacios naturales y entornos urbanos de las civilizaciones y culturas que aparecen, son tomados en palabras del dibujante, de elementos decorativos propios del teatro u ópera. 


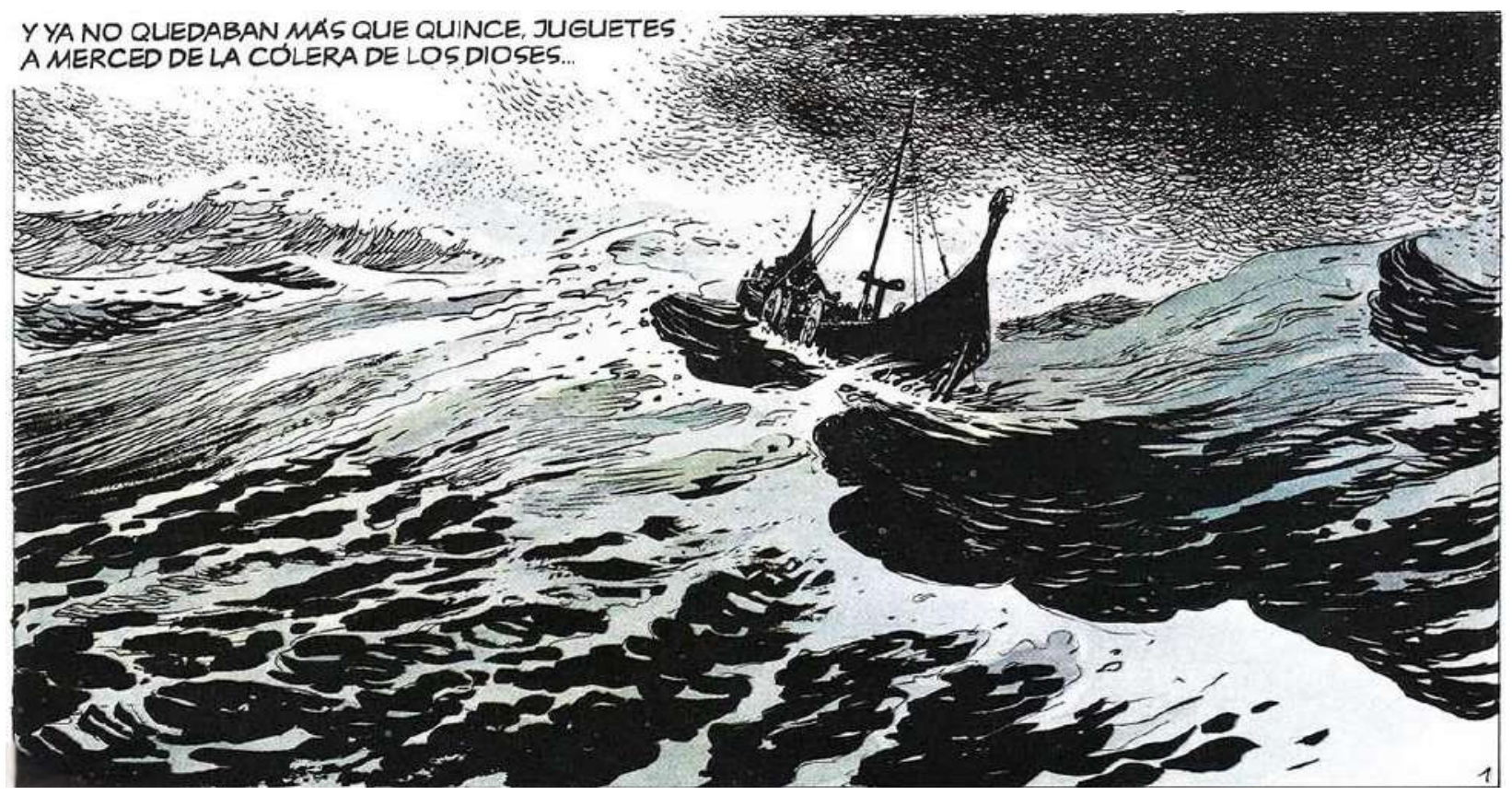

Drakkar vikingo. Fuente: Van Hamme, J. (2019) Thorgal. Norma Editorial.

Actualmente tanto dibujo como guiones no son realizados por sus autores originales, encargándose de estos trabajos Yves Sente a partir de la edición número treinta y Xavier Dorison en la treinta y cinco, aun con dibujos de Rosiński, dejando recientemente su cargo en 2018 y siendo sustituido por Fred Vignaux que colabora hoy día con Yann en los guiones.

\subsubsection{La versión más terrorífica del vikingo: Crónicas Bárbaras de Jean-Yves Mitton (1994).}

Chroniques barbares (1994), pertenece a una serie perteneciente a la bande dessinée francobelga, cuya historia pertenece al francés, Jean-Yves Mitton.

Su autor, Jean-Yves Mitton nació en Toulouse en el año 1945, trasladándose a Lyon para estudiar Bellas Artes en el año 1960. Al año siguiente encontraría trabajo como retocador fotográfico en la Editorial "Lug", donde además se encargaba de crear portadas. Es el mismo momento en el que se encuentra realizando cómics, destacando su colaboración para la revista franco-italiana de pequeño formato, "Kiwi", a través de la serie Blek le Roc, aunque sin hacer mucho ruido y con sueldo mínimo, puesto que su deseo principal era el adquirir una mayor 
formación e ir perfilando una mejor técnica en su dibujo. A la vez también realizaría la serie Sammy Sam de la revista "Pim, Pam, Poum, Pipo" en 1965 y bajo el seudónimo de "Jym". Posteriormente, se hará cargo de la serie Pugacioff de artista milanés, Giorgio Rebuffi y perteneciente a la revista "Maxi Pipo". Ya bajo el seudónimo de "John Milton" trabaja para "Nova", donde publica una gran cantidad de cómics de superhéroes como The Silver Surfer, The Fantastic Four y Spider-man (Lambiek, 2014).

En los años 80 y bajo el mismo seudónimo, creó el superhéroe Mikros en las páginas de la revista "Mustang and Titans", e hizo una adaptación al cómic de la serie de televisión Blackstar. A su vez inventa las series de ciencia ficción como Epsilon, Kronos, Cosmo y Photonik, esta última creada por su amigo Ciro Tota para la revista Mustang de la Editora Lug (Gracia y Barrero, 2009). A partir de 1987, trabaja para "Pif Gadget" y se asocia con el dibujante y sobre todo escritor de cómics, François Corteggiani, con quien hizo l'Archer Blanc y Noël et Marie. Al año siguiente empieza a dibujar Fantomen, un cómic sueco dedicado a The Phantom. Sobre los años 90 empieza a colaborar con "Soleil Productions" creando series tales como Vae Victis, con guiones de Simon Rocca; Les survivants de l'Atlantique, sobre piratas y Chroniques Barbares.

La serie Chroniques Barbares (1994) está formada por un total de seis tomos centrados en la historia de Bartholomée un antiguo novicio que relata en sus memorias la invasión que sufrió a manos de una horda vikinga durante su instancia en el monasterio de Saint-Joseph Du Havre, logrando escapar de la masacre y viviendo a raiz de lo sucedido una serie de aventuras con el fin de intentar salvar su vida, llegando incluso adoptar la identidad de un príncipe vikingo, cosa que lleva a la desconfianza de un chamán del clan con el que convive, mientras que por otro lado los vikingos planean tomar Francia. Durante el desarrollo de los acontecimientos, Bartholomée es sometido por las constumbres y barbaries propias de su entorno a las que tendrá que hacerles frente (Martínez, 2016) ${ }^{22}$.

El título es una muestra de exceso en su grado más desgarrador y de pura violencia en todos los ámbitos. A pesar de no ser agradable en ocasiones, puesto que también crea imágenes de gran belleza, es capaz de atraparte a través de su dibujo, el cual plantea tal como

\footnotetext{
${ }^{22}$ Soleil lanzó la serie durante seis años (1994 - 2000). En España se publicó entre los años 2015 y 2016 por medio de dos integrales divididos en tres tomos cada uno y publicados en Yermo Ediciones.
} 
si de una película cinematográfica se tratase mediante un ritmo acelerado que utiliza a la perfección para transmitir continua tensión. A su vez, tiene la habilidad de meternos en la piel de los personajes, tanto de los bárbaros con sus actos denigrantes como la de los habitantes del pueblo que lo sufren. Utiliza en general tonos ocres para el mar y los paisajes, a los que el dibujante no le interesa tanto su detalle más preciso, y juega con el contraste del blanco de los fríos escenarios con el rojo derramado sobre éste para remarcar la violencia.

Los vikingos son auténticos desarrapados y desaliñados sin ningún tipo de escrúpulo, que galopan con sus caballos completamente desnudos en sus gélidas tierras, o sacrifican jóvenes vírgenes esclavas con el fin de agradar al pueblo, costumbres que rechaza profundamente Bartholomée, al igual que sus leyes. Esto conecta con el modo en el que se hace advertir el engaño acerca de las creencias hacia los dioses, puesto que el chamán que descubre la auténtica identidad del monje, le revela en un momento determinado que él está ahí solo para hacer creer, y de un modo convencer que con ello se perpetúe la tradición ancestral de los pueblos, por lo tanto todo se justifica mediante la acción de dioses a los que ni siquiera se tiene la certeza de que verdaderamente existan.

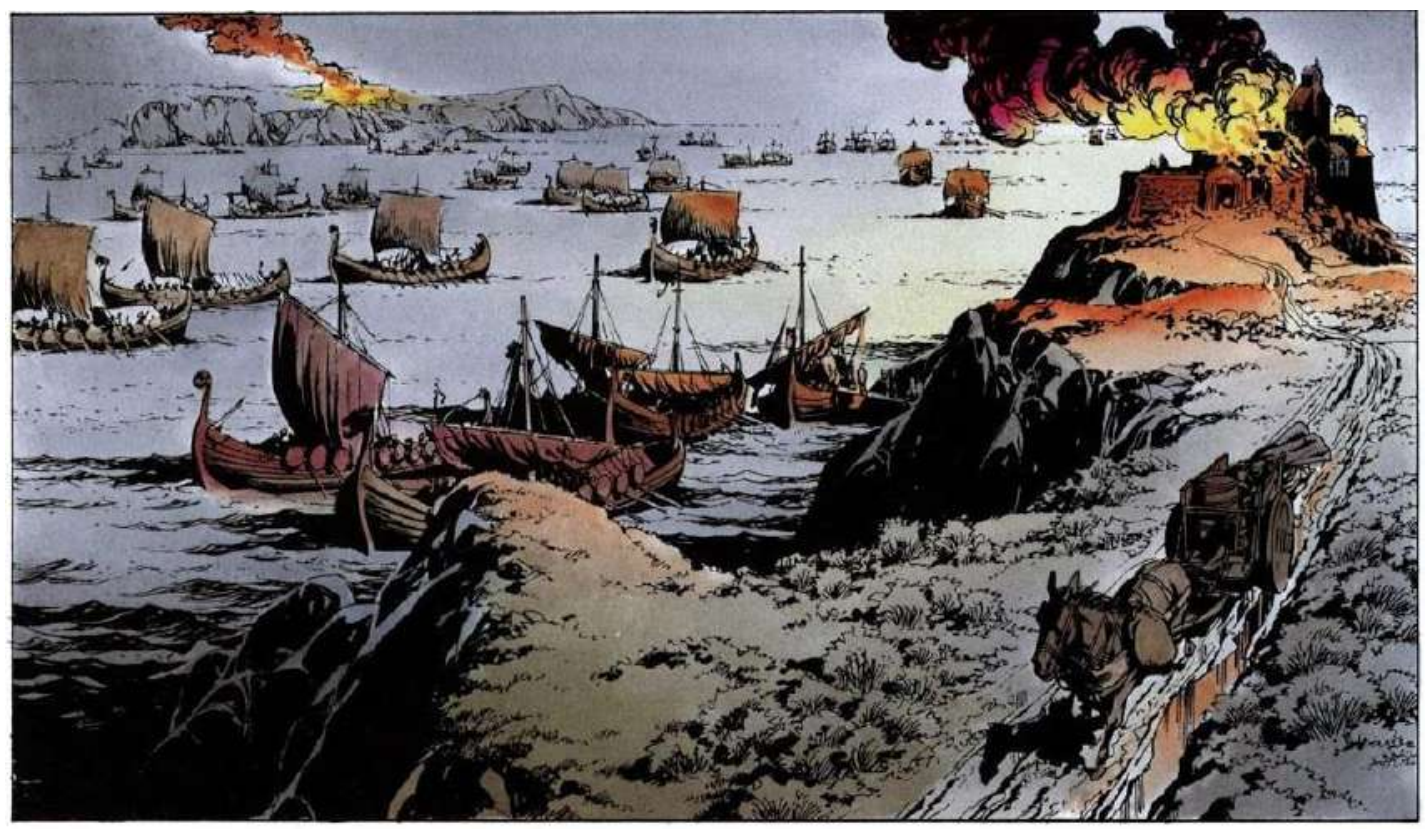

Drakkars vikingos. Fuente: Mitton, JEAN. (2015) Crónicas Bárbaras. Yermo Ediciones. 


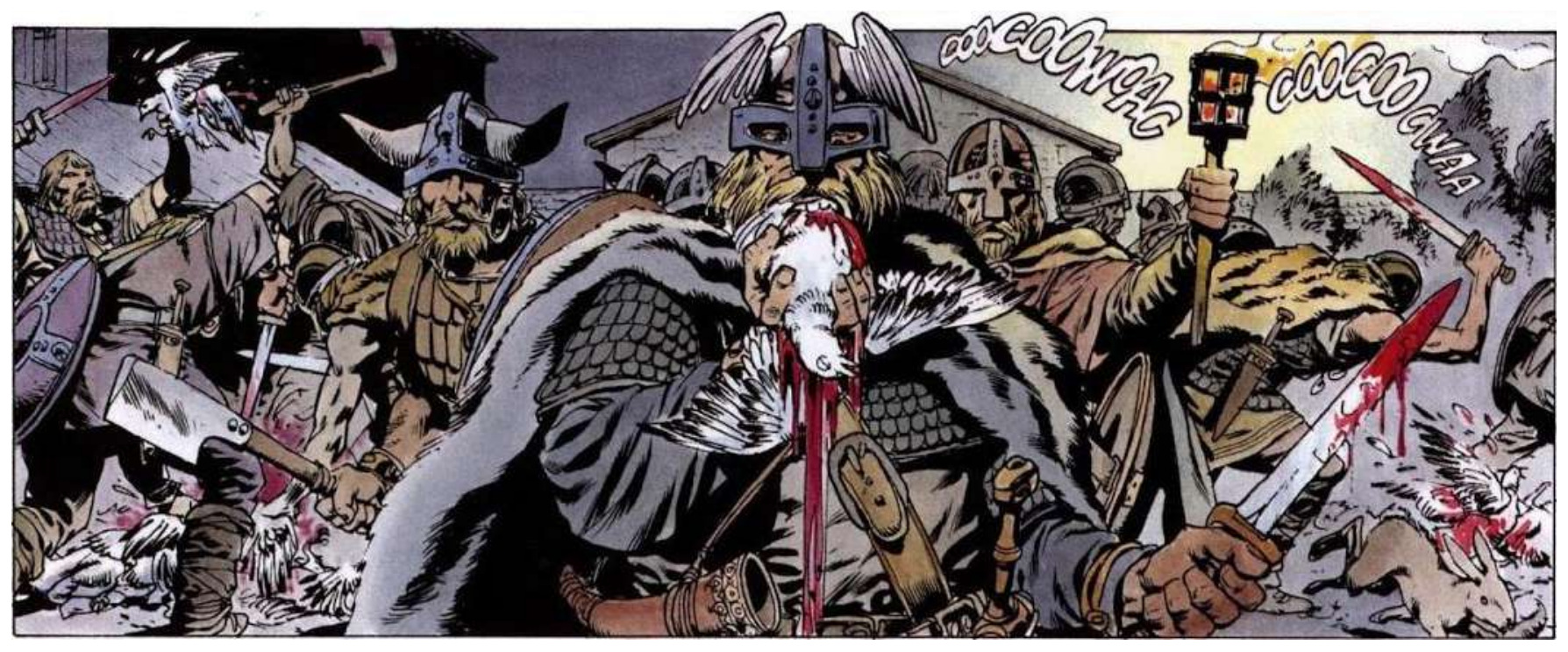

Representación de los vikingos. Fuente: Mitton, JEAN. (2015) Crónicas Bárbaras. Yermo Ediciones.

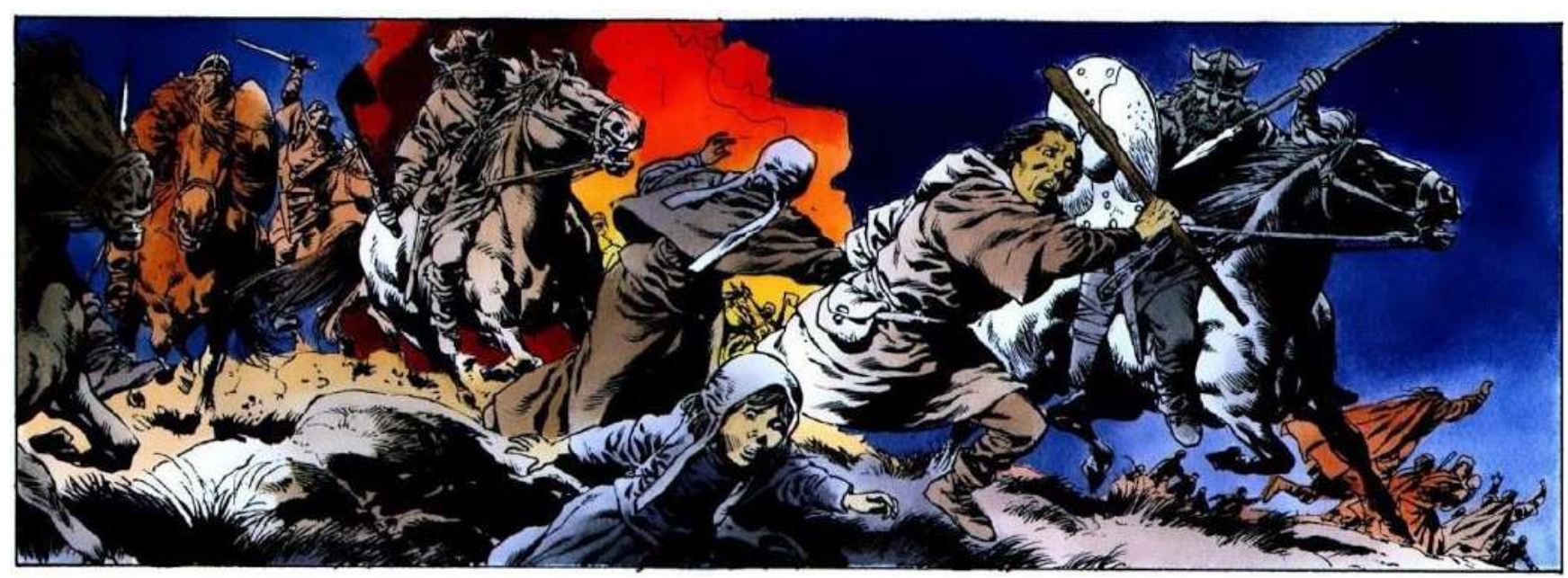

Ataque vikingo. Fuente: Mitton, JEAN. (2015) Crónicas Bárbaras. Yermo Ediciones. 


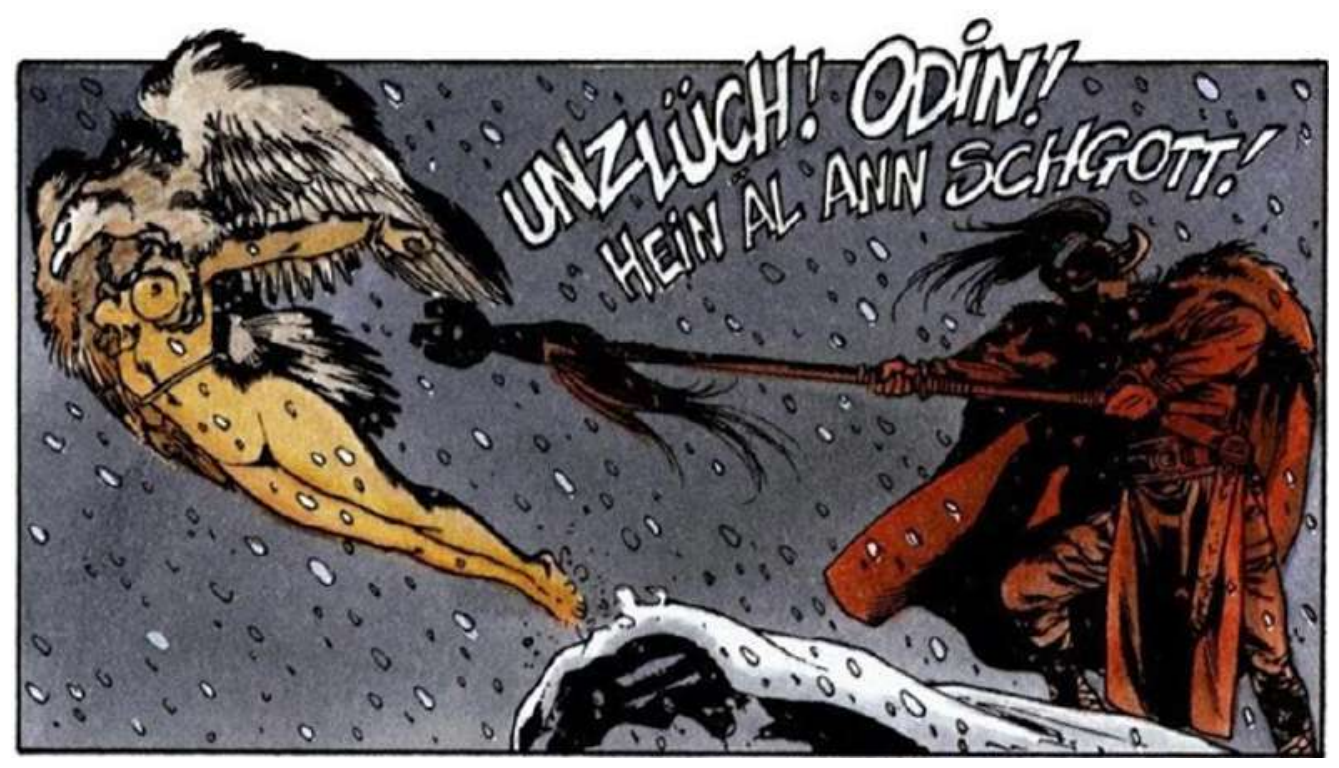

Ritual vikingo. Fuente: Fuente: Mitton, JEAN. (2015) Crónicas Bárbaras. Yermo Ediciones.

Mitton, en una entrevista para la web digital Actuabd, reconoce que trata de dar credibilidad siempre a su trabajo apoyándose en la documentación histórica, como es el caso de la escena de la huida del monje por el orificio de la letrina ubicada al exterior de la abadía, lugar donde se localizaban ${ }^{23}$. A su vez, el francés se ocupa de que nunca se aplique el mismo color para las localizaciones, tal como afirma:

'l'herbe en Provence n'est pas aussi verte qu'en Bretagne. Les arbres ne sont pas les mêmes. Quand je dessine une bataille avec des galères sur l'Atlantique, attention, la mer n'aura pas la même couleur qu'en Méditerranée”. (Chabannes, 2018).

Por otra parte, reivindica a su vez la ardua tarea de representar una batalla en comparación a una escena cinematográfica, donde todo sucede a un ritmo vertiginoso, con multitud de personajes a representar y sin la posibilidad de poder aplicar efectos especiales.

\footnotetext{
${ }^{23}$ También, en esta misma entrevista, indica que se sirvió de inspiración en esa escena a través de la película $E l$ Nombre de la Rosa (1986), adaptación de la novela homónima de Umberto Eco, del mismo modo que para el cambio de rol entre el joven monje y el príncipe Leif Erikson es una adaptación de la novela de Mark Twin, Le prince et le pauvre. https://www.actuabd.com/. Consultado el 08/06/2020.
} 


\subsubsection{La reinvención del mito de Wagner en el cómic: Siegfried de Alex Alice (2007).}

Siegfried (2007), del autor Alex Alice, es un cómic que revive el compendio de Wagner de la mitología y leyendas germanas.

Alex Alice (1974), francés de nacimiento, es reconocido principalmente por dos obras: Le Troisième Testament y Siegfried. Se graduó en la École Supérieure de Commerce de París en 1997. Ese mismo año co-crearía para Éditions Glénat junto a Xavier Dorison el cómic titulado El tercer testamento, una serie de aventuras cuya trama se ubica en el siglo XIV en tiempos de templarios y centrada en la búsqueda de un enigmático manuscrito por parte de una niña y un sabio con un oscuro pasado (Lambiek, 2013). El primer ciclo de esta saga se cerraría en el año 2003 tras el lanzamiento del cuarto trabajo, dando a lugar su continuación por medio de un nuevo título, The Third Testament: Julius, el spin-off del original. Anteriormente, se encargaría de adaptar al cómic junto con Patrick Pion "Fréon", la famosa saga del videojuego Tomb Raider en su título Tomb Raider: Dark Aeons, publicado por Glénat en 1999.

En 2007 nace Siegfried bajo su dibujo, una adaptación libre de la obra operística "El anillo del nibelungo" de Richard Wagner y la mitología nórdica. El argumento se centra en la historia de Siegfried, un humano que es criado y educado por Mine, un herrero nibelungo que vive en soledad en las profundidades de un bosque. Ambos mantienen una difícil convivencia, ya que Sigfrido se cuestiona constantemente la razón de su existir, en la que los dioses no guardan para él un lugar. Ante su incredulidad y por lo tanto falta de temeridad ante ellos, Odín trata con Mine influenciándole para que luche contra el dragón Fafnir en beneficio del dios, que con el tesoro custodiado por la criatura dominaría con absoluto poder el mundo, pero su plan se verá alterado cuando interfiera en él su propia hija, la Valquiria, que ayudará al guerrero "de liberar al mundo de la tiranía de los dioses" (Ugartondo, 2015) ${ }^{24}$.

Cada personaje encarna una acción, y aunque Sigfried sea el héroe y principal protagonista del cual gira la historia, siendo el elegido de salvar el mundo, merece la pena

\footnotetext{
${ }^{24}$ Los volúmenes que completan la serie llevan por título, tres de las óperas de Wagner: Sigfrido (Siegfried), La valquiria (Die Walküre) y El ocaso de los dioses (Götterdämmerung).
} 
analizar el papel de unos secundarios que, sin embargo, son piezas claves de la trama, comenzando por el nibelungo Fafnir, cegado por el poder absoluto que otorga el oro y que por culpa de este acabará por renunciar a todo, convirtiéndole así en un ser despreciable y tirano que acaba por conducir no solo a él, sino a su pueblo a la perdición. La Valquiria, sin embargo, es la personificación del amor y el sacrificio destinado a Odín, Sigfried y por consiguiente a cada uno de los seres de la tierra, puesto que desde el principio que conoce la voluntad de dejar en manos del destino de su padre, retirado del mundo, a un ser mortal y sin que este reciba ayuda de nadie, tal como dicta su propia ley, decide actuar en contra de ella perdiendo su valor más preciado. El tercero en discordia es Odín, el dios supremo, atormentado porque su propia ley se vuelve en su contra, y en ella implica al propio Sigfried, el único que mediante su intervención salve a los dioses, pero sin llegar a predecir que a quién verdaderamente salve y libre de su propia tiranía es a la raza humana, llegando a provocar su ocaso, porque tiene algo que el dios perdió al dictar su ley y que es superior a todo lo que pueda dominar, el amor.

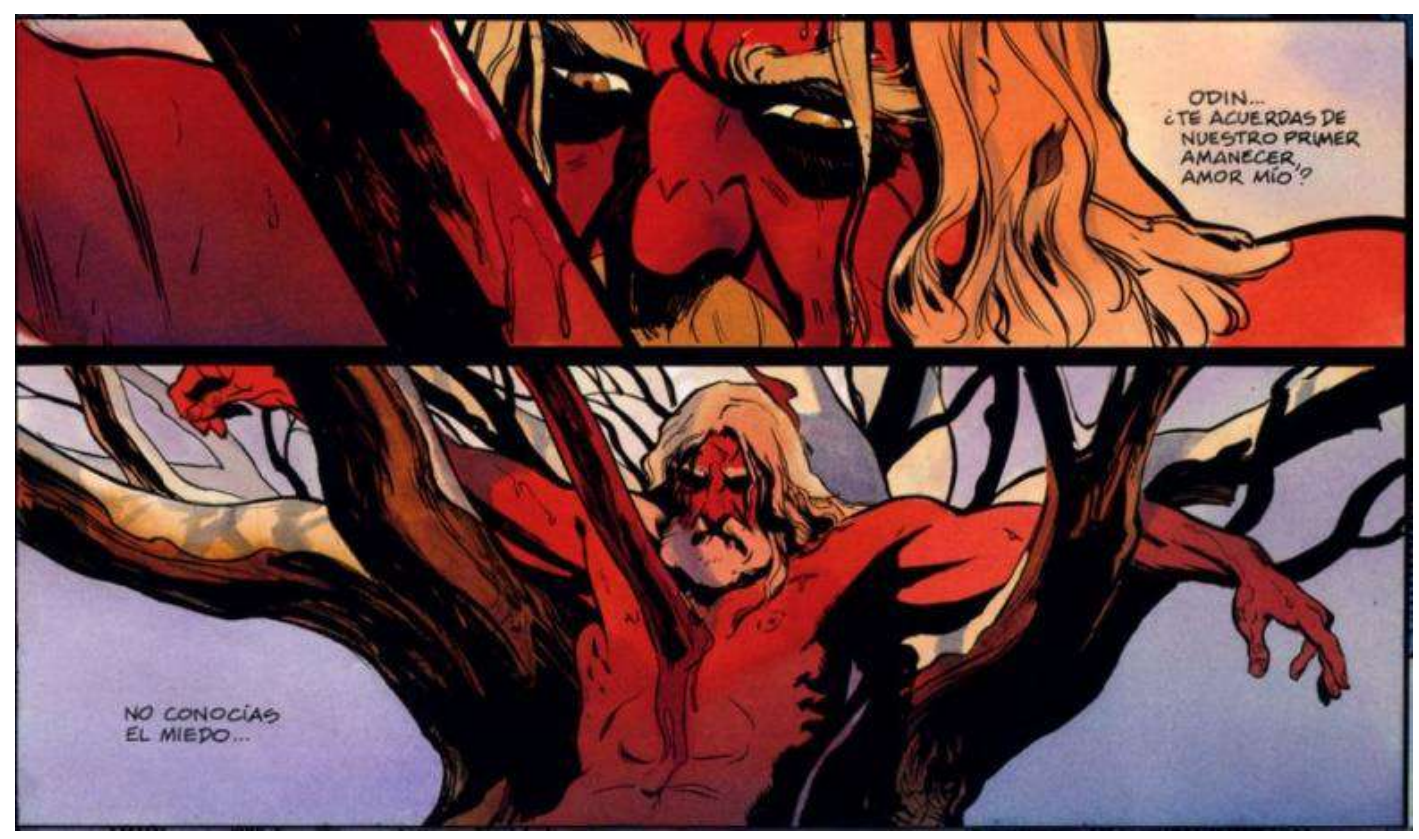

El sacrificio de Odín. Fuente: Alice, ALEX. (2008) Siegfried. Norma Editorial. 


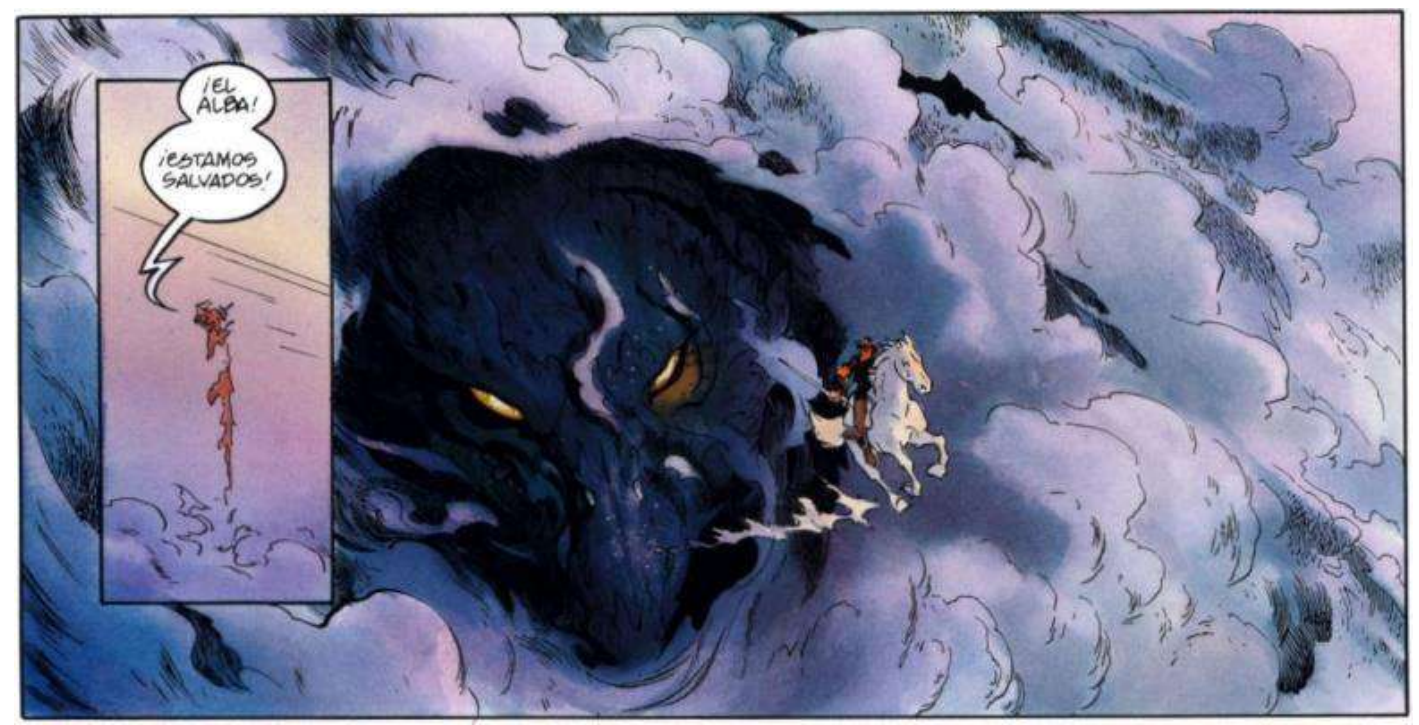

Lucha de Sigfried contra el dragón Fafnir. Fuente: Alice, ALEX. (2008) Siegfried. Norma Editorial.

En el apartado artístico, Alice demuestra su propio método para dar a los personajes que intervienen en la trama una personalidad propia, por lo que cada uno de éstos representaran rasgos absolutamente diferentes, teniendo un ejemplo en la diferencia que se produce entre el propio Siegfried y la Valquiria, que mientras el primero aparece con una figura fluida sin mancha, la segunda para reforzar su carácter divino la presenta inundada de luz. Su fluidez en el dibujo se traduce en una experiencia cinematográfica, consiguiendo crear sustancia a un relato concreto con tan solo una página en negro y una línea de texto. La manera en la que trata la naturaleza, le es influida por Mathieu Lauffray, autor de John Long Silver entre otras obras, con escenarios tan dispares como pueden ser tanto el bosque como la ciudad subterránea en donde habitan los nibelungos. Otra de sus singularidades es la de recurrir a las páginas dobles para narrar hechos transcendentales para la historia.

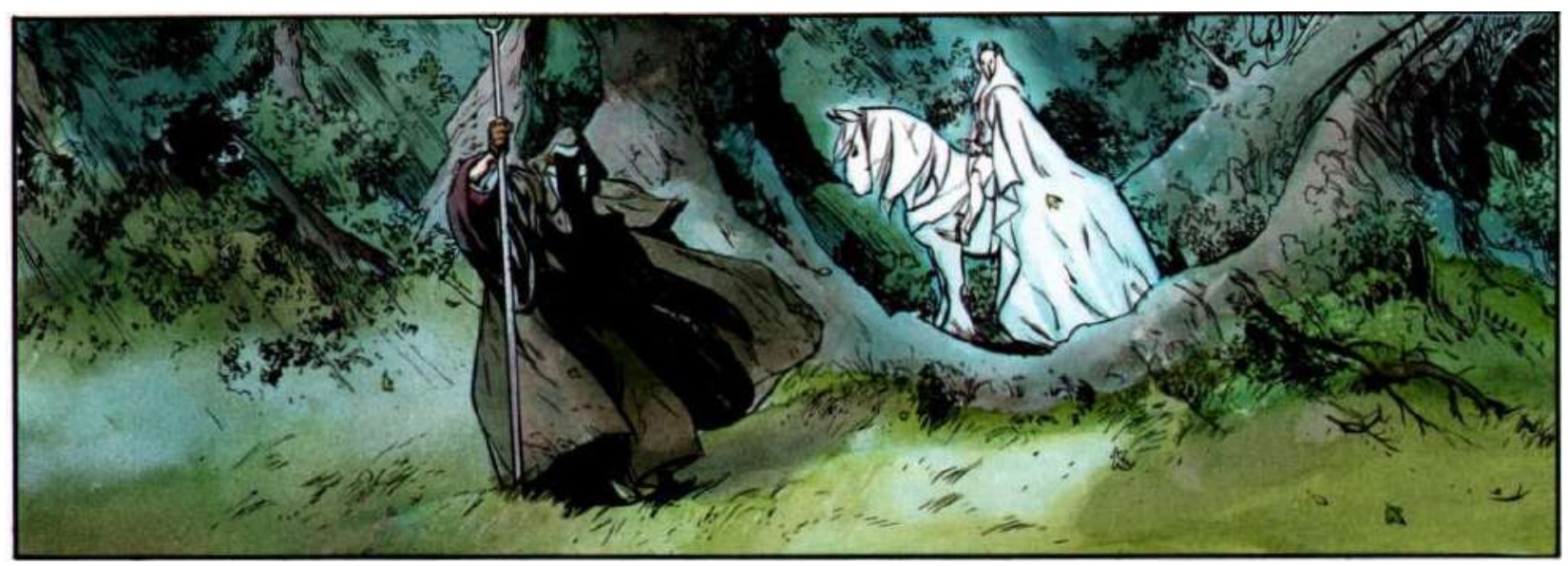

Odín y su hija la Valquiria. Fuente: Alice, ALEX. (2008) Siegfried. Norma Editorial. 


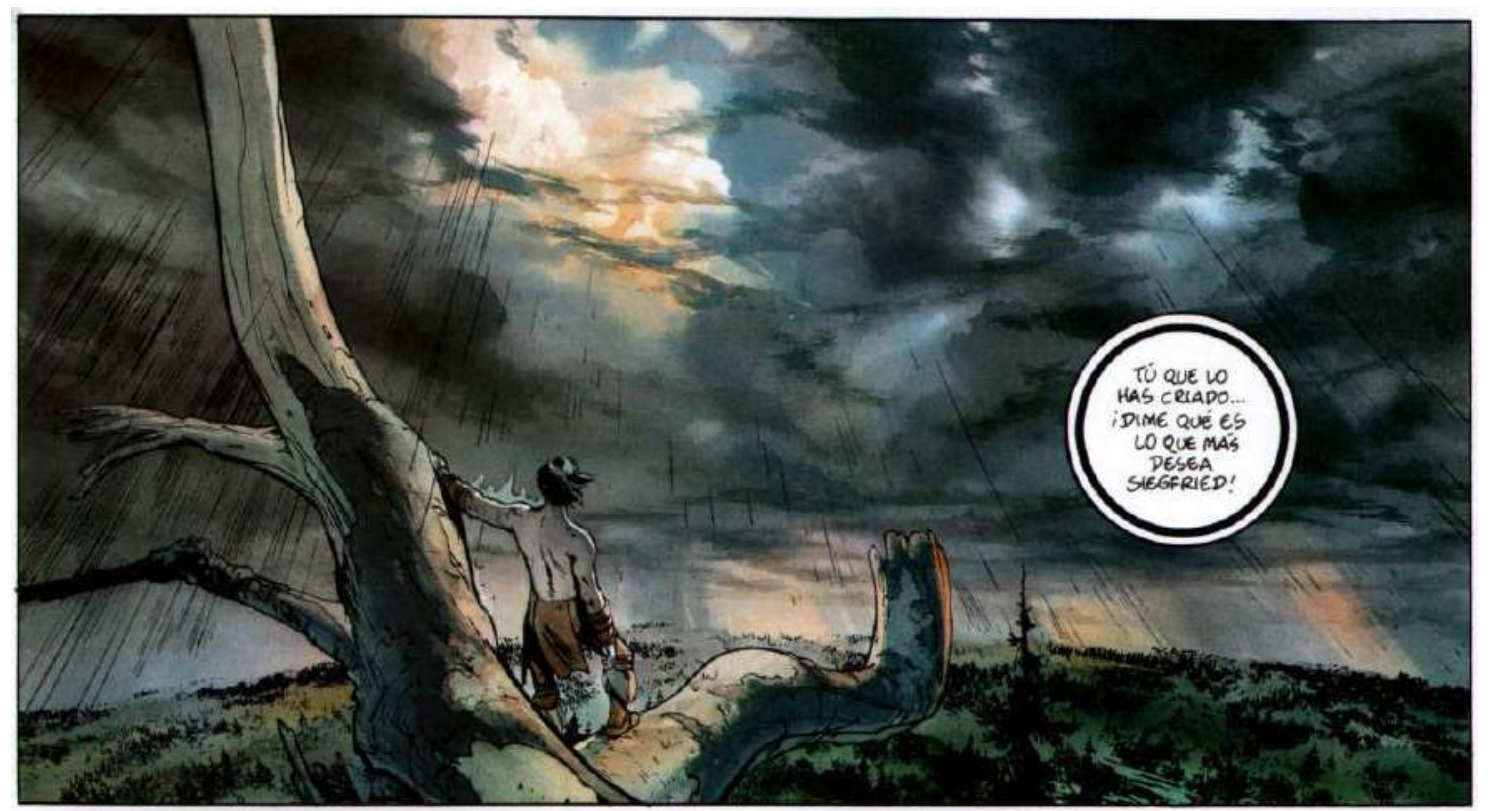

Fuente: Alice, ALEX. (2008) Siegfried. Norma Editorial.

Dargaud fue la encargada de publicar la trilogía completa de la serie, formada por Siegfried, La Walkyrie, Le crepuscule des Dieux entre los años 2007 y 2011, saliendo al año siguiente en España, cuya edición estuvo al cargo de Norma Editorial.

\subsubsection{El mundo vikingo en el cómic español: Beowulf de Santiago García y David Rubín (2013).}

Beowulf (2013), obra de Santiago García y David Rubín, se trata de una adaptación del poema homónimo anglosajón y de autor anónimo, escrito en la Edad Media.

Santiago García (1968), se inició como guionista de historietas en el año 2004. Entre sus trabajos, se encuentra El vecino, dividido en tres volúmenes y una serie de historias cortas; La Tempestad y Héroes del Espacio (2008), ambas de ciencia ficción; una adaptación de la novela de Robert Louis Stevenson, El extraño caso Doctor Jekyll y Mister Hyde (2009) y una 
larga producción de historietas cortas en revistas, como la desaparecida El Manglar. Por su parte, David Rubín (1977), cofundador del colectivo Polaqia, formado por historietistas de Galicia, es reconocido por tres libros de historietas: El circo del desaliento (2005), La tetería del oso malayo (2006) y Cuaderno de Tormentas (2008) y el Héroe (2011) en dos volúmenes (Serrano, 2013).

En 2013, ambos autores se unen, y crean para la editorial Astiberri, Beowulf, cuya historia se centra en la tierra de los skyldingos, Dinamarca, donde una horrible criatura llamada Grendel oprime a los guerreros y criados del rey Hrodgar. Tras doce años sufriendo de los ataques del monstruo, un grupo de guerreros al mando de su líder Beowulf que han emprendido un viaje en busca nuevas aventuras, visitan las tierras del rey, el cual le pedirá ayuda para librarles de su mal dándole muerte a este (Serrano, 2014).

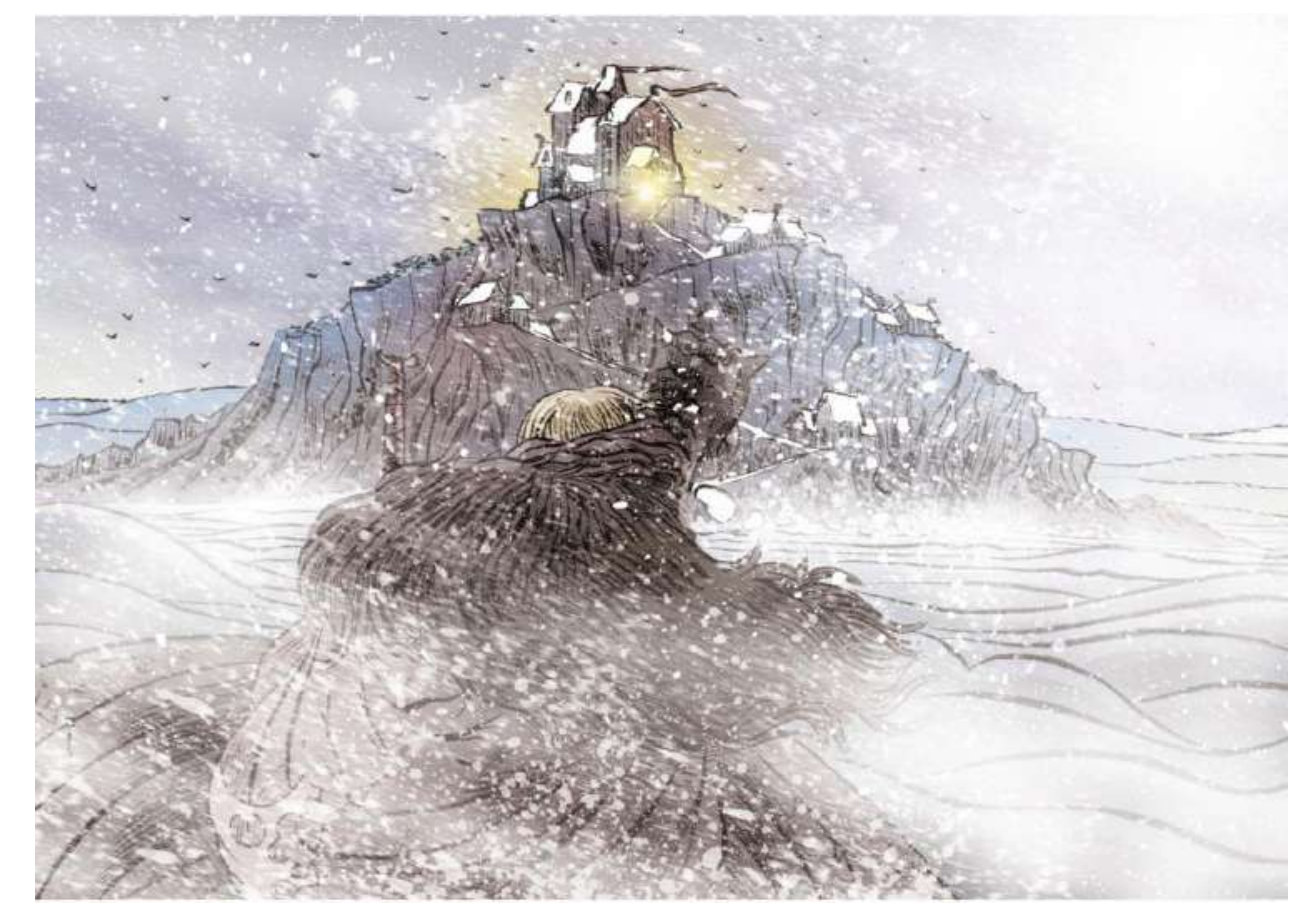

La isla de los skyldingos. Fuente: García, SANTIAGO y Rubín, DAVID. (2013) Beowulf. Astiberri.

Ambos autores, dividen la obra en tres hazañas que realiza Beowulf, dándole en primer lugar muerte a Grendel, siguiendo a la madre de este, y por último a un dragón que atemoriza a su pueblo y saltándose una de ellas, puesto que el poema se divide en cuatro 
cantos, aunque en opinión de Sedano (2013), esta fue una decisión acertada, al estar correctamente hiladas las tres historias.

En esta versión, Grendel se aleja del poema original, en la que el ser se trataba de un Jotun, el gigante de la mitología nórdica, para pasar a ser una bestia saciada de sangre y carne, impregnada de un claro tono oscuro, definida por su ausencia de moralidad, y que, en según que viñeta nos encontremos, utilizará movimientos tales que recuerdan a los de diferentes animales.

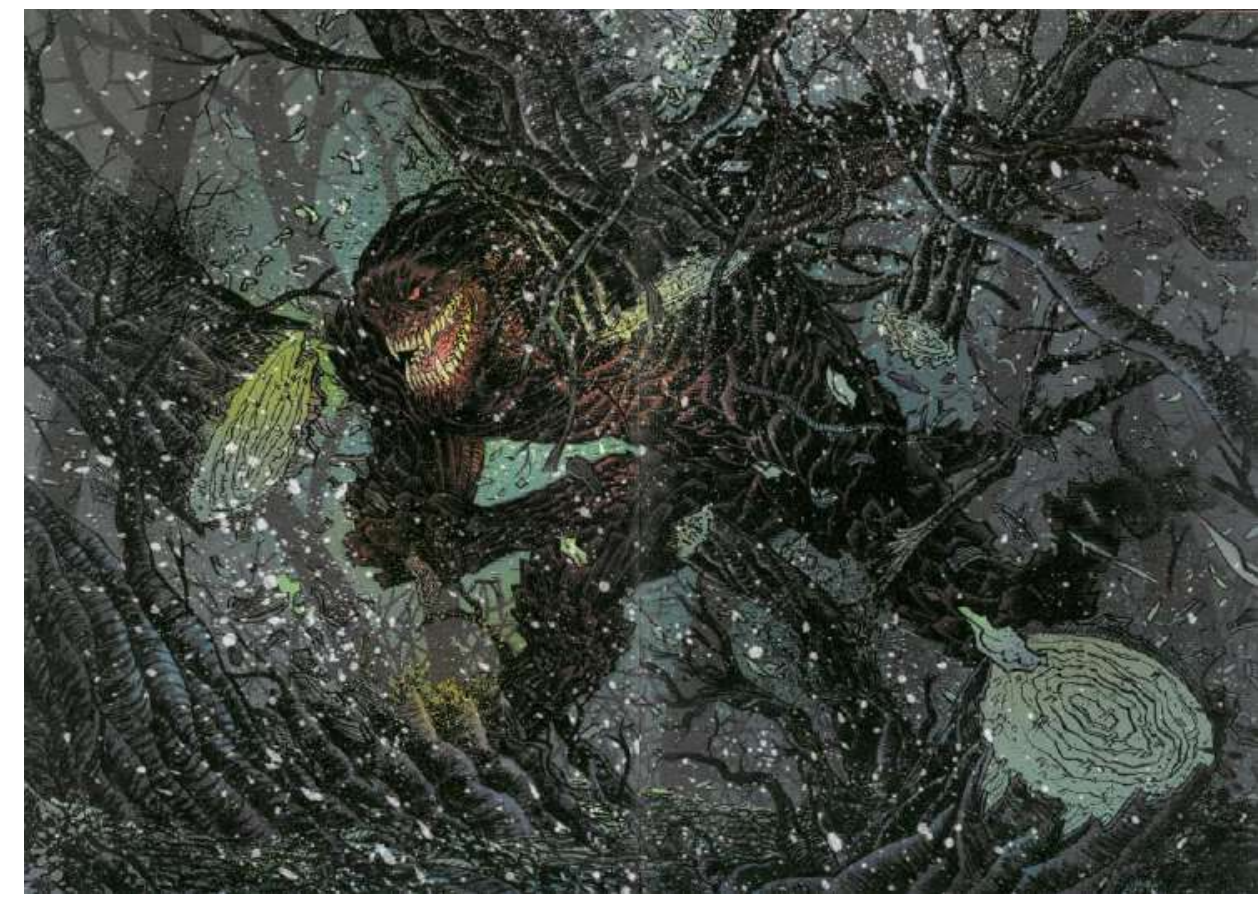

Grendel. Fuente: García, SANTIAGO y Rubín, DAVID. (2013) Beowulf. Astiberri.

Su protagonista Beowulf, se muestra como un héroe que quiere alcanzar la gloria, porque considera que esta es eterna como no lo es el oro o la misma vida, y en este caso la manera de alcanzarla es matando a todas las criaturas que aparecen en el relato, sin importarle el hecho arriesgar su vida, lo que no significa que esto venga motivado exclusivamente a su ego, puesto que el guerrero siente compasión por el rey y su gente. Esta visión del protagonista se confirmará cuando ya en estado de vejez, y siendo rey de los gautas, decida poner fin a sus aventuras matando al dragón que aterroriza a su pueblo. 


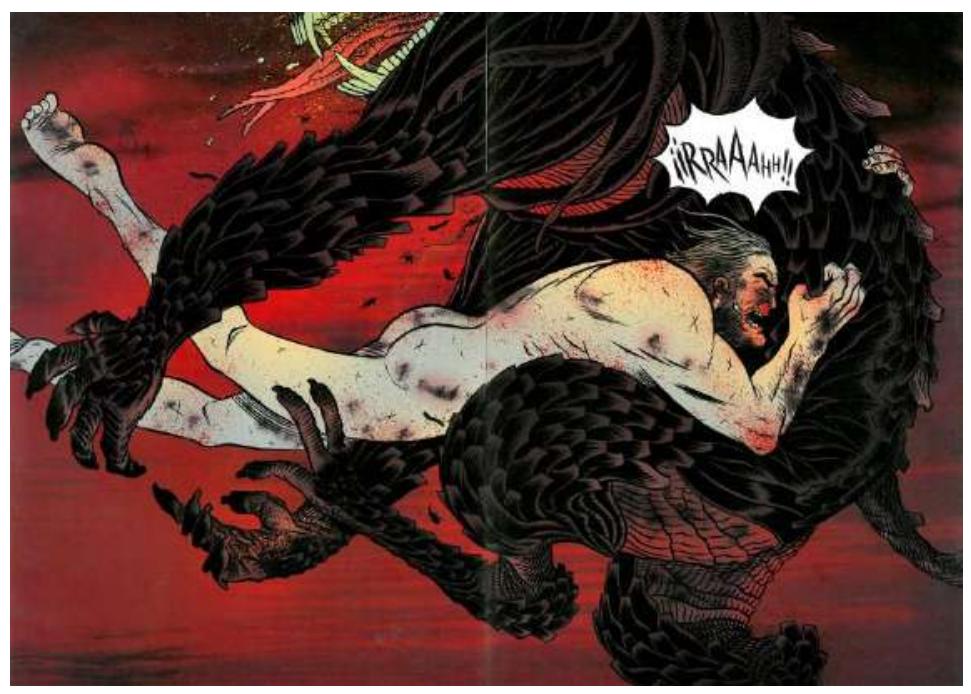

Enfrentamiento entre Beowulf y Grendel. Fuente: García, SANTIAGO y Rubín, DAVID. (2013) Beowulf. Astiberri.

En el apartado técnico, se debe mencionar la manera con la que los autores son capaces de conseguir atrapar al lector en la historia, gracias a técnicas empleadas tales como el uso de pequeñas viñetas dentro de la página y distribuidas en distintos espacios de la misma al modo de narración en paralelo, por la que una escena cotidiana como la que puede ser un banquete, aparece totalmente detallado concentrando distintas historias dentro de la principal, o el uso de la splash page, es decir, viñetas que ocupan el total de la página, o en otros casos donde una de ellas ocupa una doble.

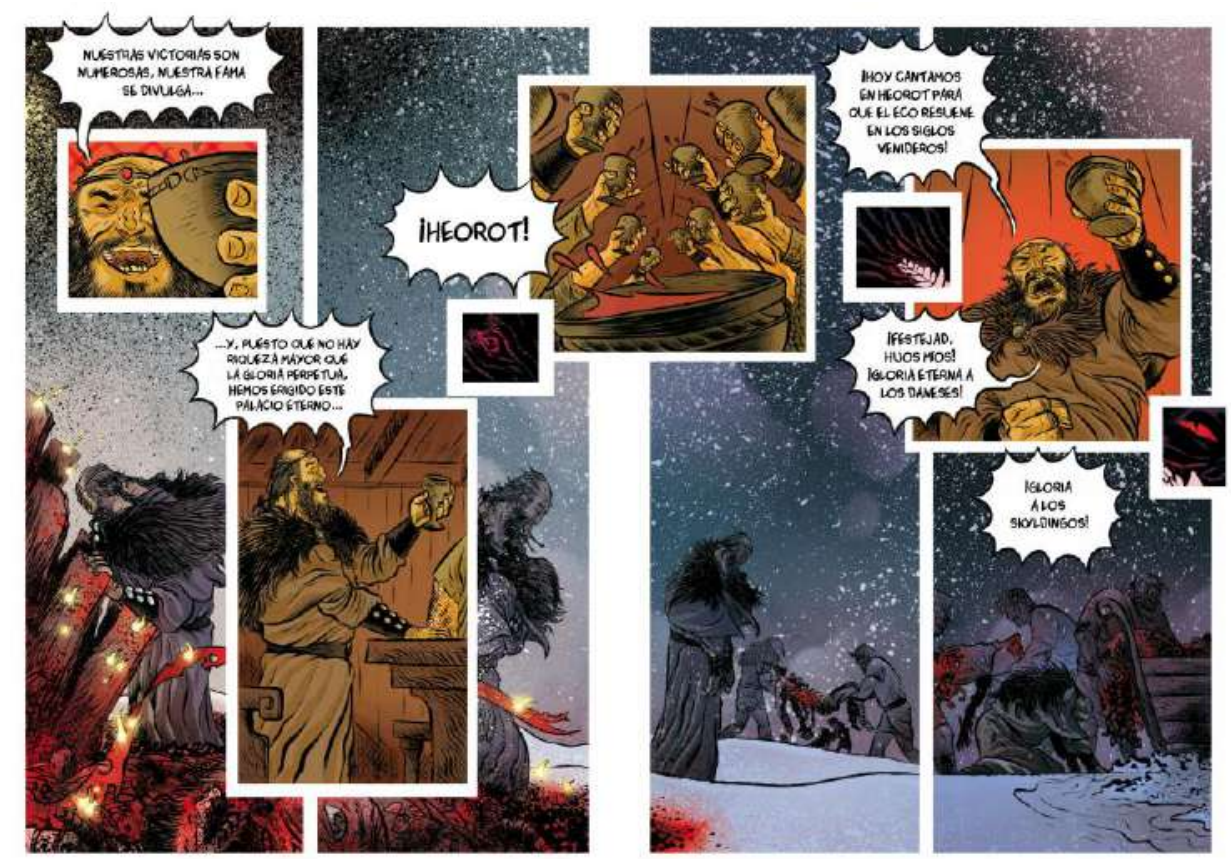

Escena del banquete. Fuente: García, SANTIAGO y Rubín, DAVID. (2013) Beowulf. Astiberri. 


\subsection{Manga japonés: Vinland Saga de Makoto Yukimura (2005).}

El manga Vinland Saga (2005), pertenece a una de las series más exitosas que existe en la actualidad, escrita e ilustrada por Makoto Yukimura.

Makoto Yukimura (1976) es un artista y autor de manga japonés, galardonado en distintas ocasiones por la calidad sus obras. Tras abandonar la Universidad de Arte Tama en Tokio, se unió como asistente de arte del creador de manga, Shin Morimura. Una vez que deja de colaborar junto al artista, se sumerge en el mundo del manga con su ópera prima: Planetes (2000 - 2004) siendo la revista japonesa "Weekly Morning" la encargada de publicar sus episodios (Alvarez, 2011). Teniendo como referencia el estilo de Yukinobu Hoshino, la serie le llevó al éxito reconocido a través de dos premios, tanto por la categoría de cómic original en 2002 como por la posterior adaptación de la serie en Anime en 2005.

A partir de este momento el trabajo de Yukimura ha ido en gran parte hacia lo histórico, comenzando por su corto さようならが近いので, Sayonara ga Chikai no de (Since Goodbye is Near) en el año 2004 y lanzado a través de la revista "Evening" (Kodansha) en el número 8. En 2005 publica el manga Vinland Saga para "Weekly Shonen Magazine" que catapulta definitivamente su carrera ${ }^{25}$.

La trama se sitúa entre finales del siglo $\mathrm{X}$ y principios del XI, con Thorfinn que es miembro de una tripulación vikinga que se dedica al saqueo y pirateo de toda Europa y cuyo líder es Askeladd, que además de raptar a Thorfinn provocaría la muerte de su padre, Thors, que había formado junto a éste parte de la invasión vikinga de Inglaterra. Desde este momento Thorfinn jura venganza y desea matar a Askeladd con todas sus fuerzas y tras intentos fallidos, Askeladd le promete a Thorfinn, basado en el código vikingo, llevar a cabo el enfrentamiento entre el uno y el otro con la condición de que realice una multitud de hazañas para él (Pardo, 2012).

\footnotetext{
${ }^{25}$ En España es publicada por Planeta Cómic.
} 
La serie es una libre adaptación de los hechos relatados en las sagas islandesas como la saga groenlendinga o la saga de Erik el Rojo, donde en ambas se citan un territorio conocido como Vinland, "tierra de vides", que sería explorado por el hijo de Erik el Rojo, Leif Eriksson "El Afortunado" en el siglo $\mathrm{X}^{26}$. De hecho el personaje en el que se basa Thorfinn, es el del explorador Thorfinn Karlsefni que en el año 1010 d.C. siguió la ruta de Leif Eriksson a Vinland en un breve intento de establecer un asentamiento permanente allí junto a su esposa Guðríður Víðförla Porbjarnardóttir y sus seguidores. Junto a ellos también aparecen personajes históricos como el rey danés Svend I "Barba partida", con sus hijos Príncipe Harald II y el Príncipe Canuto II, o el comandante de los jomsvikingos ${ }^{27}$, Thorkell "El Alto" proclamado como jarl de Dinamarca por parte de este último.

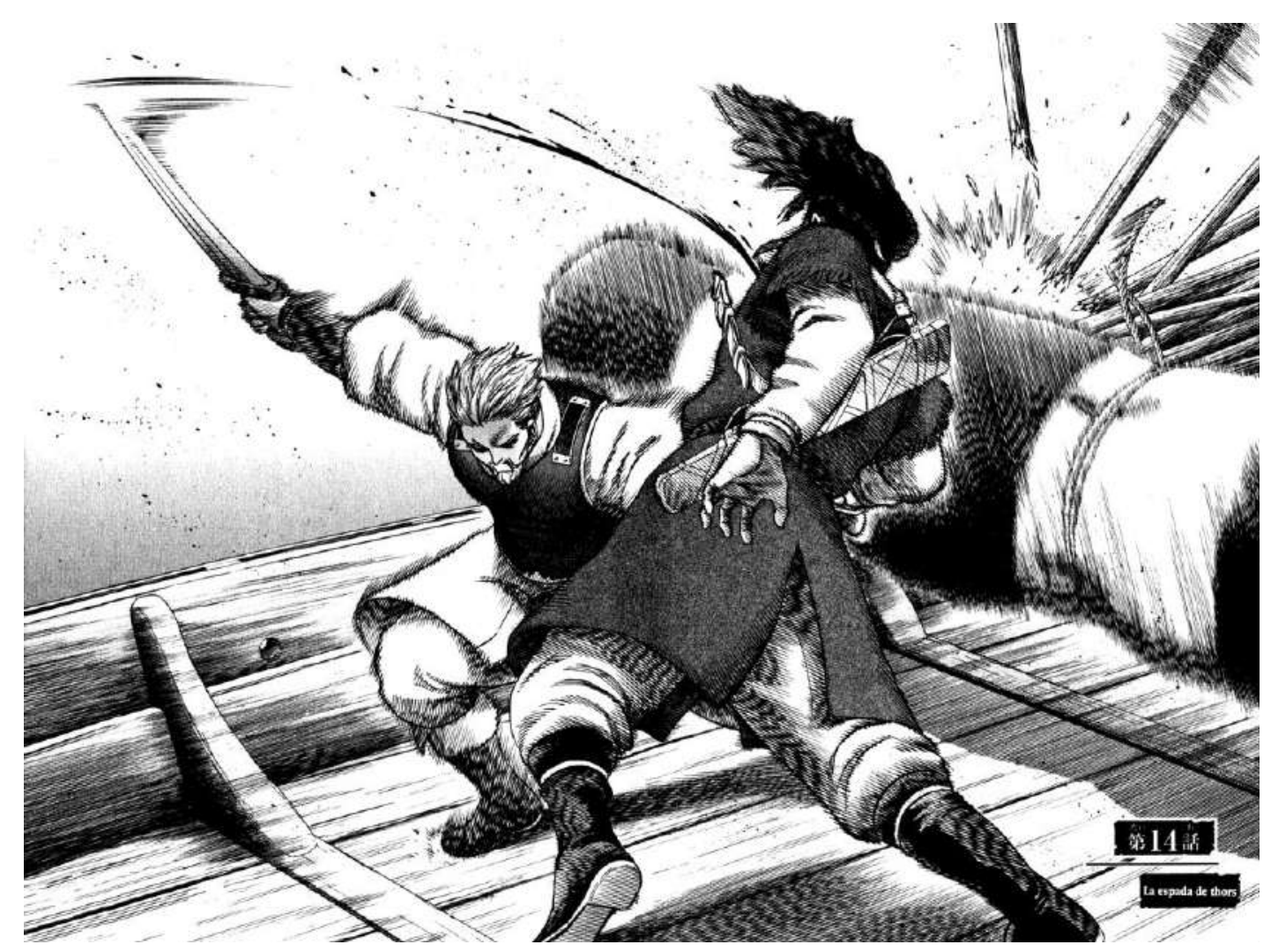

Enfrentamiento de Thors contra Askeladd. Fuente: Yukimura, MAKOTO. (2005) Vinland Saga. Kōdansha (Magazine Afternoon).

\footnotetext{
${ }^{26}$ Se cree, según las investigaciones, que se trataba de un tipo de bayas silvestres que igualmente producían un buen vino: Velasco M. Breve historia de los vikingos (versión extendida). Ediciones Nowtilus, 2012, p.188.

${ }^{27}$ Los jomsvikingos eran unos mercenarios preparados bajo el ambiente severo y célibe de la fortaleza de Jomsborg: Logan F. Los vikingos en la historia. Fondo de Cultura Económica, 2014.
} 
Yukimura, pretende no ser especialmente tradicionalista y propone a lo largo de la saga una evolución de los personajes creados por el mismo, y por lo tanto va más allá de ser una simple narración de aventuras con batallas de por medio. Por otro lado, estas referencias que son aludidas, a las que no pretende el autor con ello crear un relato histórico, se involucran en un manga denominado "Seinen", es decir, enfocado a un público adulto, donde la violencia, aunque sale a la luz en ciertos momentos, es mostrada sin ningún tipo de pudor. El dibujo del autor encuentra una continua evolución a medida que van sucediéndose los capítulos, optando de un trazo limpio a uno más sucio por el uso del "movimiento cinético" típico de los cómics que le influyeron en su juventud, tal como el del mangaka Tetsuo Hara en su obra El Puño de la Estrella del Norte.

El manga, más allá de tener acción a raudales, profundiza sobre un aspecto esencial a lo largo de la trama, como es el tema de la libertad. Los vikingos son ante todo guerreros, su única obsesión es la lucha y batallar en guerras, de hecho en los primeros capítulos se cuenta este modo de ver su destino a la perfección, donde los más jóvenes incluso "celebran" las bajas de los caídos porque así tendrán más opciones de abarcarse en la próxima aventura y alcanzar una fama que sería imposible de alcanzar literalmente como dice uno de ellos, "criando cerdos" 28 . Este pensamiento no se puede separar de sus creencias sujetas a los mitos que les son relatados e inculcados desde su infancia, como el de la imposibilidad de atravesar los mares en busca de nuevas tierras en el oeste porque hay una serpiente llamada Jörmundgander que se come los barcos, y especialmente la idea de alcanzar el Valhalla. Y aunque, el cristianismo ya se ha expandido en Escandinavia, el propio Leif viaja a por vino para celebrar el nacimiento de Cristo, aparece de manifiesto la polaridad entre ambas religiones y sus correspondientes propósitos que son incompresibles para ambos lados, puesto que mientras los cristianos ven barbarie e inmoralidad en sus actos, los vikingos ven en el cristianismo una falta de libertad al estar sujetos a una obediencia dirigida a su Dios, e incluso se permiten hacer comparaciones, llegando a la broma y desprecio, respecto al poder de sus dioses frente al suyo.

\footnotetext{
${ }^{28}$ YUKIMURA, Makoto. Vinland Saga. Japón, Afternoon KC Comics, 2005, nº 1, p. 93.
} 


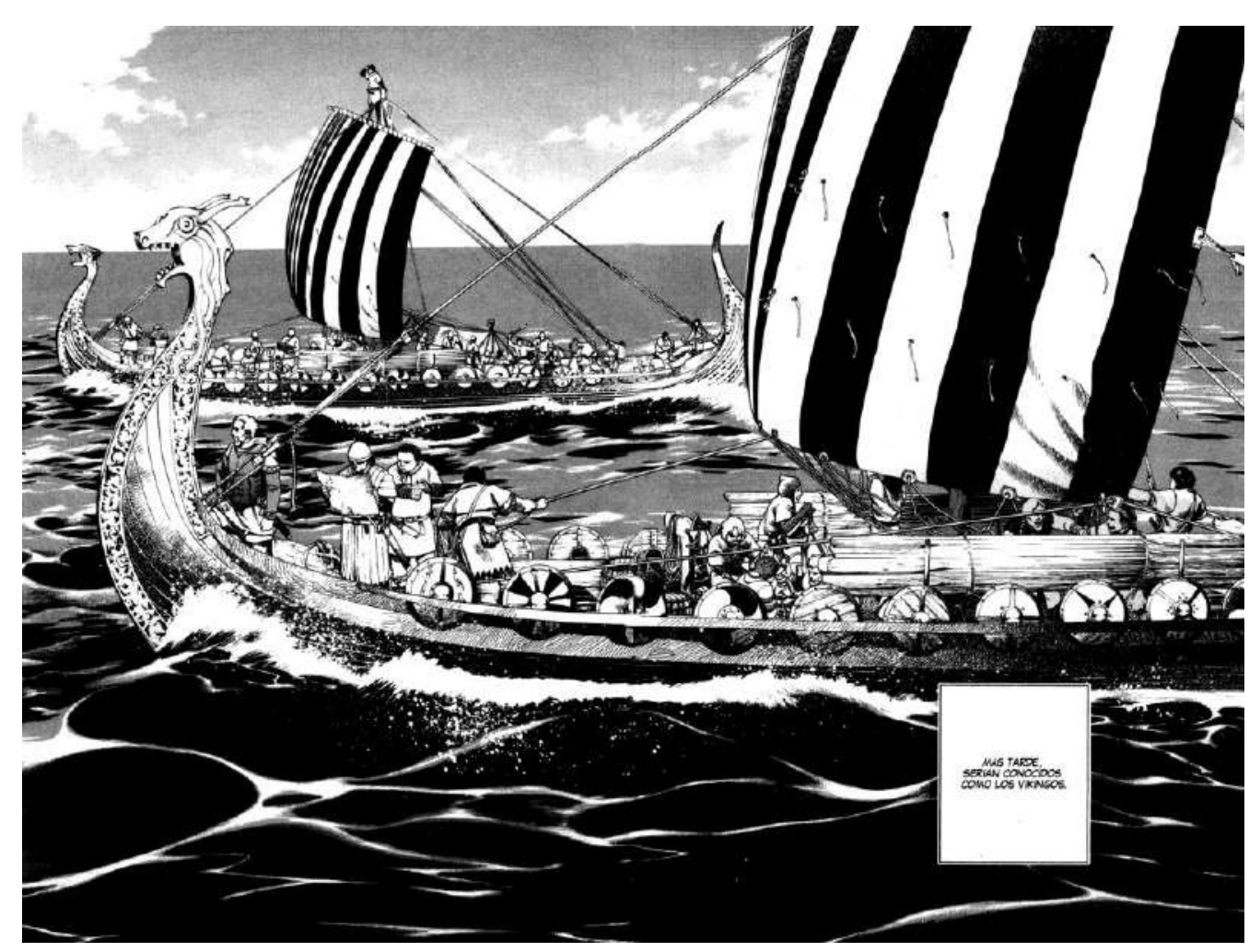

Drakkars vikingos. Fuente: Yukimura, MAKOTO. (2005) Vinland Saga. Kōdansha (Magazine Afternoon).
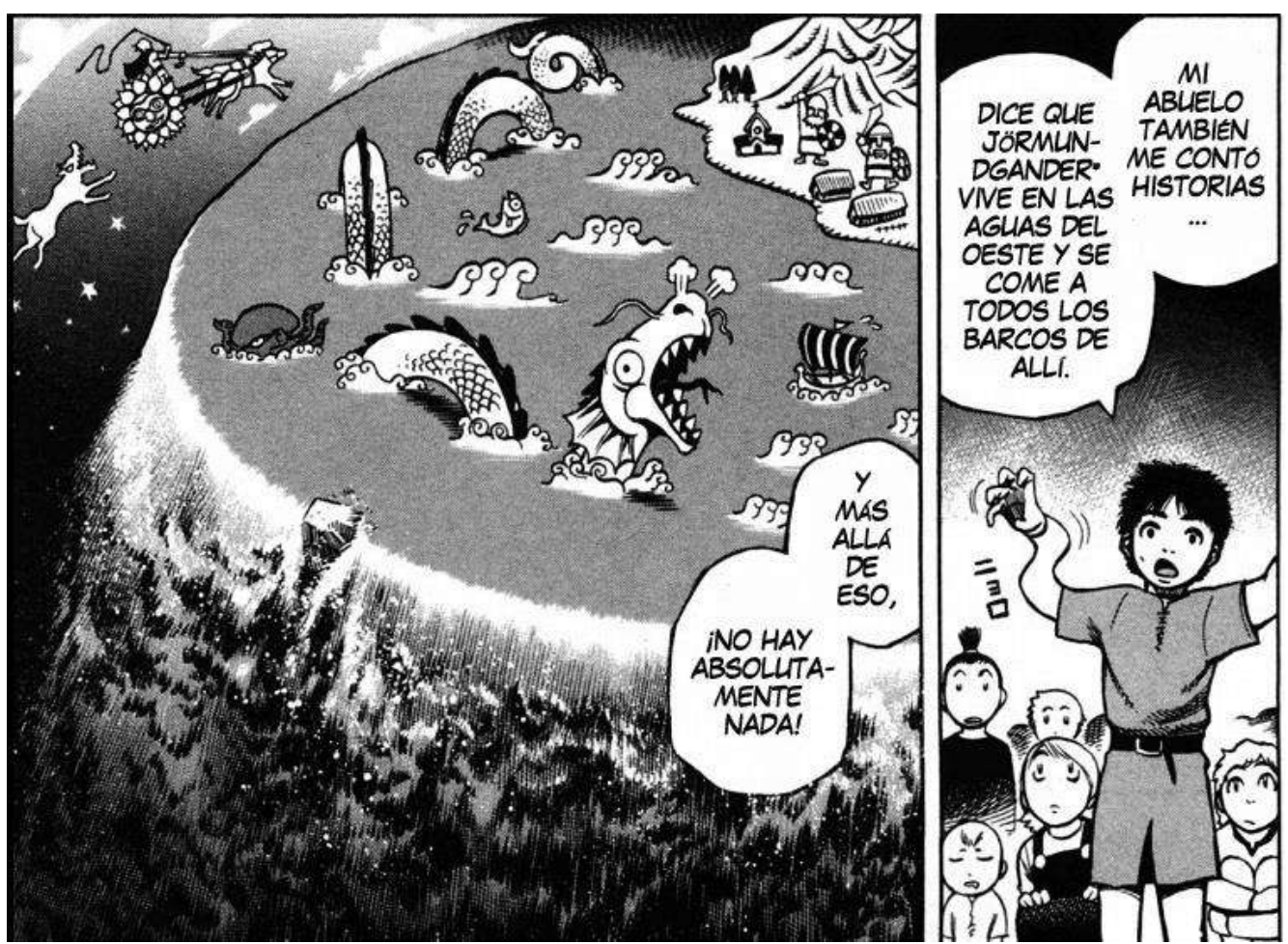

Referencia a la serpiente Jörmundgander. Fuente: Yukimura, MAKOTO. (2005) Vinland Saga. Kōdansha (Magazine Afternoon). 
Es por ello que el personaje que mejor refleja el cambio es Thors, padre de Thorfinn y antiguo capitán de los Jomsvikingos, que más posicionado al espíritu del cristiano de la expiación de sus pecados pasados, decide apartarse de la vida de guerreo vikingo para alcanzar la paz y vivir una vida en familia, donde cuidan del ganado, trabajan quitando la nieve que cubren sus casas o barcos, comen carne para celebrar la llegada del solsticio de invierno, y ante todo no existe la esclavitud, hecho que no puede ni llegar a comprender su propia familia, como en una escena donde negocia con ocho de sus ovejas para lograr la libertad de un esclavo malherido que es hallado por el propio Thors. A pesar de ello, Thors quiere inculcar esta nueva vida a sus hijos, especialmente a Thorfinn y que es representada a través de esta poderosa imagen:

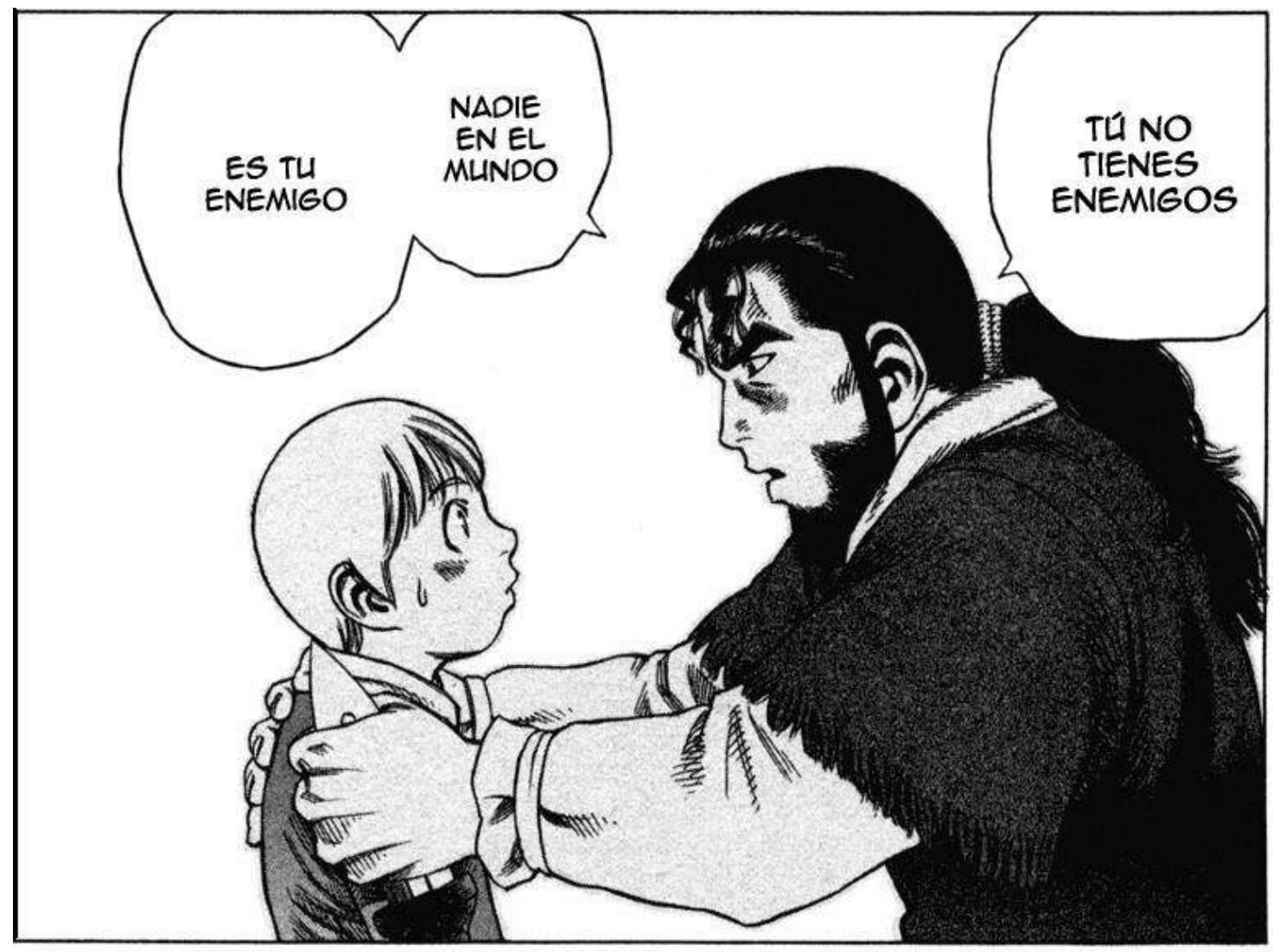

Fuente: Yukimura, MAKOTO. (2005) Vinland Saga. Kōdansha (Magazine Afternoon). 


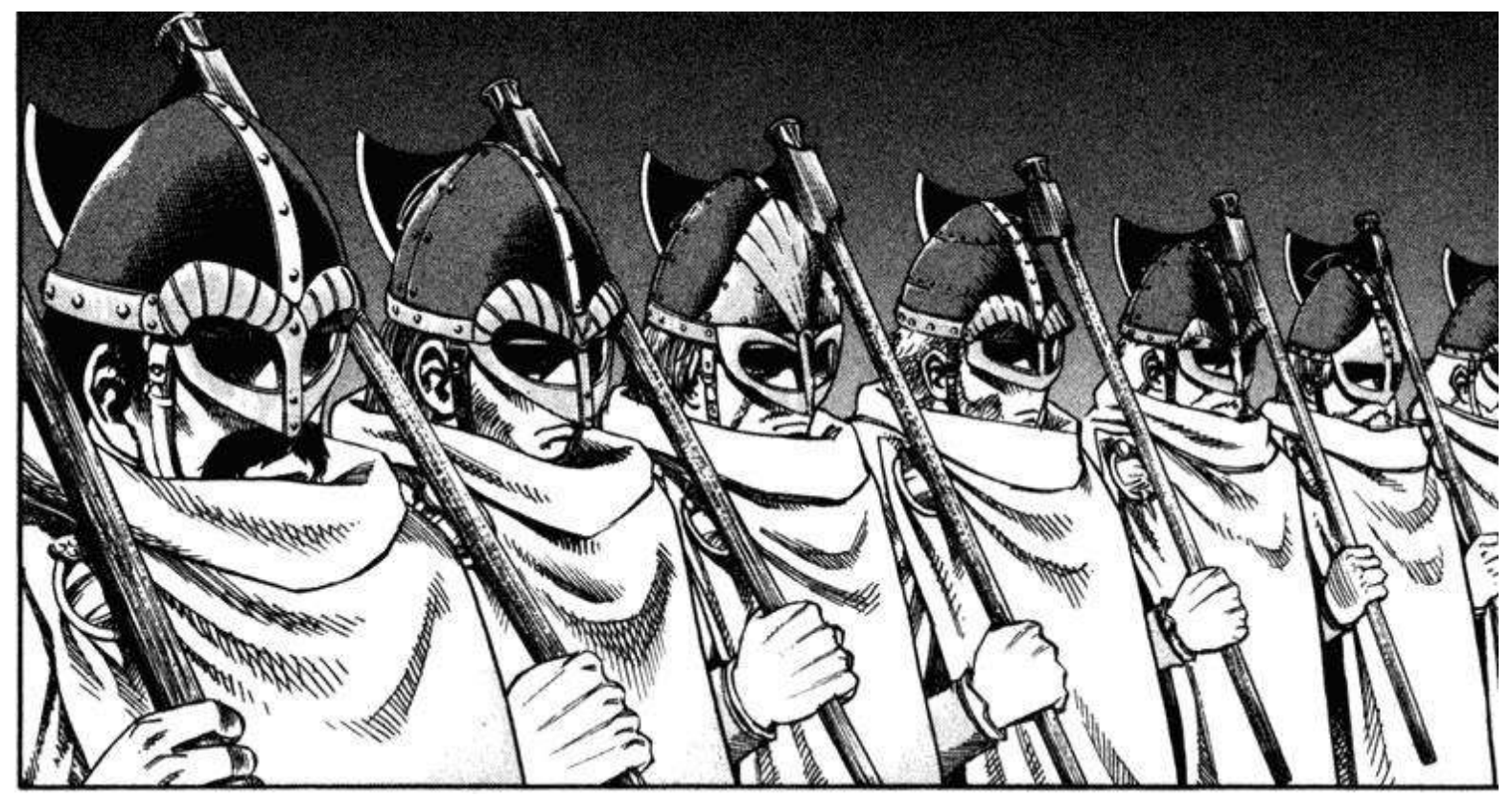

Jomsvikingos. Fuente: Yukimura, MAKOTO. (2005) Vinland Saga. Kōdansha (Magazine Afternoon). 


\section{SERIES DE TELEVISIÓN.}

En el terreno audiovisual, el mundo vikingo y su mitología han sido tratados con un mayor interés por parte del cine ${ }^{29}$. Ya en 1928, se estrenaba la primera película de temática vikinga como lo fue The Viking, película muda centrada en el vikingo Leif Erikson. Otros títulos destacables son: Vikingos (1958), protagonizado por Kirk Douglas; la producción islandesa, La sombra del cuervo (La venganza de los vikingos) (1988), que forma parte de Trilogía de los Vikingos de manos del director Hrafn Gunnlaugsson; un hilarante título como es Erik el vikingo (1989), dirigida por uno de los integrantes de Monty Python, Terry Jones; El Guerrero $n^{o} 13$ (1999), protagonizada por Antonio Banderas; una muy interesante producción danesa, Valhalla Rising (2009); Beowulf (2007), de Robert Zemeckis, y las adaptaciones de Thor dentro del mundo Marvel.

Respecto a las series, no han tenido tanta difusión respecto a dicha temática, aunque hay que indicar que existe un mayor crecimiento de producciones televisivas del siglo XXI desde la llegada de la TV de cable, o la aparición de actuales plataformas que están incluyendo en su parrilla un mayor tratamiento del mundo vikingo, siendo la serie Vikings (2013- ), la que más repercusión ha tenido en la época reciente. Tanto la serie señalada como los títulos: Vickie el vikingo (1972-1974), The Last Kingdon (2015- ), The Norsemen (2016- ) y Ragnarök (2020- ), serán parte del análisis que se mostrará a continuación.

\subsection{Vickie el vikingo (1972-74).}

El despertar, se produjo con Vickie el vikingo, considerada todo un clásico de la cultura infantil. Dirigida y producida por los japones Hiroshi Saito y Chikao Katsui (Zuiyo Enterprise Company) en 1974, y coproducida en Alemania (ZDF, ORF), siendo la primera serie de animación del país germano, se basa en el personaje literario creado en 1963 por el escritor sueco Runer Jonsson (1916-2006), (Holler, 2016).

\footnotetext{
${ }^{29}$ En este caso no han formado parte del análisis del TFM.
} 
La serie se centraba en las aventuras de Vickie, un niño pequeño de corta estatura y perteneciente a una aldea vikinga llamada Flake, situada entre Suecia y Noruega, dominada por su padre, Halvar, el jefe de los vikingos (Penélope, 2015). La serie más allá de mostrarnos algunas referencias históricas, como la incursión a América de los guerreros del norte, o el modo de vida del vikingo en sus aldeas e incursiones a través de sus barcos, tenía como propósito enseñar que el comportamiento violento y la fuerza bruta, encarnada en los personajes que acompaña a Vickie como su propio padre, no sirve de nada sin inteligencia e imaginación, que es la que albergaba Vickie, el cual siempre a través de ellas solucionaba todo tipo de conflictos, dejando la imagen icónica de su frotado de nariz cada vez que se le ocurría cualquier idea ${ }^{30}$.

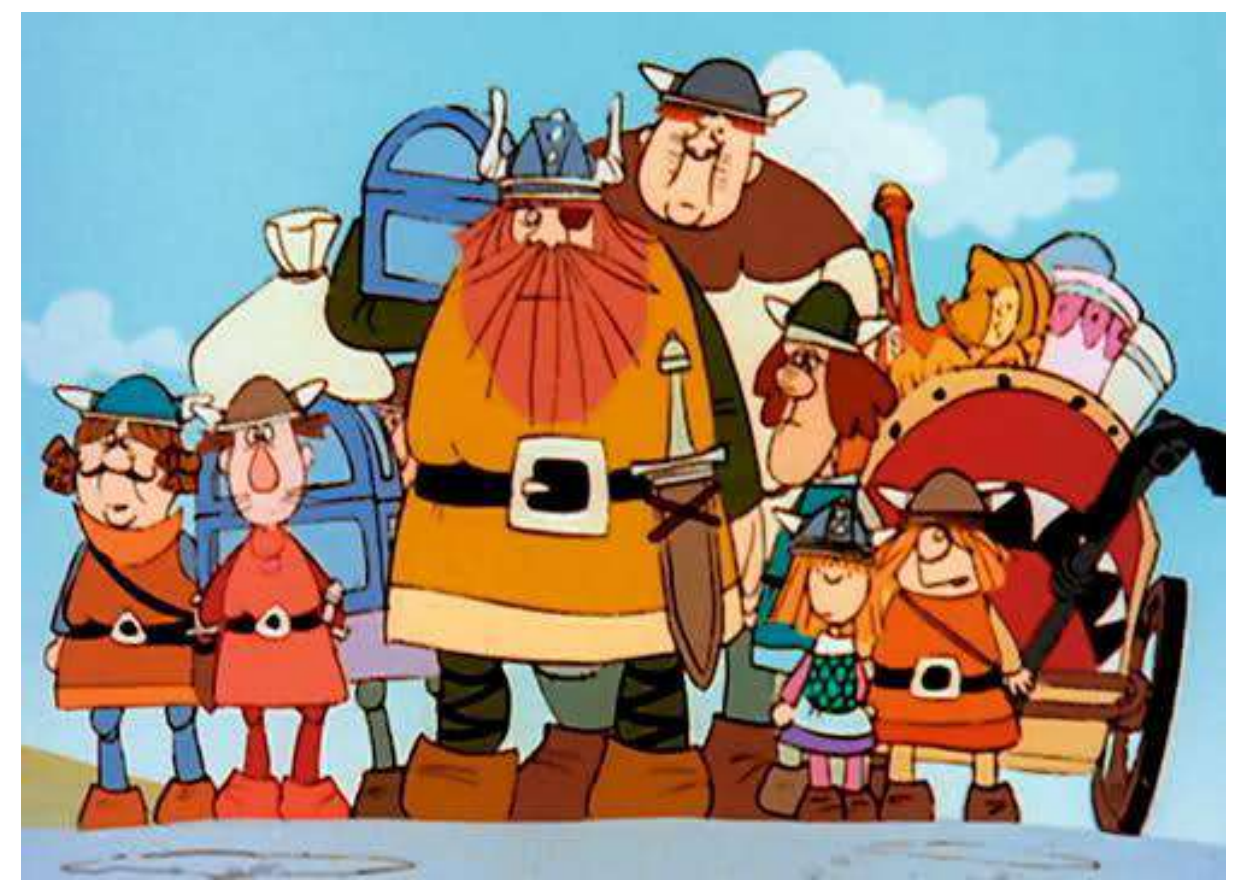

Representación del vikingo. Fuente: http://www.minigranada.com/te-acuerdas-de-vickie-el-vikingo/

\footnotetext{
${ }^{30}$ La serie tuvo un total de 78 episodios y en España se emitió a través de TVE en el año 1975.
} 


\subsection{Vikings (2013-).}

La serie emitida por el canal History y creada por Michael Hirst, Los Tudor (2007) o Camelot (2011), está ambientada sobre la vida del rey legendario de las sagas nórdicas, Ragnar Lodbrok.

Ragnar es un granjero que vive junto con su familia en el pueblo vikingo de Kattegat, un estrecho que se ubica entre Dinamarca, Suecia y la península de Jutlandia. Ragnar acaba de regresar a Kattegat tras su saqueo en los bálticos orientales junto a su hermano Rollo (Larrinaga, 2019). La tribu de la pequeña aldea es gobernada por el conde vikingo, Earl Haraldson, cansado del constante desafío y actitud de Ragnar hacia su persona, ambicioso de explorar nuevas tierras al oeste, que según el protagonista, están llenas de riqueza y que aparentemente solo él cree de su existencia ${ }^{31}$. Tras contarle la intención a su hermano Rollo de explorar las tierras occidentales y desobedecer al conde, ya que el deseo de este era que el próximo ataque fuera hacia el sur y Rusia, viaja junto con un grupo de guerreros con el barco fabricado por el amigo de Ragnar, Floki, llegando a la isla de Lindisfarne en Northumbria (gran Bretaña), donde capturan todos los tesoros del monasterio e imponen brutamente su ira contra los monjes del lugar y tomando como preso a Athelstan, quién Ragnar lo utiliza para que le guie en sus futuros viajes.

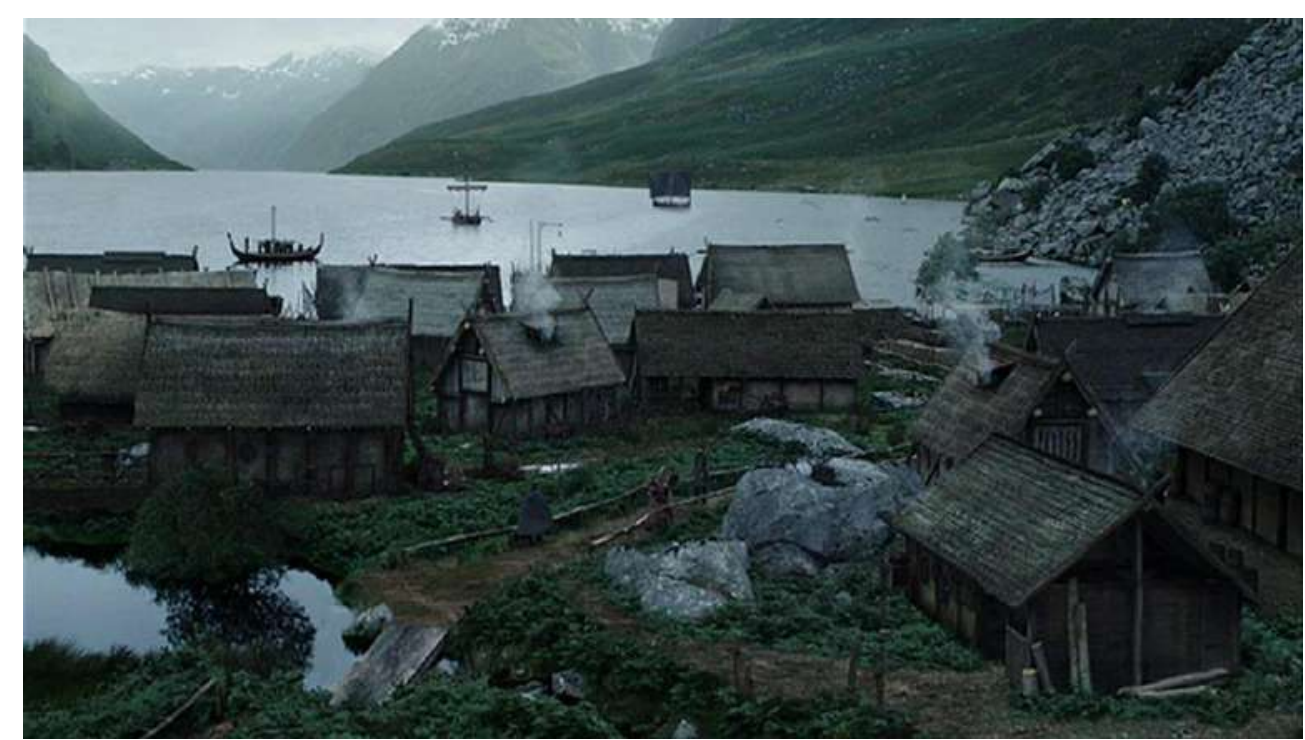

Kattegat, hogar de la familia de Ragnar. Fuente: https://www.looper.com/218488/the-village-in-vikings-that-isnt-supposed-to-exist//

\footnotetext{
${ }^{31}$ En el episodio 1x06, Sepultura para los muertos, el conde revela que el también cree de la existencia de esas tierras a su mujer.
} 
Dentro de los aspectos puramente sociales, desde el primer episodio ya están presentando el modo de vida y costumbres de este pueblo. En primer lugar, se recalca la importancia que cobra el concepto familia para los nórdicos, encarnada en la de Ragnar, ocupado en cuidar la granja, gracias a la cual se alimentan, mientras que su mujer, Lagertha, es la encargada de llevar a cabo la tarea del hogar y cuidar a sus dos hijos. Lagertha, enseña a su hija Gilda tejer y pescar, mientras que Ragnar se hace cargo de su hijo Björn para que vaya acostumbrándose a las costumbres de su pueblo, haciéndole asistir a condenas de muerte, o asistiendo a la asamblea donde recibe su brazalete sagrado que hace convertirle en hombre, además de enseñarle el arte del combate para ser un gran guerrero en el futuro.

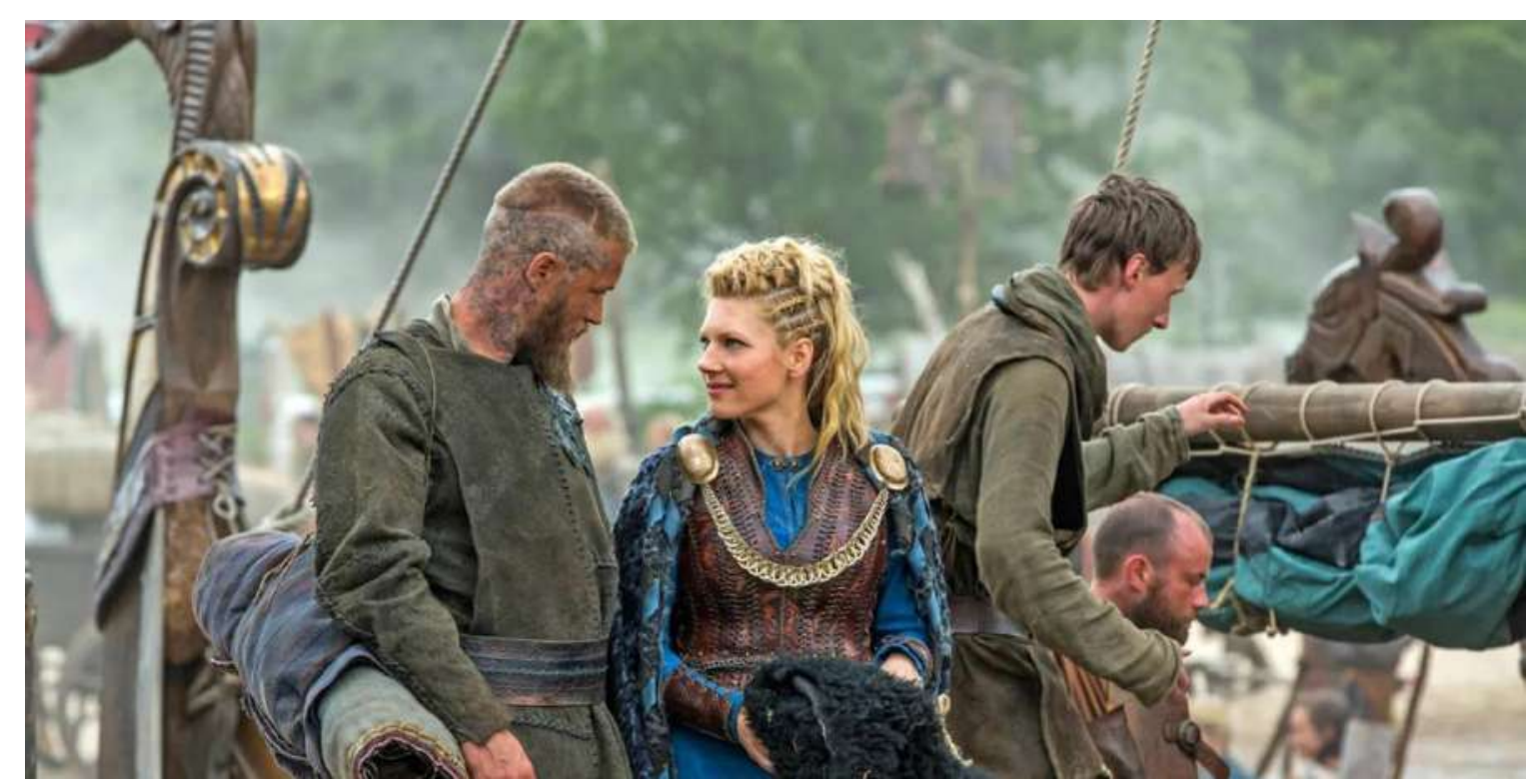

Ragnar y Lagherta. Fuente: https://vader.news/series/Vikingos-Por-que-el-amor-entre-RagnarLothbrok-y-Lagertha-nunca-termino--20200619-0003.html

Por otra parte, al hilo de sus costumbres y modo de vida, estas son totalmente motivadas por sus creencias. La mitología constantemente está presente en la serie, ya en la primera escena del capítulo de inicio se muestra una recreación de un guerrero muerto en combate que es llevado por las valquirias al Valhalla, o la misma aparición de Odín con aspecto de vagabundo, del que el propio Ragnar se cree descendiente. Lagertha, menciona a Freya, diosa de la fertilidad a sus hijos y les relata, mientras Ragnar se encuentra navegando en por el mar, la visión cosmológica nórdica y que la investigadora Donstrup cita textualmente en su artículo: 
"The great sea is held in place by Jormungand, the serpent, whose giant body encircles it, and whose keeps his tail and his mouth, to complete the circle and stop the waves breaking loose. But one day, the God Thor, son of earth, was fishing in the sea for the serpent, using a bull's head for bait. Jormungand reared up and the waves pummeled the shore and he twisted and writhed in a fury. They were well matched, serpent and God, in that furious fight. The seas boiled around them, but then the hook became dislodged, and the serpent slithered free and sank again, so quickly, beneath the waves. And soon, the sea was calm once more, as if nothing had disturbed it”. (Donstrup, 2017, p. 63).

Es tan ferviente la creencia que el pueblo vikingo tiene hacia los dioses, que ellos mismos acuden a estos para conocer el destino que le deparan, e interviniendo la figura del vidente, que habla por ellos, pero solo lo que quieran contar los dioses. En el episodio 1x08, titulado Sacrifice, aparece el templo de Uppsala (Suecia), un lugar sagrado y plagado de enormes estatuas e ídolos de los dioses Aesir principales (Thor, Odín y Freyr), que se encuentra situado en una región montañosa, y es el lugar donde los devotos realizan su peregrinación cada nueve años para festejar durante nueve días y realizar sacrificios a sus dioses, con atuendos especiales para la ocasión, y ofreciendo a estos nueve animales de cada especie incluyendo a una persona para así obtener prosperidad a su poblado durante dichos años.

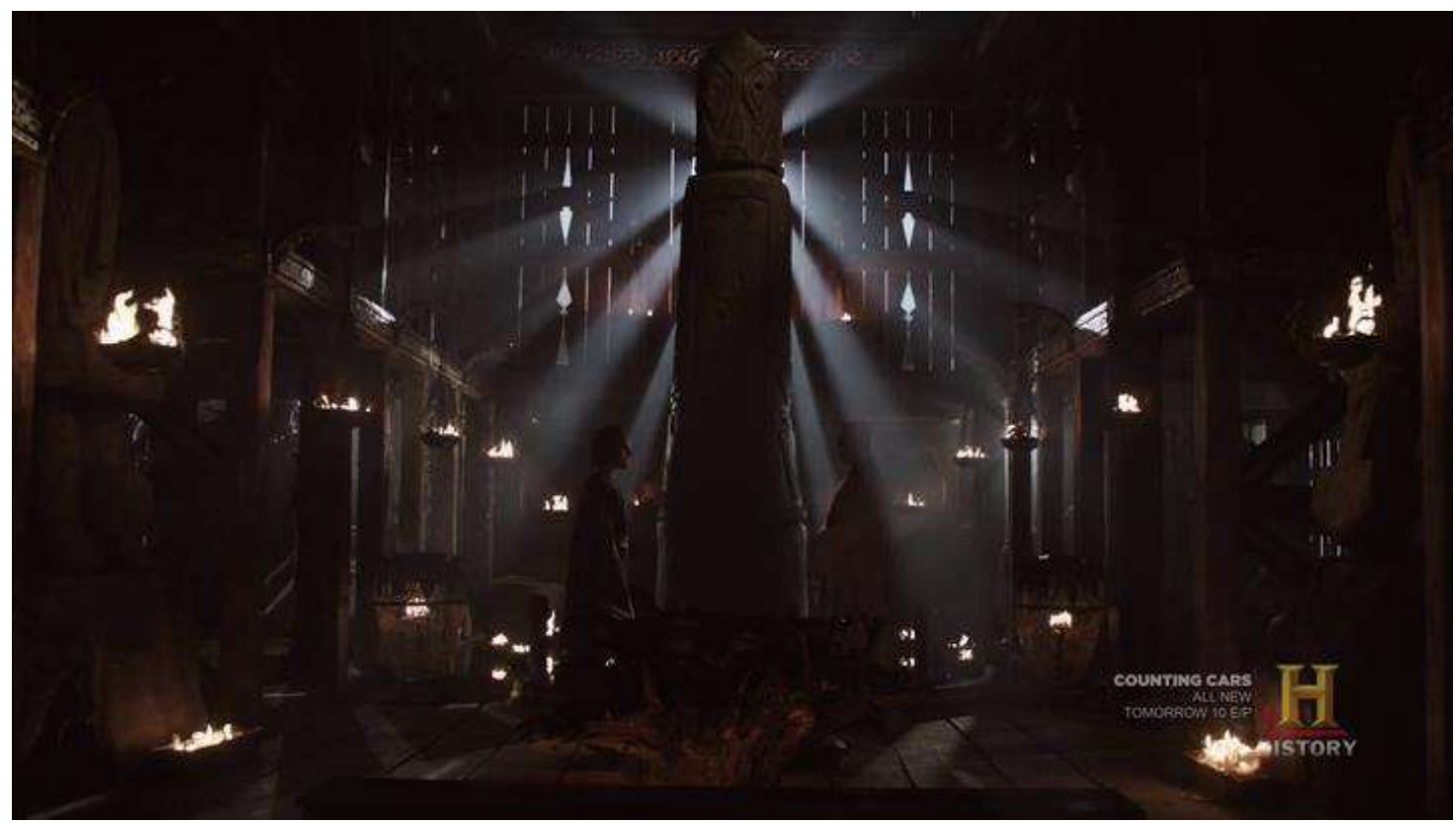

Templo de Uppsala: ídolo de Odín. Fuente: https://www.pinterest.es/pin/365495325979279605/ 
Un tema que ha generado bastante controversia, viene motivado a causa de la veracidad histórica que aparece en la serie, ya que esta ha sido cuestionada en multitud de ocasiones por los historiadores, aunque hay que partir de la base y en propias palabras de su creador, Hirst, que la intencionalidad de permitirse añadir elementos fantásticos y licencias creativas a la trama son de algún modo justificadas: "Queremos que la gente vea la serie. Un reporte histórico llegaría a cientos, ocasionalmente miles de personas. Aquí queremos llegar a millones" (Cruz, 2014).

Respecto a esta cuestión, la historiadora especializada en cultura vikinga, Laia San José Beltrán, autora de Vikingos. Una guía histórica de la serie de History Channel (2014), elaboró a través de este trabajo, un repaso acerca de los aspectos de la serie desde el punto de vista histórico, asimilando la intencionalidad creativa de su creador anteriormente indicada. Aspectos de la vida cotidiana del vikingo responden, salvando ciertos elementos de vestuario, a hechos reales, como es el caso de la posesión con todo derecho hacia el esclavo, a su propia liberación; o los funerales vikingos, siendo uno de los que aparece en la serie perteneciente a una de las múltiples formas de enterramiento que practicaban los vikingos, como es el del barco funerario ${ }^{32}$.

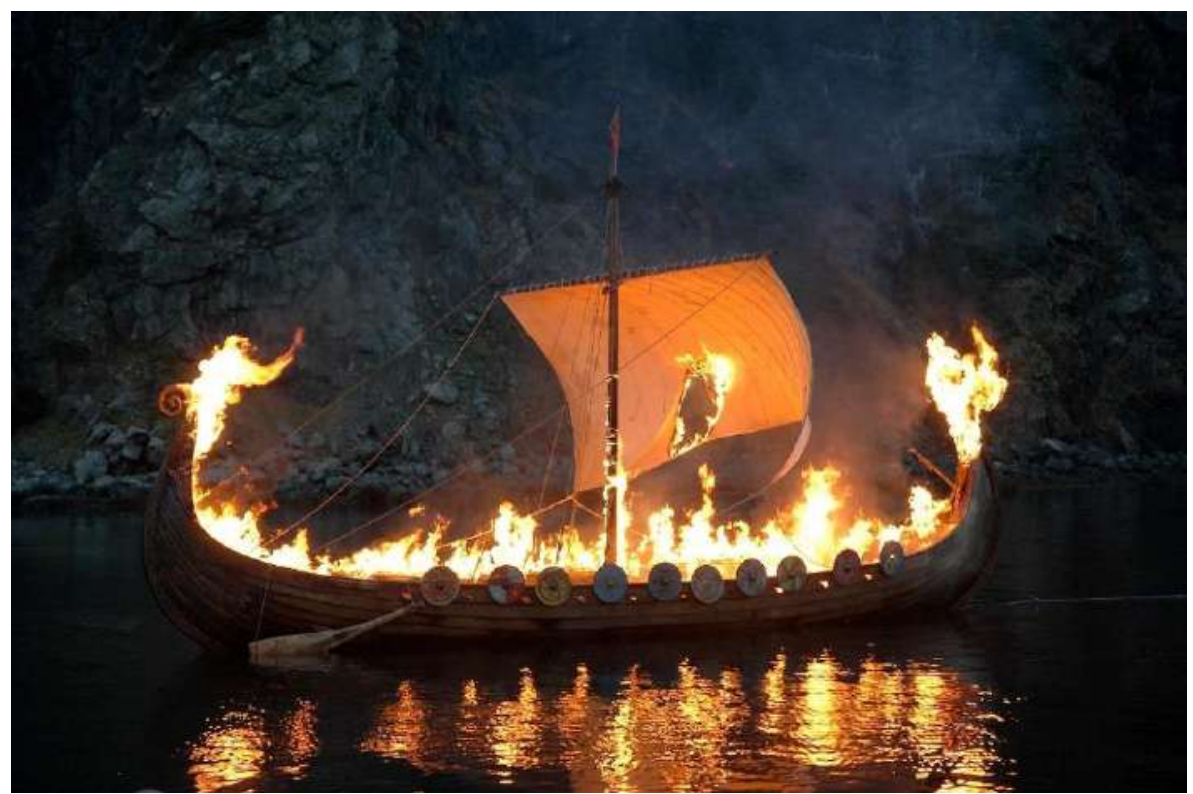

Rito funerario vikingo. Fuente: https://evilgeeks.com/2013/04/09/the-vikings-episode-6-burial-of-the-dead/

\footnotetext{
${ }^{32}$ Este tipo de ritual, tal y como aparece en la serie reflejado en la figura del conde, solo se podía permitir a personajes de un estatus y poder económico alto, a los cuales se les realizaban barcos para la ocasión, los llamados barcos vikingos de guerra, långskip, con la función simbólica de transportar al difunto y un esclavo del mismo en el Valhalla para servirle: Beltrán, L. (2015) “ Análisis histórico de la serie Vikingos de History Channel” Los Vikingos en la Historia, 2, pp. 25-72.
} 
Otros elementos, sin embargo, son más o menos discutidos, como el caso del Thing o asamblea, donde se reúnen los hombres libres para debatir ciertas cuestiones mediante un proceso similar al democrático, que aunque estos son partícipes de ellas tal y como sucedió históricamente, bajo ningún concepto daría lugar la intervención de la figura de un caudillo opresor como lo es Haraldson; o el concepto de poligamia, puesto que los vikingos tal y como expone Beltrán (2015, p. 42), no desposaban con las mujeres que quisieran, sino que tenían como amantes a concubinas esclavas ${ }^{33}$.

Destacable es el papel de la mujer en la sociedad vikinga, que como ya hemos visto, se ocupan de las tareas del hogar y de cuidar a sus hijos, pero a la vez batallan junto a los hombres, como es el caso de la escudera Lagertha, que llegaría a ser la gobernadora del reino de Kattegat. Sin embargo, tal y como apuntó la historiadora Castro (2018) para la web Filo.news, las mujeres esencialmente, y aunque sabían manejar armas, se quedaban al cuidado de las tareas domésticas, hecho que "no significa que de forma excepcional alguna mujer, que tuviera las condiciones físicas y así lo decidiera, no pudiera luchar en una guerra de forma activa, pero debía ser algo excepcional". Por otra parte, también son parte fundamental de la asamblea, donde tienen el derecho de participar de forma activa. Es por ello que el rol de la doncella guerrera, skjaldmö, en la serie sea discutido, porque como advierte Beltrán (2015, pp. 30-34), formaría parte de un elemento propio de la mitología nórdica que aparece tanto Eddas, Sagas y Gesta Danorum, y de la cual no existen evidencias arqueológicas ni documentales ${ }^{34}$.

Para terminar, merece especial atención centrarse en la figura del protagonista de la serie, Ragnar Lodbrok, personaje del cual citan las sagas legendarias, conocido como "Calzas peludas", alcanzado esa consideración de personaje icónico que se mueve entre el mito y la realidad.

Son hasta un número de tres, tal como señala García (2018) las fechas que se han manejado acorde al reinado de Ragnar Lodbrok, y que comprenden a partir del 750 d.C. hasta

\footnotetext{
${ }^{33}$ Sin embargo, se apunta que existía un matrimonio descrito por los normandos y conocido como more danico, en el que sí se podía tener más de una esposa, y especialmente con alguien de elevado estatus social para reconocer oficialmente la herencia a sus hijos y ascender al trono, como es el caso del matrimonio de Ragnar con la princesa Aslaug: Ibídem. p. 42.

${ }^{34}$ El Gesta Danorum es un texto del siglo XII escrito por el historiador Saxo Gramático, donde relata el pasado del país danés con abundante contenido mitológico: Ibid., p. 209.
} 
865 d.C. Para el filólogo británico, McTurk, escritor del libro Studies in Ragnars saga loðbrókar and its major Scandinavian analogues, Ragnar sería dos personajes distintos, el primero relacionado con el vikingo que militaba en la corte del rey Horik I de Dinamarca, llamado Reginheri que llevaría a cabo el saqueo de París en el año 845 d.C., y el segundo correspondiente a Björn Ragnarsson, identificado como su hijo en la serie.

La segunda teoría que fue llevada a cabo por el citado Saxo Gramático, autor de Gesta Danorum, en ella descubre al vikingo como descendiente de una de las dinastías con más influencia y poder que tuvo Suecia entre los siglos VIII y XI, perteneciente a la Casa Real o Dinastía de los Ynglingos. De acuerdo con esta teoría, sus incursiones por el Báltico las realizaría durante los primeros años del 840 d.C., llegando a París en el 845 d.C. junto al rey Horik, siendo finalmente derrotado en el año 865 d.C. por el rey Aelle de Northumbria, el cual le arrojaría a un pozo de serpientes venenosas, hecho que se representa. Esto descarta, tal y como aparece en la serie su participación en la primera incursión a tierras inglesas, en concreto la que se considera el inicio de la era vikinga con el ataque al monasterio de Lindisfarne en el año 793 d.C.

Más allá de las imperfecciones históricas, la serie es hoy en día un auténtico referente para los amantes del mundo vikingo y su mitología, que ha ayudado a descubrir un punto de vista alejado del tan estereotipado maligno comportamiento al que se le asocia a dicho pueblo, gracias al interés aférrimo de Hirst, el cual ratifica mediante la siguiente declaración extraído del artículo de Such (2007) para la página web Fueradeseries:

"La gente decía que no era posible escribir una serie sobre vikingos porque eran terribles, eran brutales y simplemente saqueaban y violaban a todo el mundo. Pero cuanto más leía y comprendía, más me daba cuenta de que eran una cultura rica y maravillosa que había sido estigmatizada por sus enemigos, los monjes cristianos que tenían asuntos que resolver con ellos. Me enamoré de su paganismo y de lo democráticos que eran, comparados con otras sociedades" (Such, 2017). 


\subsection{The Last Kingdom (2015- ).}

The Last Kingdom, es una producción británica basada en las novelas de The Saxon Stories, en España traducido como Sajones, vikingos y normandos, de Bernard Cornwell y emitida BBC América (Us), BBC Two (Uk) y actualmente Netflix (Us), bajo el guion de Stephen Butchard y dirección a cargo de Peter Hoar, Anthony Byrne, Ben Chanan y Nick Murphy.

La trama está ambientada a finales del siglo IX (872 d.C.) en lo que hoy día es Inglaterra, que se encontraba dividida mediante una serie de reinos pertenecientes a la Heptarquía Anglosajona, los cuales la gran mayoría de ellos han sido capturados por los vikingos, salvo el reino de Wessex, que es gobernado por el rey Alfredo, cuya pretensión es la de unificar todos ellos en un único reino cristiano.

Su protagonista es Uhtred Uhtredson, que habita en el reino de Northumbria, hijo y heredero de las tierras de Bebbanburg, que son atacadas por tropas vikingas danesas por medio de una razzia, matando a su padre durante la batalla y capturando a Uhtred (Galonce, 2017). Su secuestrador se trata del Jarl o caudillo danés Ragnar "The Fearless", a quién ve en él un futuro gran guerrero y decide adoptarlo y criarlo pasando a formar parte de su familia, adoptando el apellido Ragnarsson. Allí conoce a una niña sajona llamada Brida, también capturada por los daneses, con la que entablará una amistad entre ambos, así como la que se produce con su hermanastro Ragnar "el joven".

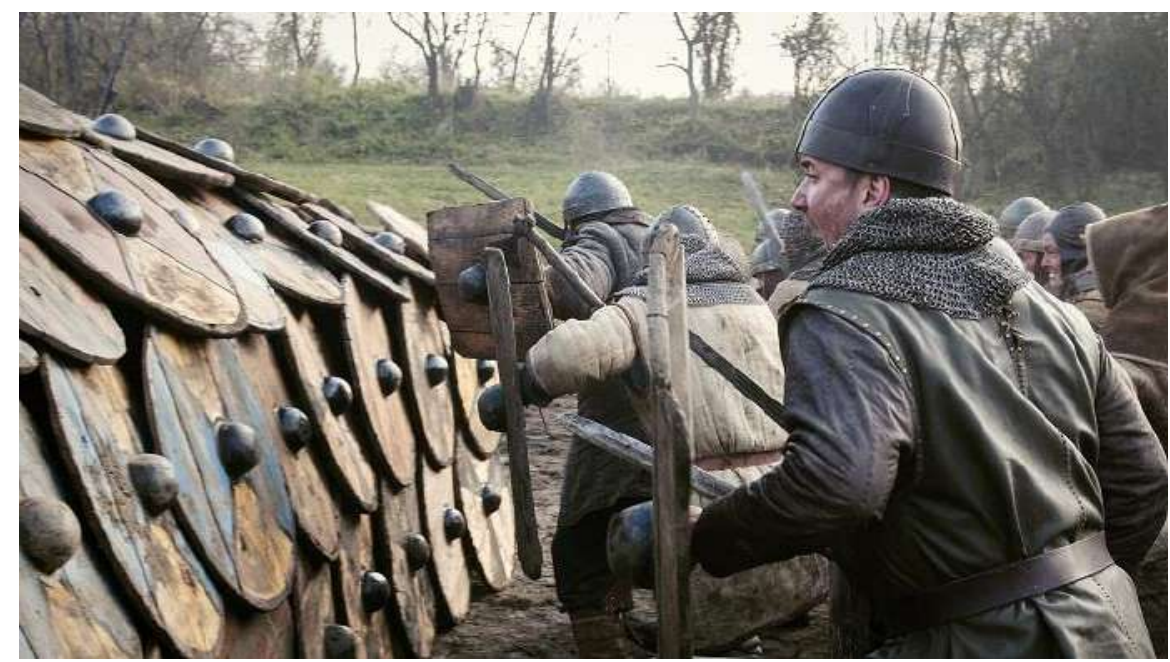

Batalla entre anglosajones y daneses. Fuente: https://history.stackexchange.com/questions/30970/howtight-were-shield-walls-in-saxon-england 


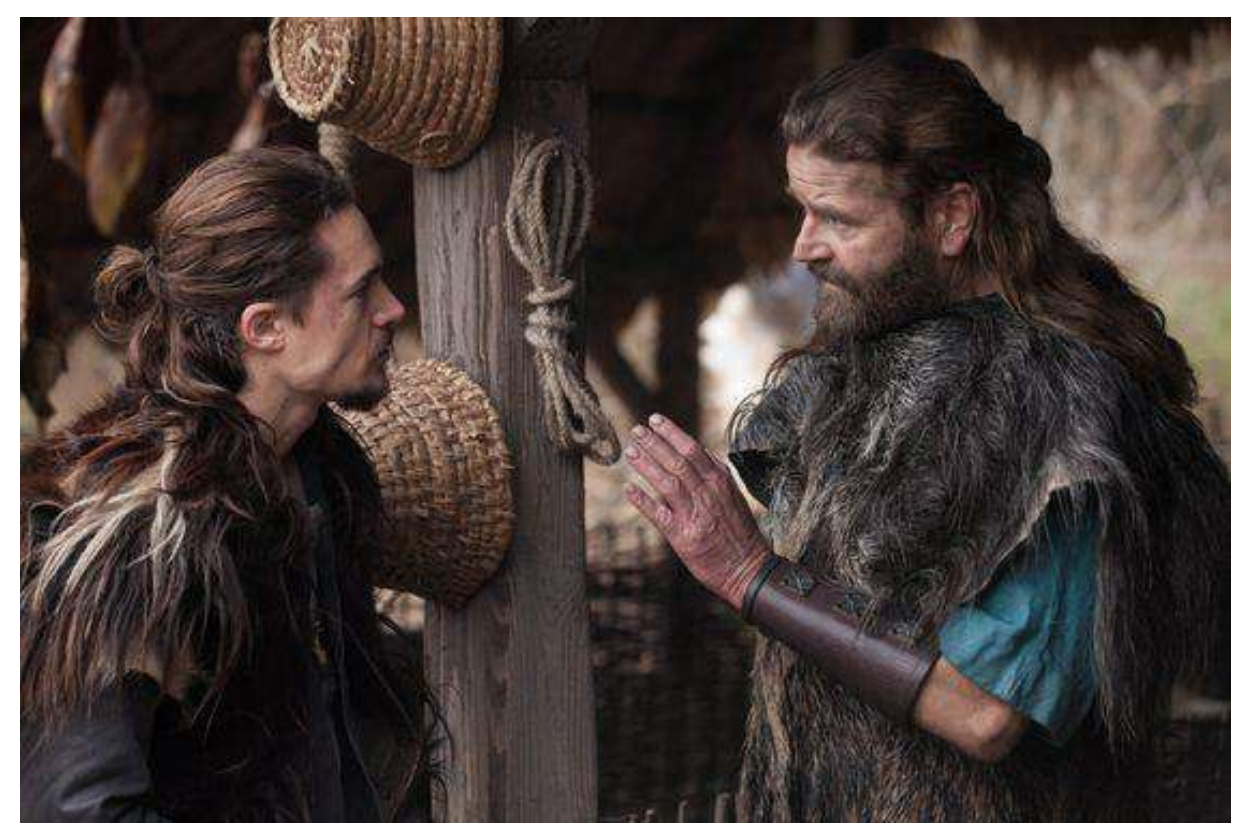

Uhtred y Ragnar “The Fearless”. Fuente: https://www.pinterest.es/pin/335940453454197257/

Un día, en lo que solo parecía un juego de niños, acabará por desencadenar un serie de infortunios, puesto que Uhtred protege a Thyra, la hija de Ragnar, ante el ataque de Sven, hijo de uno de los capitanes de los barcos de Ragnar, llamado Kjartan, por lo que Ragnar le castiga dejando a su hijo Sven ciego de un solo ojo y desterrando de su propieda a Kjartan. Este hecho no es olvidado por Kjartan, quién años más tarde arrasa con la aldea de Ragnar, quien muere durante el incendio de su casa provocado por el propio Kjartan. Tras el acontecimiento, tanto Uhtred como Brida logran escapar, cayendo en ese momento sobre su peso por una parte la venganza hacia su padre adoptivo y por otro el recuperar la tierra que le pertenece y que ha sido usurpada por su tío, que termina aliándose con los daneses.

La muerte de Ragnar supone que Uhtred y Brida huyan de las tierras para acabar en Winchester, capital del reino de Wessex. Alfredo, rey de Wessex, decide que Uhtred puede ser un buen aliado porque conoce tanto los puntos fuertes como las debilidades de los vikingos, comandados por los señores de la guerra daneses Ubba y Guthrum, los cuales, Alfredo desea negociar para poner fin y establecer la paz. Uhtred, le promete lealtad a Alfredo durante un año y prepara a su ejército para la lucha contra los daneses.

El elemento principal en torno al cual gira la trama es el tema de la lealtad. Uhtred es de nacimiento sajón, pero desde muy joven se cría en la cultura vikinga, algo con lo que 
arrastrará hasta el fin de sus días, ya que continuamente tendrá que debatirse en un conflicto interno el decantarse entre un bando u otro, pero siempre amparado bajo su lema: "el destino lo es todo". Por ello es interesante la relación amor/odio que establece con distintos personajes, siendo la más destacada la que tiene con el rey Alfredo, el cual constantemente le reprocha la falta de fe y costumbres bárbaras, lo mismo que para Uhtred lo son las sajonas, pero a pesar de los distintos conflictos que se producen entre ellos, procesan una admiración mutua, puesto que Uhtred arriesga su vida por los intereses de Alfredo, y este le reconoce su valía como guerrero.

Así como la lealtad, y relacionado con ella, la amistad es también un motivo recurrente a lo largo de la trama, y encarnada en personajes como Brida, a quién le une una fuerte amistad, pero que no renunciará nunca a sus costumbres e ideales paganos, haciendo ver en Uhtred un traidor por defender a los ingleses y posicionarse en contra de la causa danesa. Pero al contrario de lo que pueda parecer, esos ideales nunca serán rechazados por él, como por ejemplo cuando tiene que enterrar a su hermano tal y como se merece, junto a su espada, para ser recibito en el Valhalla, realizando el mismo ritual a su enemigo Ubba cuando este es derrotado. Por otra parte, hay un personaje muy importante en la vida de Uhtred, que es el padre Beocca, que conoce a Uhtred desde que este era un niño, al cual bautiza, haciendo el papel de padre aconsejándole en todo momento, ya que quiere lo mejor para este, y no cesará en reconducirle hacia la cristiandad para ganarse el favor de Alfredo.

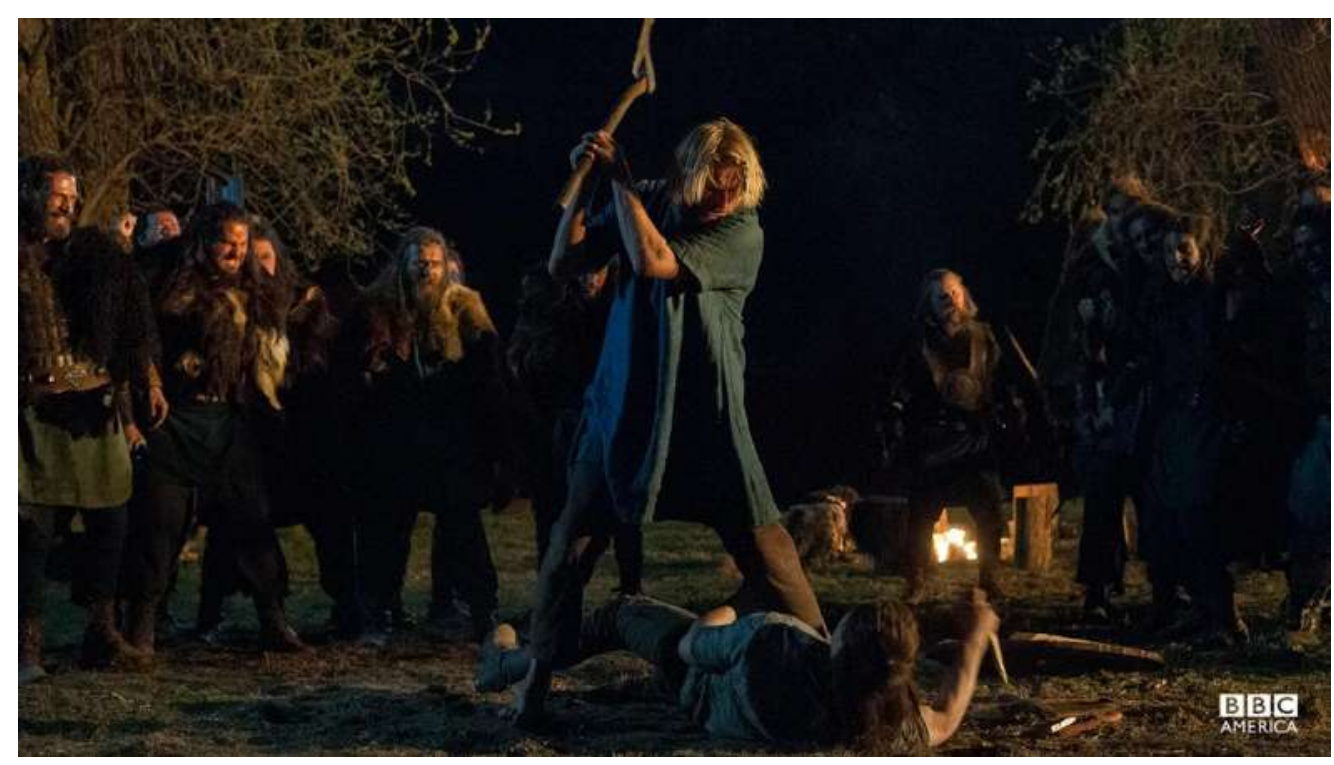

Enfrentamiento entre Ubba y Uhtred, junto al grupo de vikingos de Ubba al fondo. Fuente: https://timeslipsblog.wordpress.com/tag/ubba-ragnarsson-of-last-kingdom/ 
Es destacable, que aunque es evidente la existencia del choque entre culturas, esta no sea del todo una barrera que impida la amistad entre personajes, puesto que Uhtred llega a establecer relación con personas afines al cristianismo, como son los casos ya comentados del rey Alfredo y el padre Beocca, así con la abadesa Hild, o el guerrero de Alfredo, Leofric, cuyas habilidades hacen que se respeten mutuamente. Por otra parte, ese conflicto no es tampoco motivo para que vikingos como es el caso de Guthrum, sienta una inquietud hacia el Dios cristiano, llegando a bautizarse y a abrazar la religión cristiana para resarcirse de sus violentos actos contra sacerdotes. Todos estos aspectos tratados en la serie respecto a la convivencia de costumbres de ambas sociedades, tal como sucedió en la Inglaterra anglosajona históricamente está reflejada a la perfección a través de su personaje principal, tal como comenta Molina (2015) para web Rirca, ya que "en ella podemos observar el proceso de hibridación a gran escala que aconteció en el lugar y en la época personificado en la insólita figura de Uhtred".

\subsection{Norsemen (2016- ).}

Norsemen (Vikingane), es una comedia noruega creada por Jon Iver Helgaker y Jonas Torgersen, producida para NRK por Viafilm y emitida por el canal noruego NRK1, actualmente también en Netflix.

Es el año 790 d.C., la acción transcurre en la aldea noruega de Norheim, en el momento clave de la expansión vikinga hacia tierras occidentales, creándose nuevas rutas y por lo tanto produciéndose cambios que afectan a lo político, comercial y social entre otros aspectos. En este contexto, un grupo de guerreros regresa a la aldea tras pasar una temporada alejados de esta en busca de riquezas y esclavos (Mejino y Cascajosa, 2018). La expedición resulta exitosa, cuyo líder es Olav, que regresa con una gran cantidad de riquezas y un esclavo romano llamado Rufus, que entablará una estrecha relación con Orm, hermano de Olav, que junto al romano tendrán la misión de transformar la sociedad a través del arte. 


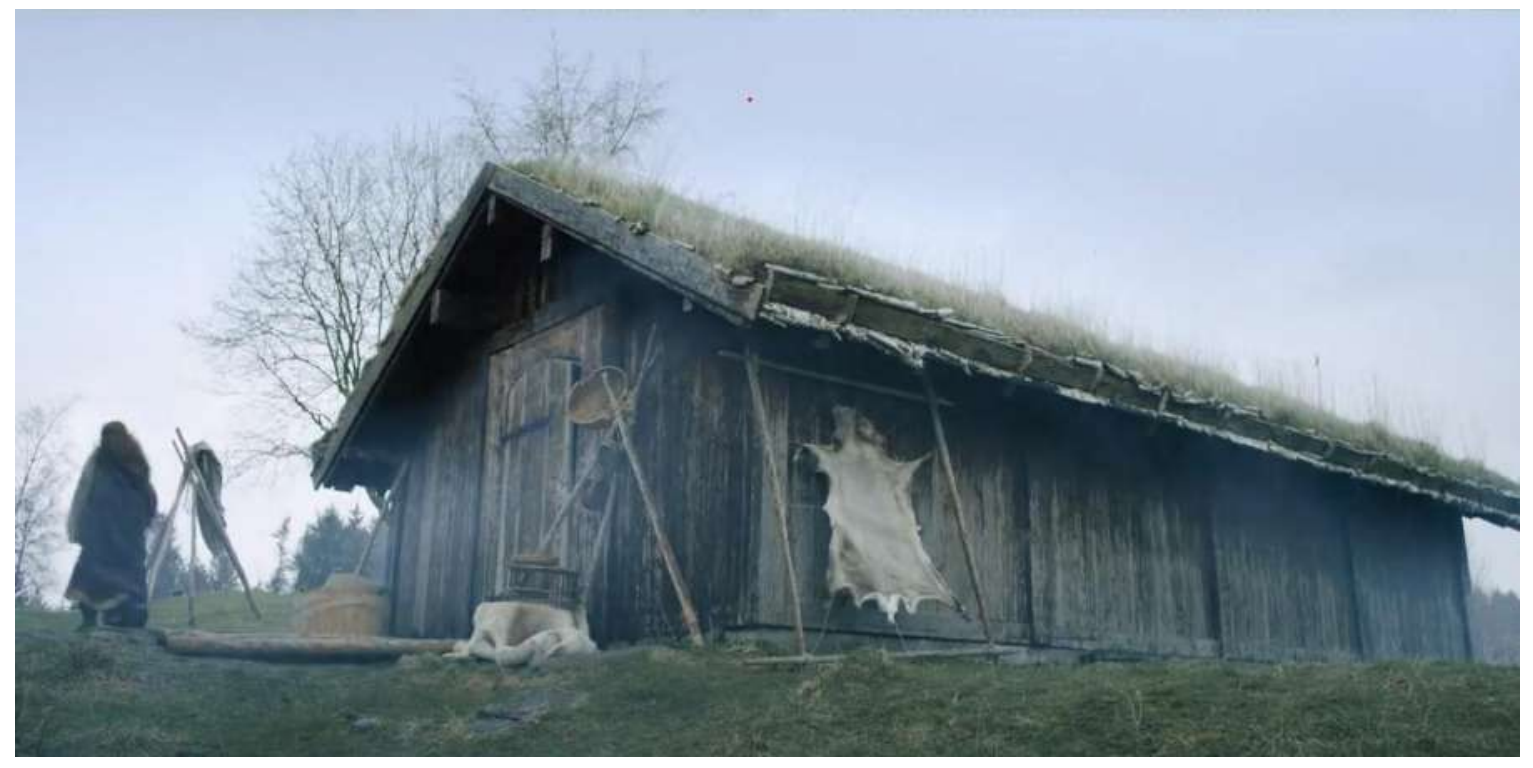

Hogar de un vikingo en Norheim. Fuente: imagen propia.

Norsemen está tratado en clave de humor, en palabras de Galonce (2018) para la web Fueradeseries, indica que "es como si en un cóctel mezclaras drakkars, valkirias y el Valhalla con un cómic de Astérix y el humor irreverente y caótico de los Monty Python”. Pero, a pesar de estar impregnado de ese tono humorístico, a base de gags que rozan lo políticamente incorrecto y lo escatológico, la serie tiene un trasfondo más bien social, profundizando en los temas más críticos de la actualidad en general, y en especial de la sociedad noruega.

En ella se cuestiona repetidamente, hasta qué límite vale todo respecto a las costumbres y modos de vida que los habitantes de Norheim practican en su día a día, ya que vistas desde el punto de vista actual, la gran mayoría serían totalmente reprobables. Aunque no solo hay que acudir a nuestros días, porque hasta un romano de aquella época, criado en una cultura totalmente opuesta, tampoco puede llegar a comprender estas prácticas tan radicales, y Rufus, desde su llegada al poblado intentará erradicarlas para siempre. Por otra parte, no solo se cuestiona externamente, sino por los propios habitantes de Norheim, que ven estas, carentes de toda lógica.

El propio Rufus, que convive con los esclavos, estos se encuentran totalmente adaptados a la forma de vida en el poblado, de hecho uno de ellos le comenta al romano que después de ser liberado, no se adaptó a su nueva vida y regresó de nuevo porque para él "no 
hay nada más gratificante que hacer un trabajo para otros sin que te paguen", y es ese momento cuando Rufus comprende que ya no queda nada de amor propio en esa persona.

Las luchas de poder son otro de los asuntos que trata la serie, desde la perspectiva de cómo por ambición se puede llegar a límites insospechados. Es el caso de Orm, hermano del jefe de la aldea y el primero en la línea sucesoria al trono, que no le interesa de ningún modo. Así cuando suple a su hermano porque este se encuentra de viaje, prácticamente no gestiona nada, más bien se para en cuestiones intrascendentales y que en ningún caso favorece la calidad de vida de su gente. Sin embargo, cuando Olav le lega su puesto a Ardid, un guerrero temible, Orm cambia de opinión y consigue de la forma más rastrera el puesto, matando a su hermano y haciéndole creer a Ardid que era solo un engaño de Olav. Pero aun así sigue despreocupado incluso por lo que el mismo manda hacer, llegando a olvidarse de lo que había ordenado justo un momento antes, por lo que deja claro que llegar al trono es solo un mero hecho simbólico.

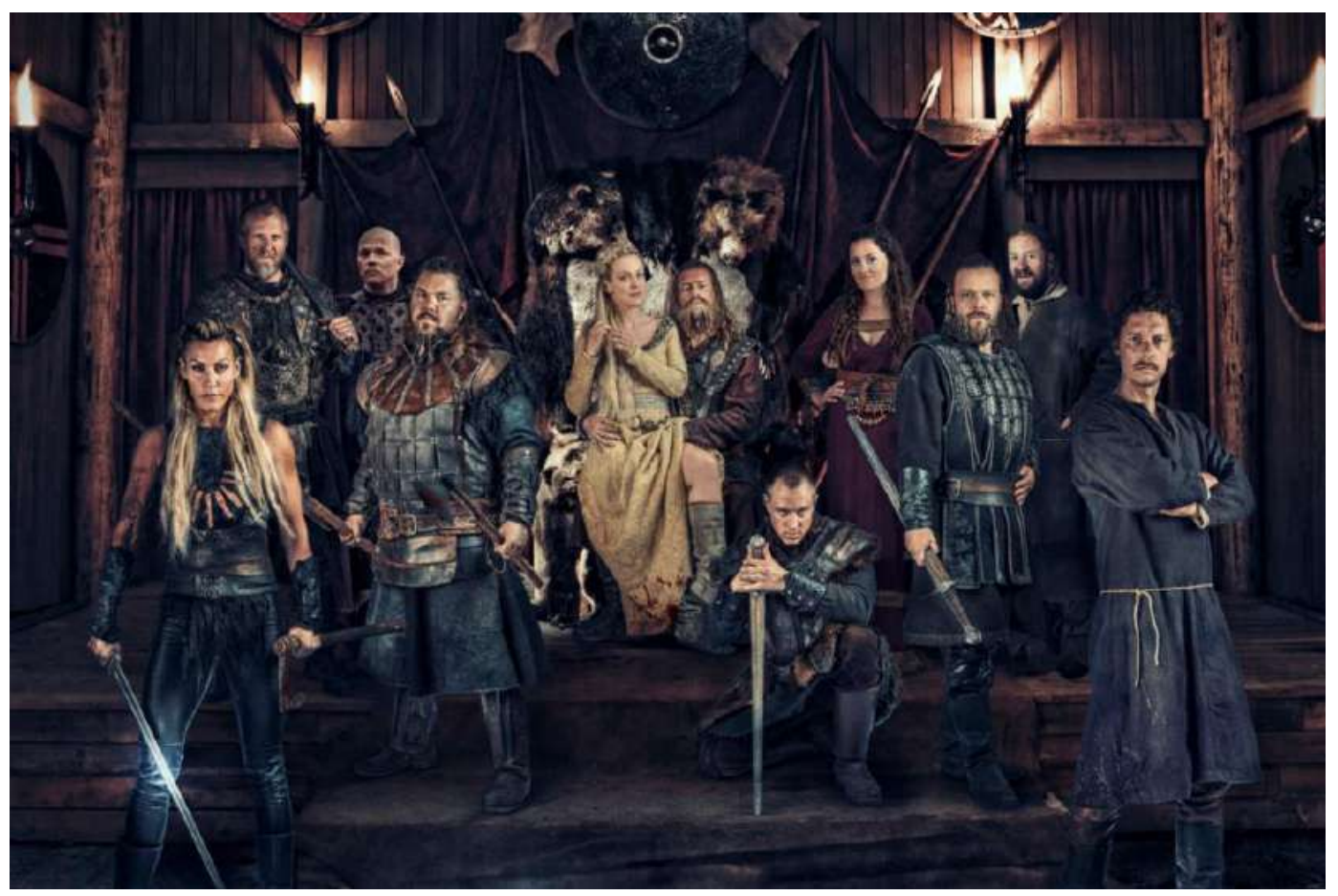

Los vikingos de Norsemen, junto al romano Rufus a la derecha. Fuente: https://fueradeseries.com/criticanorsemen-una-parodia-de-vikingos-entre-los-monty-python-y-asterix-7d33f3al750f 


\subsection{Ragnarök (2020- ).}

Ragnarök, es una coproducción noruega-danesa, dirigida por Adam Price, creador de Borgen, y distribuida por Netflix, siendo la más actual de las series que ha adaptado los mitos nórdicos.

La trama sucede en Edda, una localidad noruega de apenas 5000 habitantes, que se ve alterada por la alta contaminación que producen las grandes industrias, trayendo consigo el ascenso de temperaturas que provocan el deshielo y abundantes lluvias (Hernández, 2020). Los causantes de dichas desgracias son los Jotul, una familia que maneja la empresa minera del pueblo, y que es denunciada por una activista preocupada por el medioambiente llamada Isolde, amiga de Magne, un chico que se acaba de mudar junto a su familia a Edda, su pueblo natal, desarrollando allí unas habilidades sobrenaturales que adquiere casualmente tras el encuentro con un anciano tuerto.

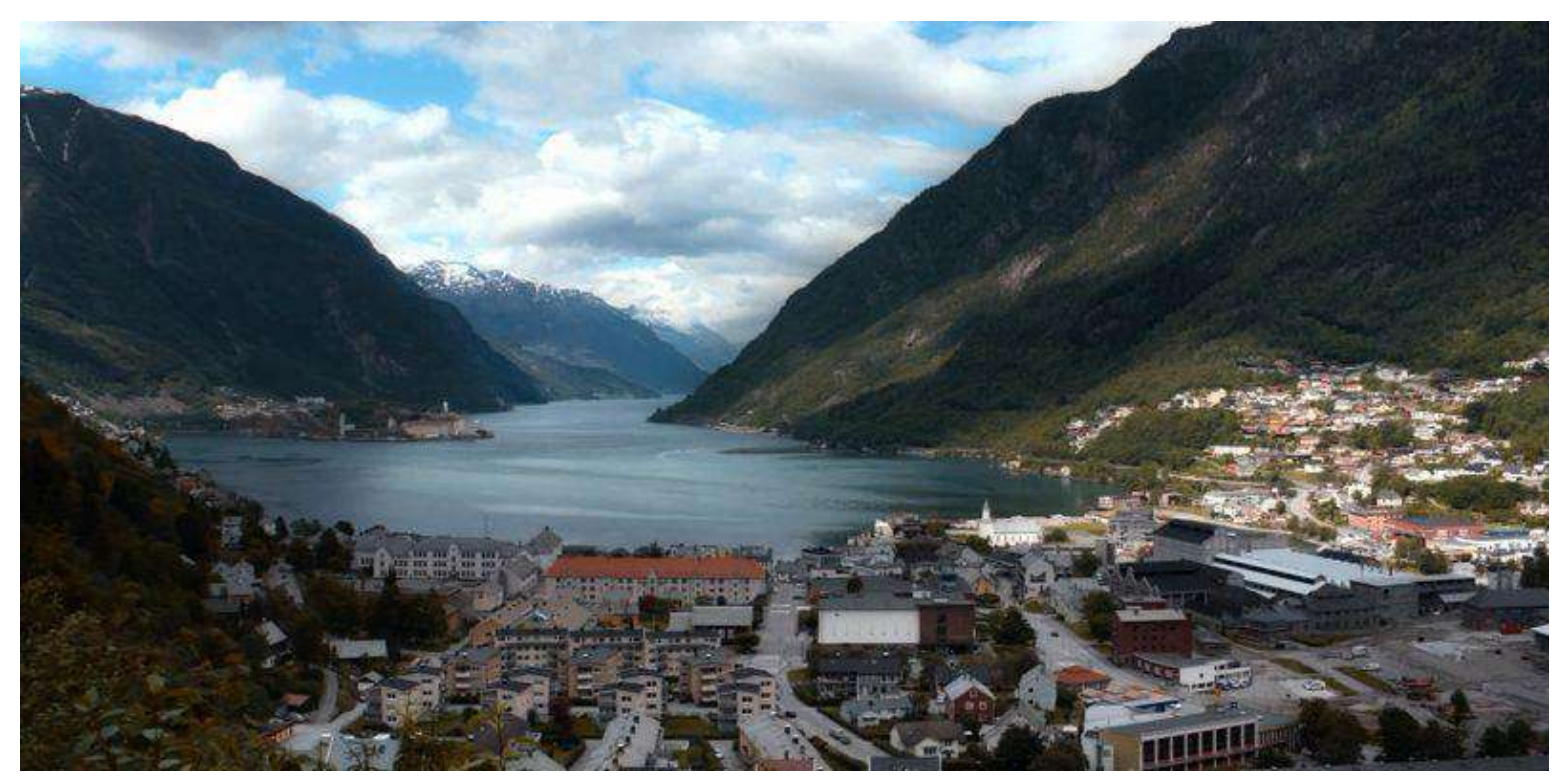

Escenario de rodaje de la localidad de Odda en Noruega, Edda en la ficción. Fuente: http://es.atlasofwonders.com/2020/02/donde-se-rodo-ragnarok-serie-netflix-edda.html 
El espíritu de la serie es fundamentalmente criticar los efectos del cambio climático tal como anuncia su creador, "el mundo está cambiando y podríamos decir que nos dirigimos hacia un nuevo Ragnarok (la batalla del fin del mundo según la mitología nórdica) si nadie hace nada para detenerlo" (Morillo, 2018). A partir de esta premisa, se le da un giro al mito nórdico, cuyas referencias son constantes a lo lardo de la serie.

En una de las primeras escenas de la serie, ya te anticipa la aparición de uno de los principales dioses, Odín, que es tuerto tal y como es el misterioso anciano. Por otro lado, la población en la que habitan los personajes, Edda, que aunque su nombre real es muy parecido, Odda, es un claro guiño a la fuente fundamental de mitos recopilados de la mitología nórdica.

Magne, el joven protagonista, adquiere los poderes del dios Thor, incluido el manejo del martillo Mjölnir, que utilizará para enfrentarse a los Jotul, nombre tomado de los gigantes de la escarcha del país de Jötunheim, llamados Jotun. Esta familia, según Arries, físico y autor del libro Magia y religión nórdicas tal (2020) tal como deduce en un artículo publicado por Pozo (2020) para la web Hipertextual, es igual de arrogante y violenta al igual que lo son los gigantes Jotun, llegando incluso a disputarse entre ellos el poder ${ }^{35}$.

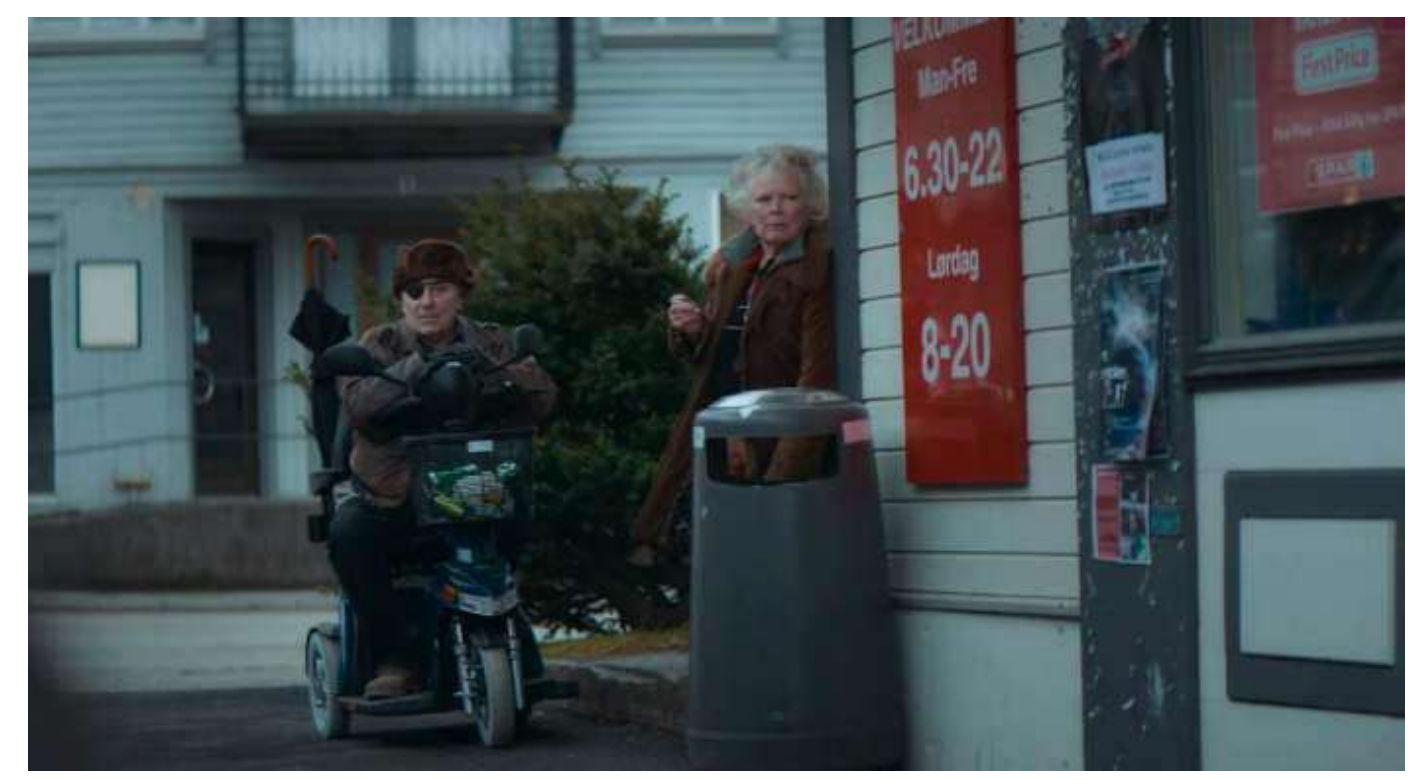

Referencia a Odín. Fuente: https://www.desdelacuna.net/series/odin-wotan-ragnarok-serie-actor-bjorn-

\section{sundquist-quien-es/}

\footnotetext{
${ }^{35}$ El padre de la familia Jotun, se llama Vidar (Viðarr) dios del silencio, e hijo de Odín y la giganta Gríðr, que en el Ragnarök es el causante de la muerte del lobo Fenrir: Velasco, M. Op. Cit. p.122.
} 


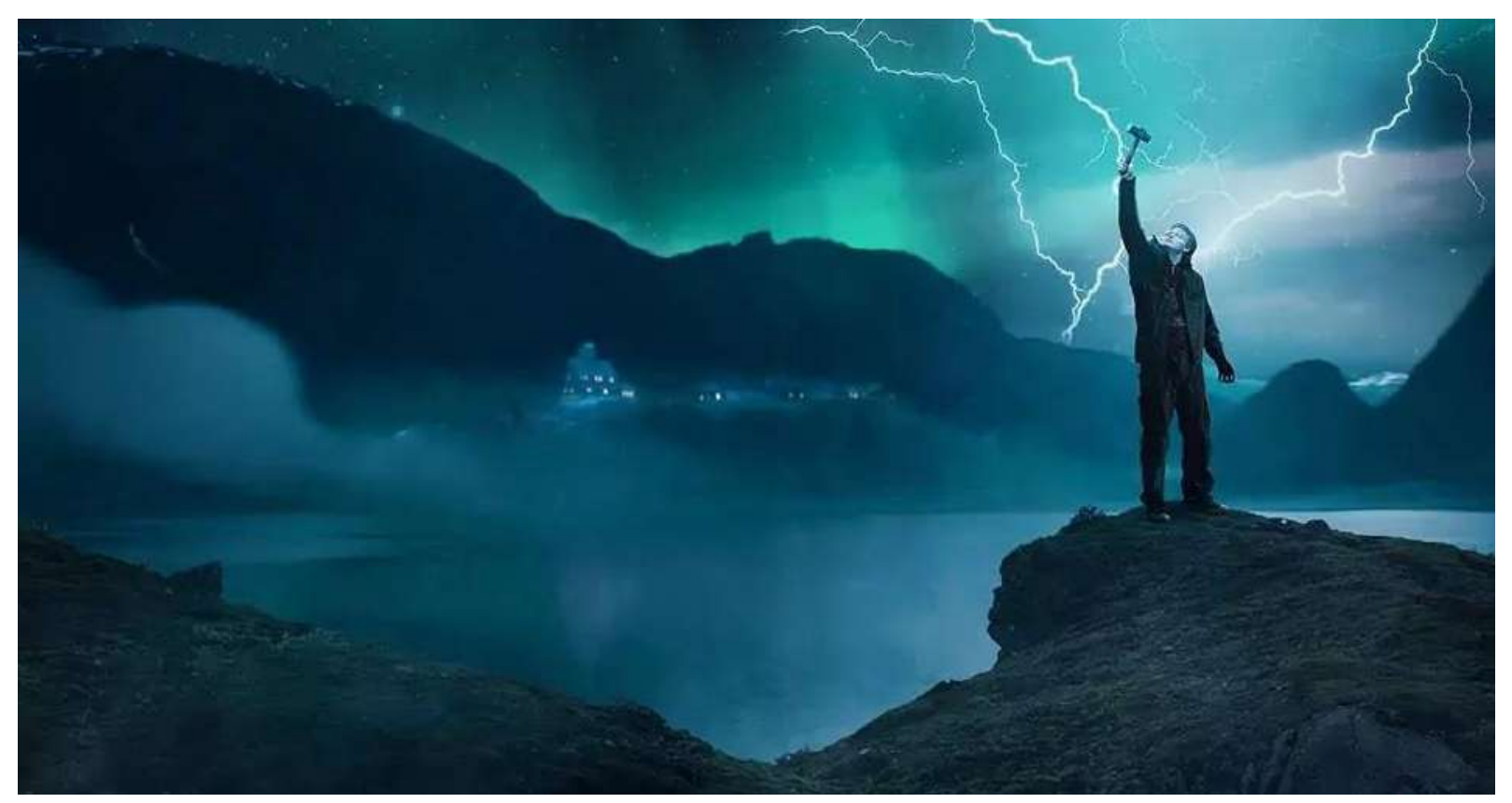

Magne, recibiendo los poderes de Thor. Fuente: https://www.lascancionesdelatele.com/2020/01/bso-ragnaroknetflix-canciones-soundtrack.html

Otras figuras notable que conectan con la mitología nórdica, son la anciana Wenche, que predice acontecimientos del futuro, en relación a la función que desempeñaban las Volvas, o el perro Trym, el perro de los Jotul, que en este caso se encarna en Fenrir, el lobo gigante hijo de Loki. Por otra parte, aparecen escenas que recogen los textos de las eddas, como la que cuenta el intento de humillación por parte de los gigantes hacia Thor en su viaje con Loki a Utgard, donde este es retado a jugar a las vencidas con la niñera de un rey, y que es representada en la secuencia en la que Magne y Lauritis van a casa de los Jotul y estos intentan emborrachar al primero, pero juega en este caso con Ran, esposa de Vidar que en la mitología nórdica es la diosa de los mares que recoge con las redes a los ahogados.

Por último, otro personaje a destacar es Laurits, hermano de Magne, y que es todo lo opuesto a este último, siendo más bien extrovertido y peculiar en su comportamiento, además de mostrar empatía por la familia Jotul, lo malos de la trama. Por todo ello, hace sospechar que dentro de Laurits se esté gestando el personaje de Loki, que precisamente durante el Ragnarök luchará en el bando de los gigantes. 


\section{VIDEOJUEGOS.}

La temática nórdica ha ido ganando presencia en la cultura de masas durante los últimos años tal como venimos anunciando, sin ser la excepción aquella que pertenece al mundo de los videojuegos. Destacan múltiples de ejemplos, desde los puramente estratégicos como Northgard (2017), Tribal Trouble (2005), Vikings: War of Clans (2015); pasando por el rol, con ejemplo como The Banner Saga (2014), Viking: Battle for Asgard (2008) y en extensiones de sagas reconocidas como Attila Total War (2015), Age of Empires II, en su versión Age of Mythology (2002) y la esperada entrega dentro del mundo Assassi’s Creed, con el título: Assassin's Creed: Valhalla, cuya fecha de estreno está prevista para el 17 de noviembre de 2020. Otros juegos, beben directamente de esta mitología, como es el caso de The Elder Scrolls V: Skyrim (2011) y la futurista, Too Human (2008).

\subsection{The Lost Vikings (1992).}

Uno de los primeros videojuegos en desarrollar la temática acorde a la cultura vikinga fue The Lost Vikings (1992), desarrollado por Silicon \& Synapse, actual Blizzard, bajo la figura de Allen Adham, Frank Pearce y Michael Morhaime. El juego tuvo tanto éxito, que tal como apunta Bouzo (2016) fue principal culpable de que el equipo recibiese el premio por parte de la revista VideoGames Magazine, en la categoría de "mejor desarrollador de software del año"${ }^{36}$.

La historia de The lost Vikings, cuenta la aventura de tres vikingos: Olaf, Erik y Baleog, que viven en una aldea tranquila y familiar. Pero la cosa se tuerce cuando llega a esta una invasión alienígena comandada por Tomator, líder de los Croutonians, decide transportarlos a su base espacial, puesto que el objetivo de esta raza es la de reclutar especies

\footnotetext{
${ }^{36}$ El juego fue lanzado para las plataformas Amiga, PC, Super Nintendo y Mega Drive: https://es.ign.com/.
} 
autóctonas de cada mundo "consistente en ejemplares de sus especies autóctonas para su zoo particular" (García, 2016).

Sentada esta base, el juego explora la vía del arcade de plataformas mezclado con puzles, lo que posibilita ponerse en la piel de cada uno de los personajes mencionados, los cuales tendrán habilidades distintas, que habrá que combinarlas para pasar de nivel superando dichos puzles. Así, Eric es el más ágil del grupo, posee una gran velocidad y es el único que puede saltar de todos ellos, además de ser capaz de romper muros gracias a la embestida producida por su casco; Olaf puede, a través de su escudo, tanto bloquear a los enemigos y sus disparos como usarlo a modo de plataforma, de modo que el ágil, Eric, pueda llegar a alturas inalcanzables, quedando por último Baleog, que a gracias a su espada y arco puede alcanzar a los enemigos a distancias cortas y largas.

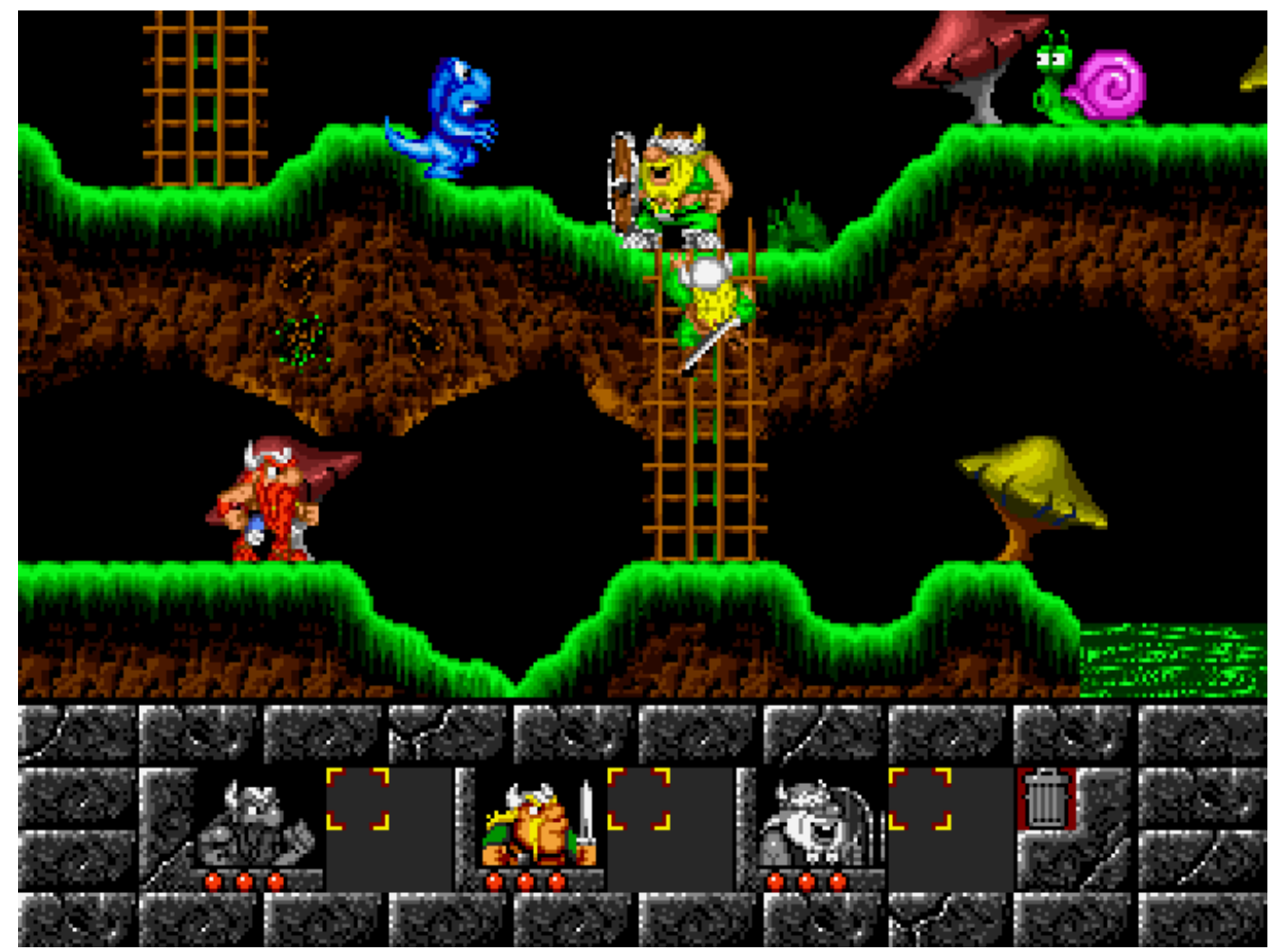

The Lost Vikings. Fuente: https://www.dosgamesarchive.com/download/the-lost-vikings/

Aparte de usar el razonamiento, partiendo de la estrategia y cooperación con el uso de cada personaje y su combinación, el atractivo de esta plataforma está en la posibilidad de transportarse a otros lugares y épocas mediante una máquina del tiempo. Gracias a ella, los 
tres vikingos se encontrarán con distintas generaciones de Croutonianos: desde la prehistoria; pasando por el antiguo Egipto, donde se enfrentarán a sus momias; hasta mundos totalmente irreales y carentes de toda lógica, que harán forzar más el cerebro.

El juego ofrece guiños a su propia mitología, pudiendo, en caso de caída de algún personaje, realizarle un funeral al estilo vikingo, al mismo tiempo que se puede invocar a Thor para devolverlo a la vida.

\subsection{Rune (2000).}

Rune, es un videojuego de acción y aventuras de la desarrolladora Human Head Studios, que contó con la tecnología Unreal Engine, para llevar a cabo el máximo rendimiento de entornos de fantasía y física del mundo real de Rune.

La serie justo como explica Rouse para la web IGN (2000), está ambientada en la mitología escandinava, donde el jugador se pone en la piel del vikingo Ragnar, que tendrá que defender a su pueblo de los monstruos malvados propios de la mitología nórdica y de entidades malignas que intenta que intentan provocar el fin del mundo, es decir, el Ragnarök.

Ragnar, pertenece a una orden de guerreros entrenados en Odinsblade, los cuales juran proteger en Midgard, la tierra, las piedras rúnicas mágicas creadas por Odín cuyos poderes evitan que el dios maligno, Loki, desate el Ragnarök. Tras completar su proceso de iniciación, ganando Ragnar durante el entrenamiento a un guerrero temido, llamado Ulf, otro vikingo les advierte de que el líder vikingo Conrack del grupo llamado Dark Vikings, ha iniciado una masacre contra las aldeas cercanas. Ante esta noticia, Ragnar, junto a su padre y un grupo de guerreros, se embarca para encontrar el drakkar de Conrack, que cuando dan con él, el padre da la orden de atacarlo, pero justo en ese mismo instante un rayo destruye a todos menos a Ragnar, que es salvado por deseos de Odín. Tras este suceso, Ragnar se esconde en una cueva submarina. 
A partir de aquí, Ragnar en palabras del supervisor del proyecto del videojuego, Tim Gerritsen, para la web Gamespot, viaja hacia los mundos propios de la mitología donde:

\begin{abstract}
"You explore the depths of Muspelheim and Jotunheim as well as lands in Midgard. The game is based on the myths and lore of the Vikings, and as such, it provides a deep story that captures the excitement of the period in a game of epic adventure". (Personal de Gamespot, 2006).
\end{abstract}

Durante el desarrollo del juego nos encontramos, a parte de los ya mencionados mundos de Muspelheim, el reino de los muertos dominado por la hija de Loki, Hel, o el de los gigantes de Jotunheim, criaturas propias de mitologías germánicas como es el caso de los Goblins, duendes, e incluso accede a la tierra de los enanos, representados estos últimos como seres de piel morada, de proporciones abultadas y baja estatura, y además son aliados de Loki, ya que trabajan para el dios creándole armamento a su ejército.

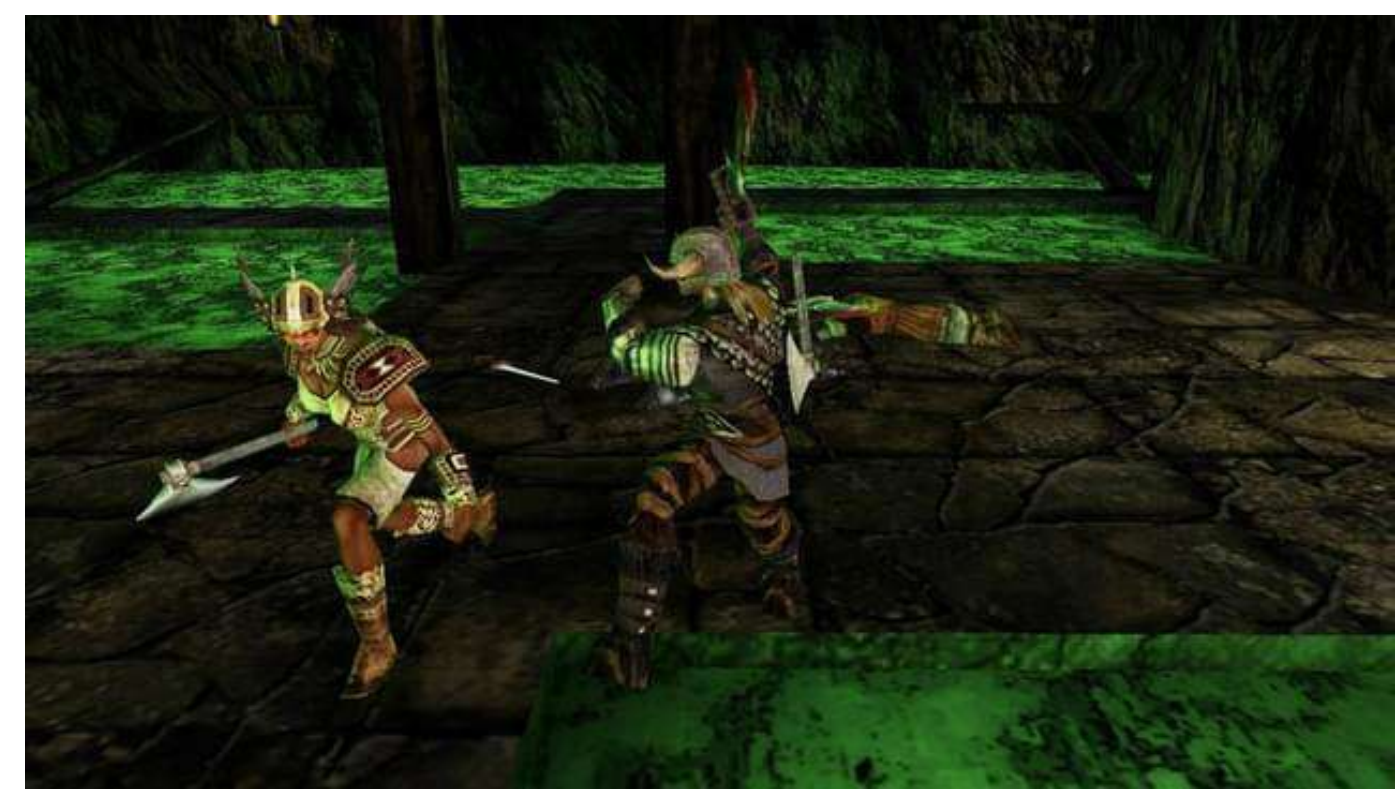

Rune. Fuente: https://www.gog.com/game/rune classic

Por otra parte, Loki aparece representado siendo atado por una serpiente, la cual vierte ácido sobre la herida abierta del pecho, volviendo la sangre de color verde a púrpura. Esta referencia está tomada de la Edda, que la misma serie Vikings en su último episodio de la segunda temporada, The Lord's Prayer, es narrada a través de su personaje Floki, en la que Loki, por todos sus intolerables comportamientos, es encadenado a tres rocas afiladas en 
venganza por parte de los dioses Aesir, convirtiendo estos sus ataduras en hierro y colocando Skaði sobre él una víbora para que su ácido goteara en su cara.

\subsection{Jotun: Valhalla Edition (2015).}

Juego con diseño hecho a mano y distribuido por Thunder Lotus Games, Jotun salió para PC en 2015 y un año más tarde para las plataformas: PS4, Xbox One y Wii U.

En este título, la protagonista de la historia es Thora una guerrera vikinga que muere durante un naufragio. Este hecho, supone un punto de inflexión y de desarrollo en la protagonista, puesto que al morir de esta forma, tal y como son las bases establecidas por la mitología nórdica, no puede acceder al Valhalla (Brenlla, 2016). Odín, se apiada de ella y le permite viajar hasta el Ginnungagap, lugar donde se encuentran las entradas al resto de los reinos, para dirigirse hasta los Jotun, a los que tendrá que derrotar para ganarse el favor de los dioses y acceder al Valhalla.

Con esta premisa, la especial atracción del videojuego será conocer los distintos mundos y personajes de la mitología nórdica que irán apareciendo a lo largo del mismo. Uno de los primeros escenarios por donde se moverá la guerrera será recorriendo las hojas del Yggdrasil, para toparse con el halcón que habita en su copa, llamado Veðrfölnir; para visitar seguidamente las tierras frías de Nifelheim, cuyas ventiscas son amenazantes para la vida de Thora, pudiéndose resguardar de ellas cada cierto tiempo en una zona helada, o pasar ciudades de plagadas de enanos muy poco amistosos y escapar de las garras de la serpiente Jörmungandr.

Aunque la finalidad del juego sea derrotar los cinco Jotun una vez completada la búsqueda de las runas, el verdadero entretenimiento se encuentra en las múltiples áreas del juego que permiten ser exploradas tal como el usuario desee, y en las que dan la posibilidad de resolver puzles, replicando constelaciones mediante el golpeo de pararrayos en las nubes; también encontrar objetos ocultos; descubrir habilidades secretas, y todo ello siendo 
intercalado por animaciones, las cuales van dando pequeñas pinceladas sobre elementos interesantes del pueblo vikingo.

Estas mejoras que ayudan a ganar experiencia durante el combate contra los Jotun, están divididas por medio de las manzanas doradas de Idunn, con las cuales restauran la salud del personaje y alargan su barra de vida; los santuarios de los dioses, otorgando el poder de los dioses Frigg, Loki, Thor, Freya, Odin, etc. mediante la acción de sus estatuas, y el Pozo de Mimir, restableciendo la salud y los poderes de dichos.

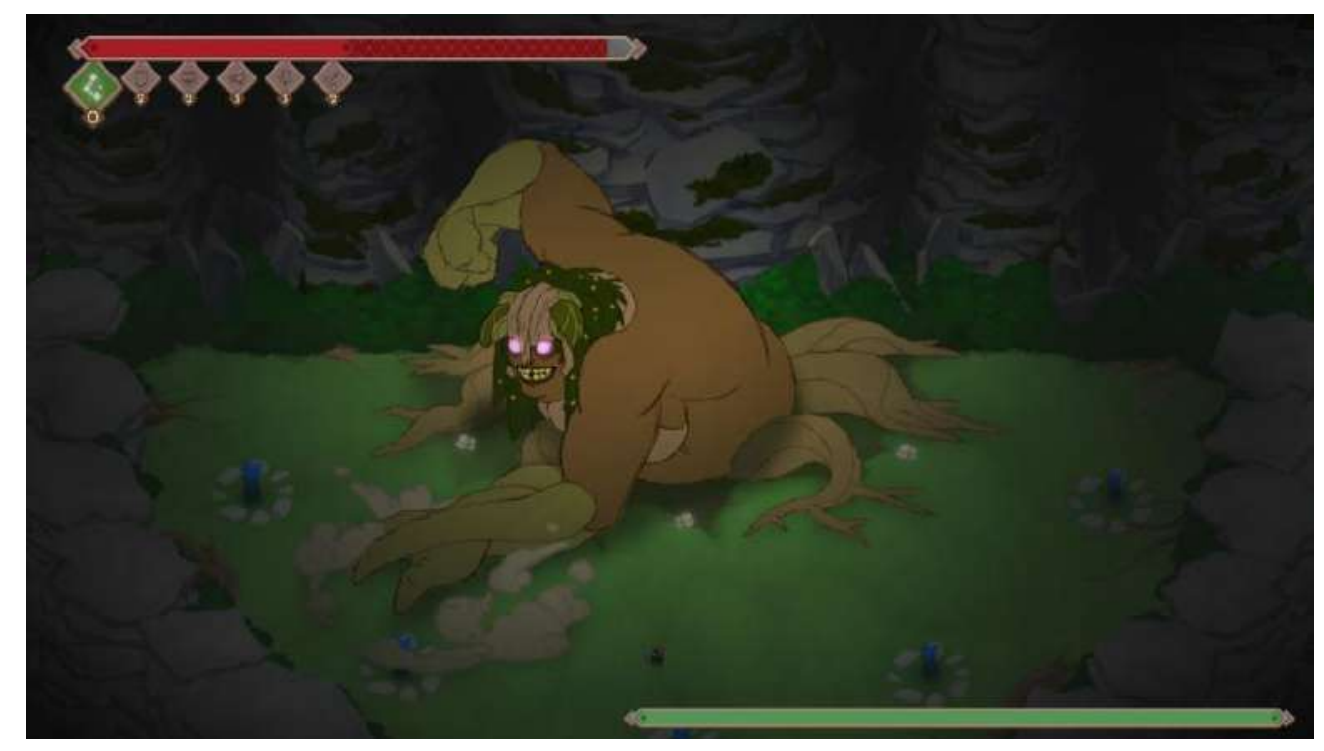

Jotun: Valhalla Edition. Fuente: https://www.hobbyconsolas.com/reviews/analisis-jotun-valhalla-editionnintendo-switch-ps4-pc-xbox-one-203184

\subsection{Hellblade: Senua's Sacrifice (2017).}

Hellblade: Senua's Sacrifice, para plataformas PlayStation 4, Xbox One, Microsoft Windows y Nintendo Switch, es un videojuego de acción-aventura y terror psicológico desarrollado y producido por la compañía británica, Ninja Theory, (Enslaved, Heavenly Sword y DmC). 
La aventura se ubica a finales del siglo $X$, momento en el que los vikingos invaden las islas Orcadas de Escocia. El hilo argumental del videojuego, gira en torno al personaje de Senua, una joven guerrera celta (picta), que es apartada de su pueblo al padecer psicosis, puesto que la enfermedad según Govea (2020), “era repudiada por sus contemporáneos al ser considerada una maldición de los dioses". Su lugar de exilio es un bosque cercano a su aldea, a la que regresa de la manera más traumática posible, ya que a su marido, Dillion, lo han asesinado mediante el rito torturador del Águila de sangre, como sacrificio a los dioses ${ }^{37}$.

Ante esta tesitura, Senua emprende su camino hacia el reino de Helheim, regentado por Hela, cuya función es la de proteger a los muertos, en busca del alma de Dillion, cortándole a este su cabeza para unirlo a su alma, tras recordar las palabras de un erudito llamado Druth, quién le relata los mitos nórdicos, recordándole, en palabras textales del juego, que "En todos los nueve reinos, sólo Hela puede resucitar a los muertos. A Hela sacrificaron a tu Dillion, y con ella debes negociar" (Montes, 2016).

La historia de esta travesía que realiza la protagonista, está directamente relacionada con la edda poética y el Gylfaginning de la edda poética, que relatan cómo tras la muerte del hijo de la diosa Frigg, Balder al ser alcanzado por una hoja de muérdago por estratagema de Loki, esta envía a Hermóðr para negociar en Hel la vuelta a la vida de Balder, accediendo la diosa de Helheim con la condición de que todos los seres vivos derramasen una lágrima, pero Loki, de nuevo hábilmente se disfraza de gigante resignándose a llorar, por lo que Balder seguiría preso en el reino de los muertos ${ }^{38}$.

\footnotetext{
${ }^{37}$ El rito es representado por la serie Vikings en el séptimo episodio de la segunda temporada, titulado Águila de Sangre.

${ }^{38}$ Velasco, M. Op. Cit. pp. 162- 166.
} 


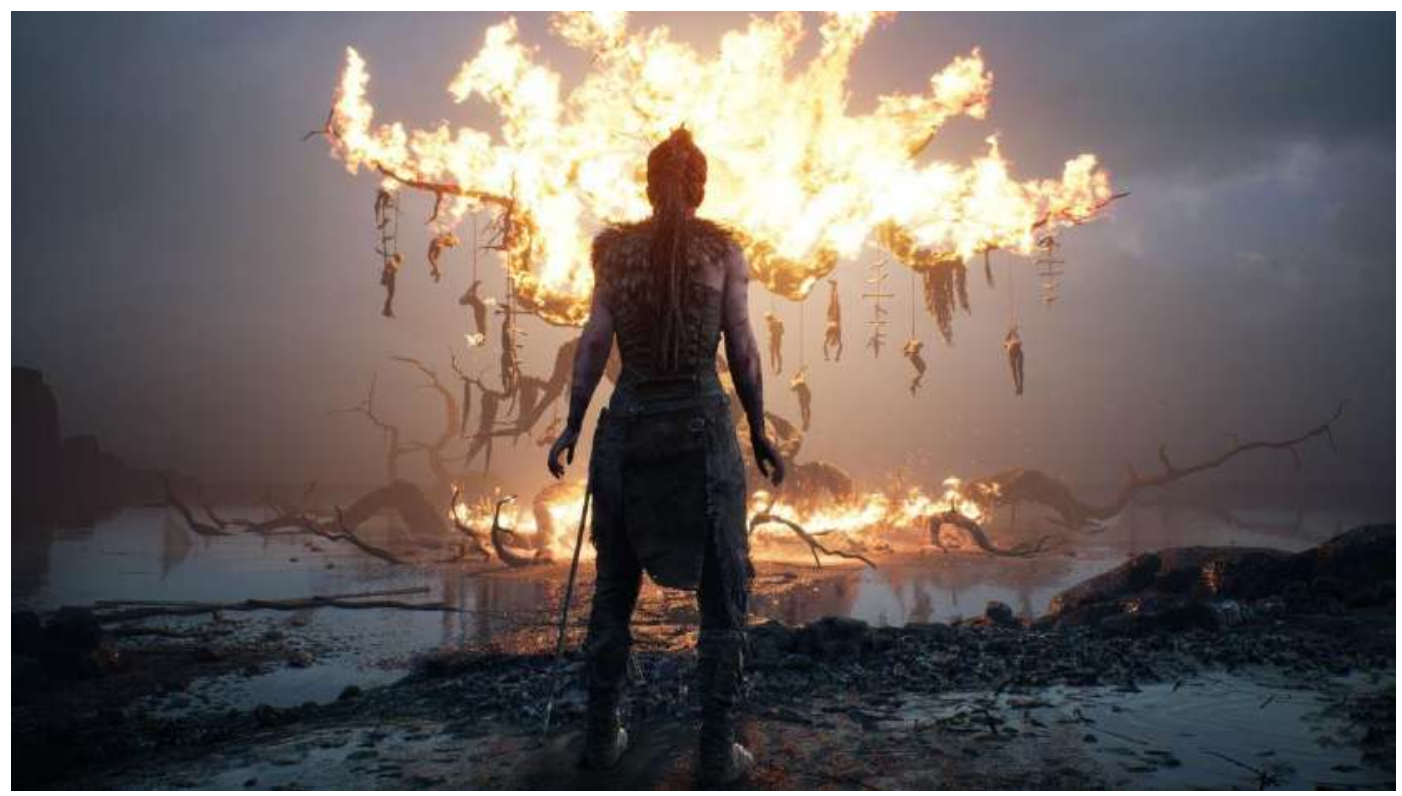

Hellblade: Senua's Sacrifice. Fuente: https://ag.hyperxgaming.com/article/3002/how-to-get-the-trueending-in-hellblade-senuas-sacrifice

Todo este viaje hacia los infiernos, no es sino una metáfora sobre un tema tan delicado como es la psicosis. La propia productora, se encargó de reflejar lo más fielmente posible los efectos que pueden producir a una persona que padece de esta enfermedad, consultando a expertos y trabajando con pacientes que la sufren (Montes, 2016), además de introducir un documental al inicio del juego, advirtiendo que "algunas personas podrían hallar estas representaciones (de la psicosis) perturbadoras, incluyendo aquellas que hayan tenido experiencias similares". Por ello Senua, al ser afectada por la enfermedad, cree que es perseguida por una especie de ente, La Oscuridad, además de sufrir voces en su cabeza, según ella provocadas por las Furias, junto a recuerdos de su pasado. A raíz de ello y para reforzar la experiencia, Senua tendrá constantemente a lo largo del juego alucinaciones y delirios. 


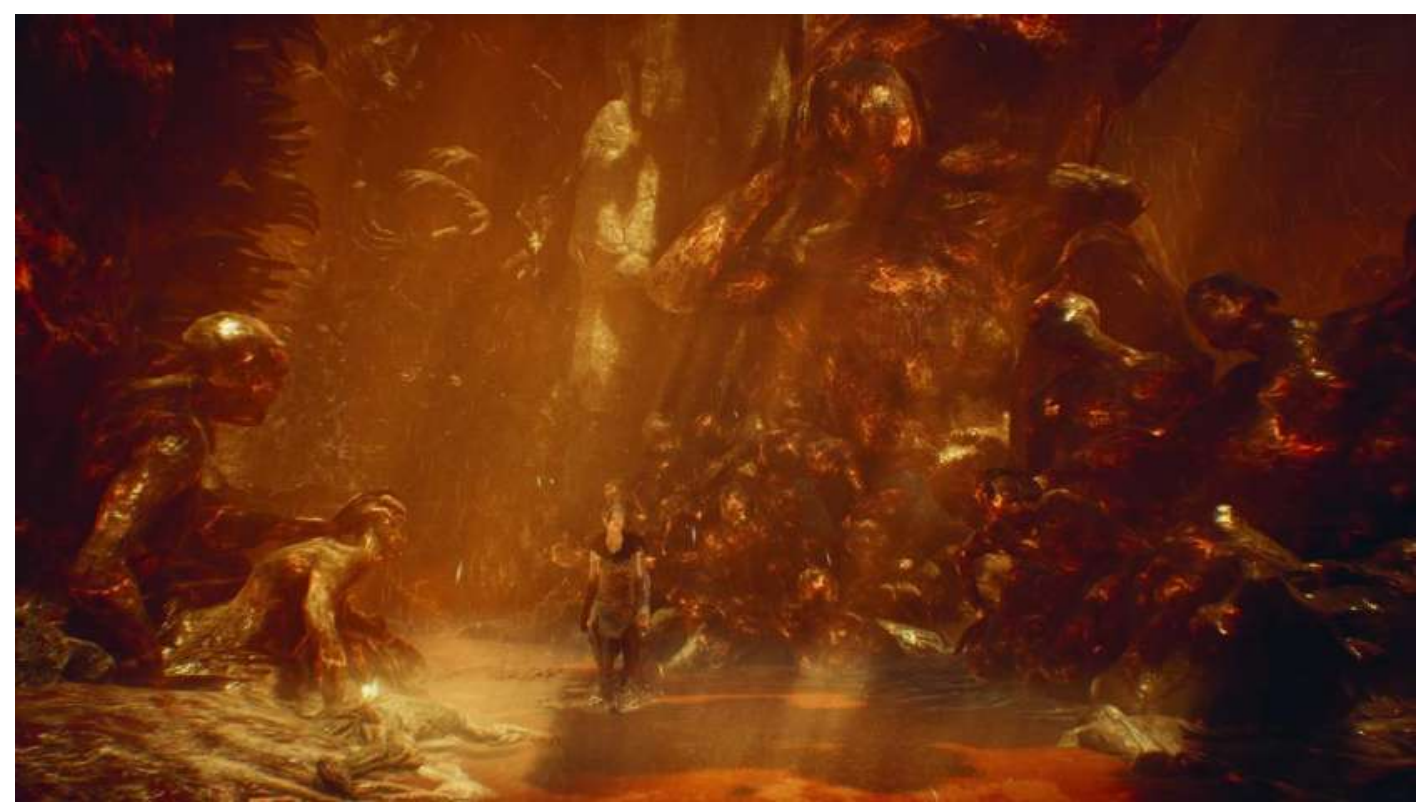

Senua, en el Helheim. Fuente: https://imgur.com/a/LAUIu

\subsection{God of War (2018).}

La serie God of War, creada por el estudio estadounidense de SIE Santa Monica y distribuida por Sony Computer Entertainment en el año 2005, es una de las sagas de mayor relevancia en los videojuegos, que inicia con la mitología nórdica desde el punto de partida, acabando con la nórdica en la reciente entrega del año 2018.

El videojuego, como se ha indicado, está basado en la mitología griega y cuyo protagonista es Kratos, hijo de Calisto y Zeus, criado por su madre en Esparta, donde es instruido para dominar el arte de la Guerra (Pérez, 2020). Su hermano, Deimos, es raptado por Ares y Atenea, una vez que el oráculo le revelara a Zeus que uno de sus hijos mortales con una marca en su cuerpo causaría, según la profecía, el final de los dioses del Olimpo. Deimos tenía una marca en la cara de nacimiento, por lo que es el principal sospechoso, pero Kratos, en su intento de salvarlo es herido en el ojo por Ares, que tras dar por muerto a su hermano, este decide en su honor marcar todo su cuerpo. 
Tras este suceso, posteriormente Kratos se hará poderoso y llegará a comandar un numeroso ejército de espartanos. Será cuando un hecho le cambiará para el resto de su vida, al tener que establecer con Ares un pacto por el cual este mataría a todos los enemigos de Kratos a cambio de su eterna servidumbre. El dios de la guerra ordena a Kratos arrasar con la aldea donde se encontraban su mujer e hija, a las que mata para deshacerse de todos sus lazos afectivos, motivo por el cual lleno de ira renuncia a servir más al dios, con la consecuente maldición del oráculo, quedando su piel impregnada por las cenizas de mujer e hija.

Una vez es roto el pacto, las Furias le castigan eternamente, pero consigue escapar y matar a cada una de ellas y también al hijo de Ares, Orkos, para romper el pacto definitivamente, aunque este suceso hará que rememore todos los hechos sucedidos en el pasado y decida redimirse sirviendo a los dioses del Olimpo. Atenea le cuenta a Kratos que la única manera de poder vencer a un dios es abriendo la Caja de Pandora, al que finalmente accede, pero Ares acaba matándolo, volviendo a resurgir gracias a la ayuda de Zeus y logrando abrir la Caja de Pandora acabando con el dios de la guerra. A pesar de ello, Kratos no puede liberarse de esa maldición y decide quitarse la vida, siendo una vez más salvado por los dioses y erigido como el nuevo dios de la guerra. Finalmente tras una serie de acontecimientos, mata a todos los dioses del Olimpo cumpliéndose la profecía, pero quedará marcado de por vida, ya que la maldición lo hace inmortal.

A partir de este momento se inicia la nueva entrega, a cargo del director Cory Barlog. Kratos vive en Midgard junto a su hijo Atreus, fruto de la relación con Faye, una giganta guerrera que muere, encomendándole en su lecho de muerte a Kratos que "talara los árboles que rodeaban su casa, en los que había colocado una barrera protectora mágica para que Odín no pudiese sentir que había un gigante en Midgard" (Rubio, 2018). Padre e hijo salen a cazar, cuando por error Atreus da con los Draugr, que tal como explica Balsas (2019) en su análisis para la página web Cineverso, "estos seres son no muertos, monstruos que habitan en Hel, cavernas profundas o lugares mágicos de acceso prohibido". 


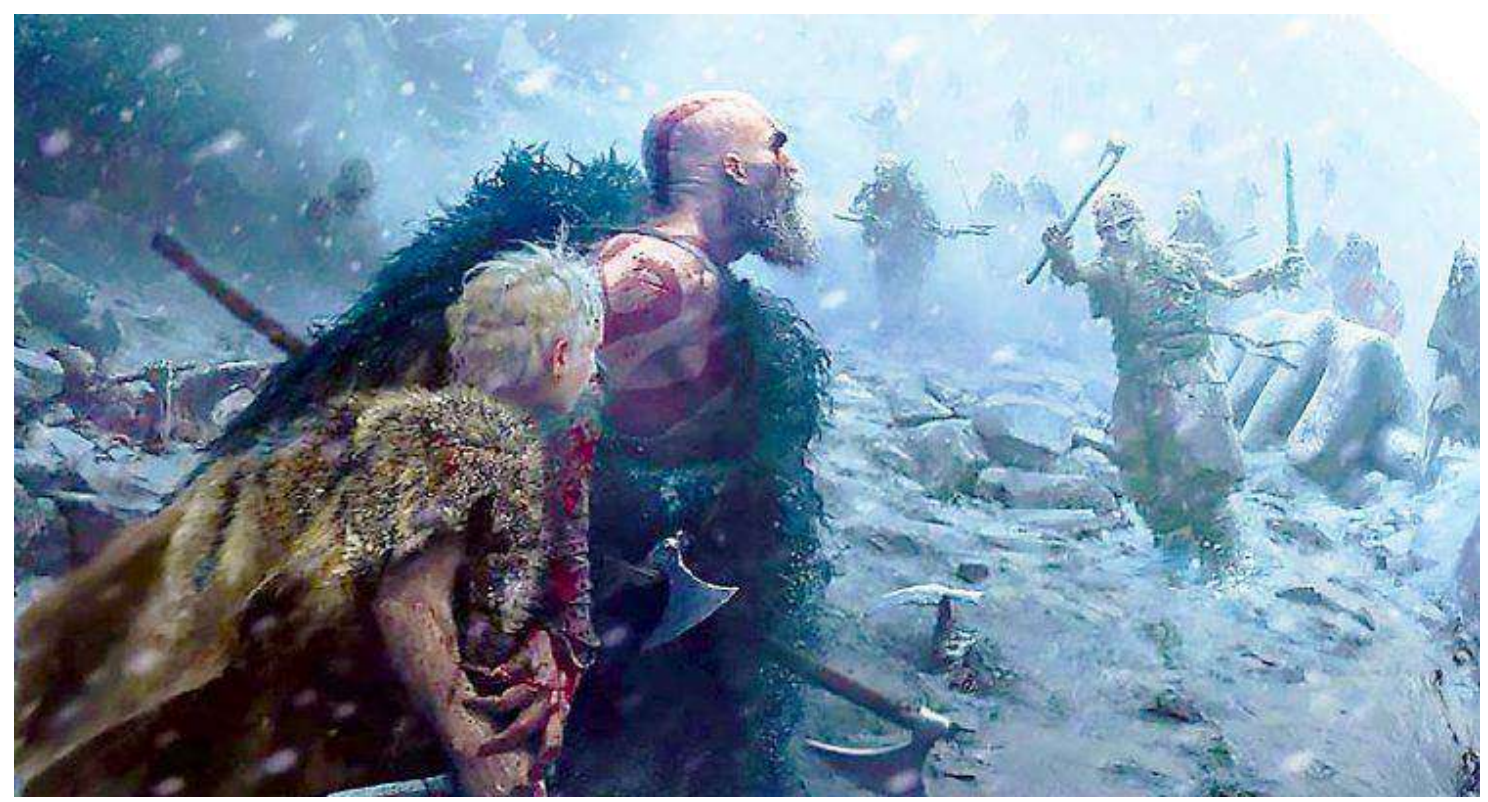

Kratos y Atreus. Fuente: https://www.gamingaccessweekly.com/2018/03/god-war-director-explains-franchisestransistion-norse-mythology/

A continuación, Baldur es enviado por Odín, que ha descubierto a Kratos, en busca de respuestas. Padre e hijo inician el camino hacia la cima más alta guiados por Faye a través de sus señales. En el transcurso de su viaje se topan con un enano llamado Brok, quien le revela que el hacha que porta fue hecha por su hermano y conocerá a una bruja que le hará una marca de protección en el cuello de Kratos, tal como llevaban los vikingos y cuyo nombre es Aegishjalmur. El siguiente destino le lleva a justo el centro de Midgard, conocido como el lago de los nueve. Allí se encuentra con la serpiente Jörmungandr y posteriormente en la montaña con el hermano de Brok, Sindri, quien se ocupa de manifestarle que el hacha que porta es obra suya y que la creo para Faye.

El videojuego está ambientado absolutamente en la mitología nórdica. Durante la breve síntesis expuesta de la historia del juego, han aparecido nombres que tendrán gran importancia durante el desarrollo del mismo, como los de los enanos Brok y Sindri, que eran hijos de Ivald, encargados de realizar la cabellera de oro para Sif, la esposa de Thor; la lanza de Odín, Gungner; y el martillo de Thor, Mjölnir, tras los malvados actos de Loki (Niedner, 1997, pp. 56-57). Pero a lo largo de la trama también son recurrentes personajes como Magni y Modi, dos de los hijos de Thor, o Mimir, el guardían gigante del pozo de la sabiduría que se haya en una de las ramificaciones del árbol Yggdrasil, lugar donde Odín, sobrino suyo, pierde un ojo como sacrificio al beber del manantial, y que aquí aparece representado como un ser 
con cuernos y fusionado en una de las ramificaciones del Yggdrasil. Pero, a raíz de esta presentación de personajes propios de esta mitología, el verdadero encanto del juego es descubrir la identidad de otros muchos que se esconden bajo disfraces.

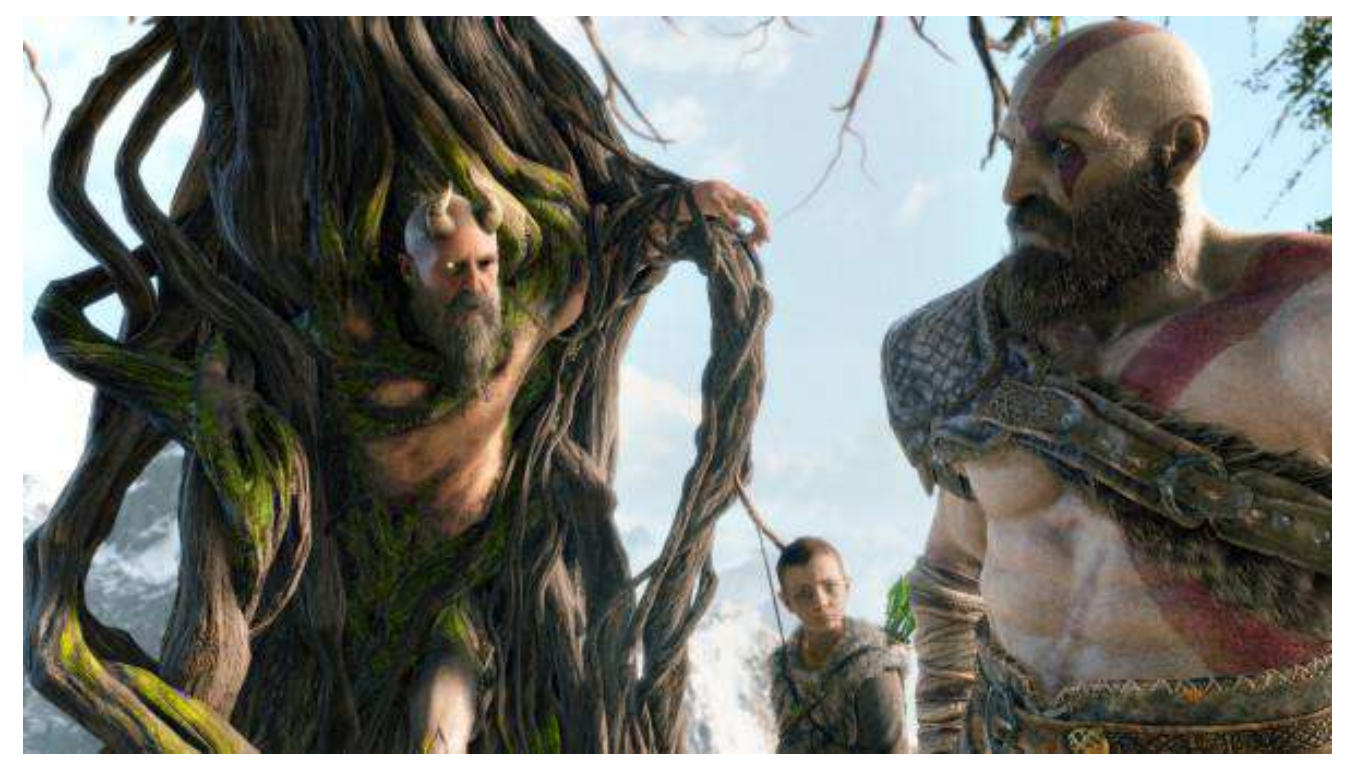

Kratos y Mimir. Fuente: https://variety.com/2018/gaming/features/god-of-war-norse-mythology-1202823019/

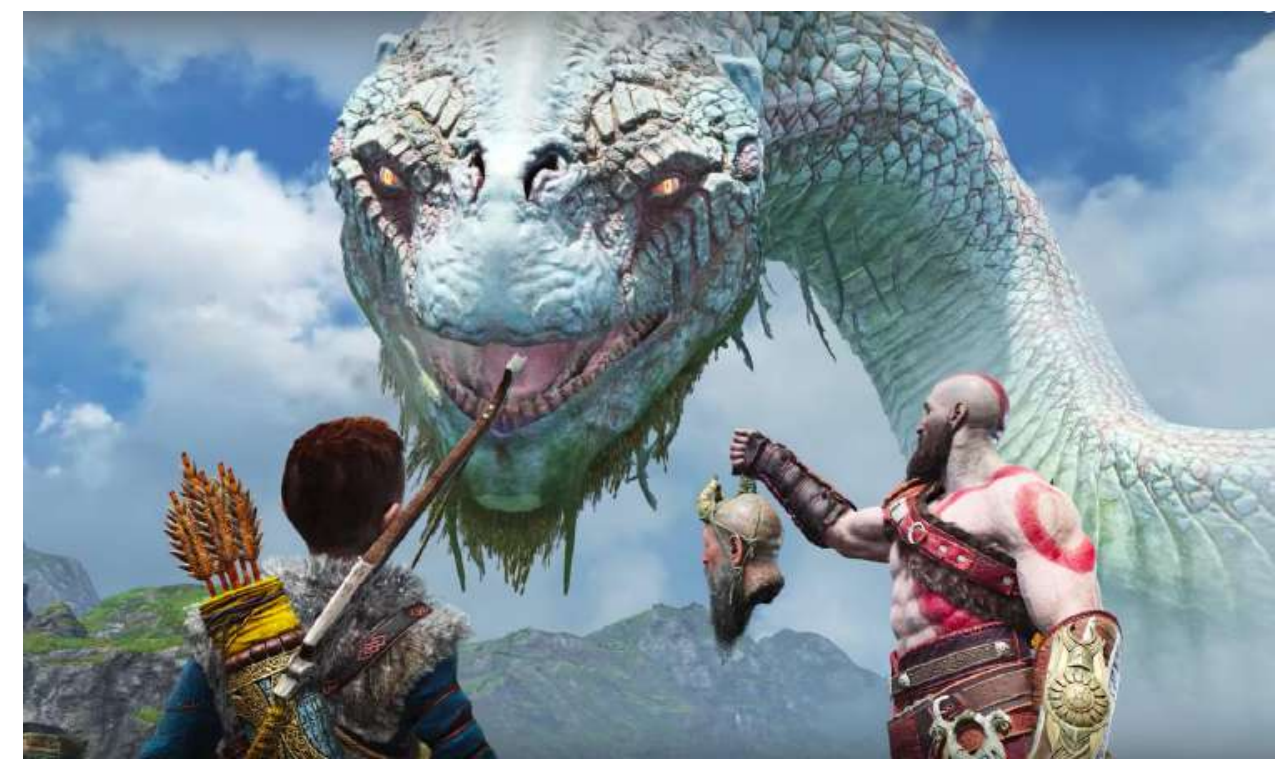

La serpiente Jörmungandr. Fuente: https://godofwar.fandom.com/wiki/J\%C3\%B6rmungandr 


\section{CONCLUSIONES.}

Como hemos podido comprobar a lo largo del desarrollo del trabajo, el mundo vikingo y su mitología ha tenido, y sigue teniendo, un papel presente dentro de los mass media, especialmente en el terreno de las artes que han sido objeto de nuestra investigación, como es el caso del cómic, series de televisión y videojuegos.

Cada uno de ellos, en su respectiva área, ha abordado esta temática desde distintos puntos de vista, con la presencia del vikingo en especial como principal centro de atención. En el cómic, unas veces ha sido directamente el protagonista central de la acción, guiado mediante una serie de aventuras, generalmente a la que el destino le ha puesto a prueba, y otras como personajes secundarios dentro de la trama. Asimismo, tanto en las series como en los videojuegos, estos, no han dado lugar a dudas de la obtención de un papel esencial en sus respectivas historias.

Un aspecto digno de comentar, y que es algo que ha aparecido durante el análisis de series particulares, es la desubicación del personaje en el propio entorno que habita, como ocurre en la primera de ellas que se ha tratado, Príncipe Valiente, donde Val, un vikingo, acaba en Inglaterra sirviendo en la corte del rey Arturo. También ocurre el caso contrario, en el que un extranjero, es acogido y convive con vikingos tal como sucede en la historia de Thorgal, o en la de Siegfried, que vive alejado en un bosque rodeado de fieras y sin nadie de su especie.

Un aspecto fundamental que ha aparecido en el trabajo, es el relacionado con la investigación o la propia carencia de ella, que es lo que ha determinado hasta qué punto se ha sido consecuente y cuidadoso con los hechos históricos asociados al pueblo vikingo. Es por ello que es fácil descubrir aquellas en las que por centrarse más bien en la aventura, han acabado despreocupándose en indagar su historia, con la consecuente distorsión estereotipada de la imagen del guerrero norteño. Sirviéndonos de ejemplo tenemos la obra de Harold Foster, donde el vikingo aparece representado portando cascos con cuernos y plumas, al igual que en la serie de Vickie el vikingo, o en el videojuego, The Lost Vikings. En otras directamente, en referencia al cómic de Jean-Yves Mitton, son presentados respecto a su 
comportamiento, peores que animales sin ningún tipo de código ético ni moral, los cuales tienen como único objetivo saciarse de sangre y arrasar con todo.

En otras ocasiones, los personajes se ven forzados a usar la violencia para sobrevivir, o proteger a sus más allegados, hecho que acontece en series como la de Thorgal, donde el mismo guerrero no quiere involucrarse en las actitudes de sus congéneres, pero que igualmente no dudará en sacar la espada cuando esté en juego la vida de su mujer e hijo. Otros, en cambio, sufren reveses en la vida, que hace que nunca se agote su sed de venganza, representado en la figura de Thorfinn; así como el protagonista de The Last Kingdon, Uhtred, que ansía en recuperar el legado que le corresponde por derecho, o los personajes de los videojuegos, Kratos y Senua.

A raíz de la fidelidad histórica y su aproximación sobre este valor en mayor o menor grado, y siguiendo en la línea del cómic, se ha llegado a una aproximación del valor real que tienen dibujantes a las obras, un proceso en el que como hemos llegado a ver es muy complejo, porque no solo está en la capacidad técnica propia del dibujante, sino que a ella hay que añadirle un contexto, es decir, la persona que está detrás de la pluma o el pincel, se ha documentado e incluso ha llegado a explorar las localizaciones para conseguir un mayor realismo.

Sin embargo, aunque el tratamiento de la cultura nórdica en el cómic es muy extenso, tal y como se ha apreciado, se advierte que el medio de comunicación de masas contemporáneo que más apuesta en dicho subgénero, es el correspondiente a las series de televisión. En este aspecto, hemos podido observar, que cada una de ellas la retrata desde perspectivas diferentes, empezando por la más aclamada, Vikings, la más fiel en lo que se refiere al contexto histórico de la cultura vikinga, aunque no exenta de elementos surgidos desde la ficción; en The Last Kingdom, se recoge un momento histórico en el que estuvieron implicados los vikingos cuando los daneses ocuparon los reinos anglosajones, para dar cuerpo a la historia de Uhtred; Norsemen, se sirve de las antiguas costumbres de los nórdicos para criticar e ironizar sobre aspectos de la sociedad que hoy día siguen intactos; o la más actual de ellas, Ragnarök, que utiliza exclusivamente la mitología nórdica para concienciar acerca de las terribles consecuencias producidas por un elemento tan actual en nuestra sociedad como es el cambio climático; sin olvidarse, por último, de Vickie el vikingo, que fue la serie pionera 
en tratar el mundo vikingo desde un cierto rigor histórico, utilizando la figura del vikingo para dar un sentido didáctico.

Siguiendo en esta misma línea, al igual que en las series televisivas, los videojuegos siguen incorporando dicha temática. Pero el proceso tal como se ha estudiado, ha ido evolucionando en el tiempo, pues desde un principio, poniendo como ejemplo al primero que ha formado parte del análisis, The Lost Vikings, no nos ofrece apenas detalles de su cultura, sino que básicamente se utiliza al vikingo para encajarlo dentro del género de plataformas. Por el contrario, todos aquellos que han surgido durante las dos últimas décadas, comenzando especialmente por Rune, han integrado en sus tramas de un modo más profundo la mitología nórdica, e incluso llegando a cambiar su discurso narrativo, como el caso de la saga God of War, que se aleja de la mitología griega con la que se concibió para dar paso a la nórdica, o que en un caso especial, como lo es el del nuestra protagonista Senua de Hellblade: Senua's Sacrifice, ha servido para desarrollar escenarios que forman parte del imaginario de un personaje que sufre de la enfermedad anteriormente referenciada, y a la misma vez para sensibilizar sobre este aspecto.

Lo que es ineludible, más allá de todas estas cuestiones, es que la temática vikinga y su mitología no dejan de cesar en su interés tal como hemos podido comprobar con los títulos que han formado parte de este análisis. No obstante, queda la incógnita y es fácil hacerse la pregunta de cuál es el motivo real de esta fascinación, o la razón del porqué la hace tan atractiva, y es que desde mi punto de vista, la clave está, no solo en su innegable capacidad para entretener, sino más bien afirmaría que la causa principal, se encuentra en el correcto tratamiento y respeto que se les está dedicando últimamente a los vikingos y sus creencias, desmarcándose de la historia negra repleta de falsas afirmaciones con la que se le venía atribuyendo debido a su casi inexistente estudio. 


\section{BIBLIOGRAFÍA Y WEBgRAFÍA.}

\subsection{Bibliografía.}

- Alary, V. (2002) Historietas comics y tebeos españoles. Toulouse: Le Mirail, Presses Universitaires.

- $\quad$ Alice, A. (2008) Siegfried. Norma Editorial.

- Barreiro, S. y Birro, R. (2017) El mundo nórdico medieval: una introducción. Sociedad Argentina de Estudios Medievales.

- Beltrán, L. (2015) “Análisis histórico de la serie Vikingos de History Channel”. Los Vikingos en la Historia, 2. pp.25-72.

- Bernárdez. E. (1984) Sagas Islandesas. Traduccion, Introduccion y Notas De Enrique Bernárdez. Barcelona: Espasa-Calpe.

- Bernárdez, E. (1984) Saga de Egil Skallagrimsson. Madrid: Editora Nacional.

- Borges, J. L. y Vázquez, E. (1966) Literaturas germánicas medievales. Buenos Aires: Falbo.

- Coipel, O. (2015) Thor: Tales of Asgard by Stan Lee and Jack Kirby. Limited Edition. Giclee.

- Coma, J. (1983) Historia de los Comics. Barcelona: Toutain Editor.

- Donstrup, M. (2017) "Vikings: poder e identidades culturales en la serie de History Channel. Revista de comunicación, (17), 1, pp. 57-73.

- Foster, H. (2011) Príncipe Valiente. Planeta DeAgostini.

- García, S. y Rubín. D. (2013) Beowulf. Astiberri. 
- Gonçalves, C. y Guimarães, E. (2018) "Eduardo Teixeira Coelho”. Mestres das Histórias em Quadrinhos, (2), pp. 1-20.

- Holler, A. (2016) "Temas de identidad infantil en una animación vikinga: Vicky el vikingo desde la perspectiva infantil”. programa de investigación, (29), pp. 38-41.

- Ibáñez Lluch, S. (1995) La saga de los Ynglingos. Valencia: Tilde.

- Khoury, G. (2004) True Brit: A Celebration of the Great Comic Book Artists of the UK. TwoMorrows Publishing.

- $\quad$ Lee, S. y Mair, G. (2002) Excelsior! The Amazing Life of Stan Lee. Simon and Schuster.

- Lerate, L. (1984) Edda menor (Edda prosaica o de Snorri). Madrid: Alianza Editorial.

- Logan, F. (2014) Los vikingos en la historia. Fondo de Cultura Económica.

- Martínez-Conde, J. (1994) "Harold Foster: príncipe de la aventura en el reino de la fantasía", Peonza: Revista de literatura infantil y juvenil, (30), pp. 21-29.

- Mitton, J. (2015) Crónicas Bárbaras. Yermo Ediciones.

- Murray, A. y Borrego, C. (2013) Quién es quién en la mitología. Edimat Libros.

- Niedner, H. (1997) Mitología nórdica. Edicomunicación.

- Pálsson, H. (1995) "El más grande poema del norte pagano Volüspá, "La profecía de la Sibila”, Acta Poética, 16 (1-2), pp. 37-54.

- Segarra García, M (2015) "La narrativa de Harold Foster: más allá de la grandeza del ilustrador". Cuco, Cuadernos de cómic, (4), pp. 35-58.

- $\quad$ Thomas, R. y Fingeroth, D. (2011) The Stan Lee Universe. TwoMorrows Publishing.

- Van Hamme, J. (2019) Thorgal. Norma Editorial.

- Vázquez de Parga, S. (1983) Cuando el Comic es nostalgia. Barcelona: Toutain Editor. 
- Velasco, M. (2012) Breve historia de los vikingos (versión extendida). Ediciones Nowtilus.

- Wood, B. (2007) Northlanders. Vertigo (DC Comics).

- Yukimura, M. (2005) Vinland Saga. Kōdansha (Magazine Afternoon).

\subsection{Webgrafía.}

- Álvarez, A. (2016) Crónicas Bárbaras, el último vikingo: la furia de los vikingos.

Disponible en:

https://www.tebeosfera.com/numeros/cronicas barbaras 2015 yermo 2. html

(Consultado 26/08/2020)

- Balsas, A. (2019) Un viaje por la mitología de 'God of War' (Parte Uno). Disponible en: https://cineverso.es/un-viaje-por-la-mitologia-de-god-of-war-parte-uno/ (Consultado $25 / 08 / 2020)$

- Belmonte, F. (2002) Thorgal. Primera época, (7). Disponible en: https://www.tebeosfera.com/1/Obra/Tebeo/Norma/Thorgal.htm (Consultado 27/07/2020)

- Belmonte, F. (2010) Thorgal (Les Fils des Orages). Disponible en: https://www.tebeosfera.com/sagas/thorgal_1977_van_hamme_rosinski.html (Consultado 06/08/2020)

- Blanc, W. (2017) Interview de Grzegorz Rosinski. Disponible en: https://www.2dgalleries.com/articles/interview-de-grzegorz-rosinski-55 (Consultado 27/07/2020)

- Bouzo, O. (2016) De The Lost Vikings hasta Warcraft: así era Silicon \& Synapse antes de convertirse en Blizzard, Disponible en: https://www.vidaextra.com/industria/de-the-lost- 
vikings-hasta-warcraft-asi-era-silicon-synapse-antes-de-convertirse-en-blizzard (Consultado 25/08/2020)

- Cardona, T. (2019) Thorgal. Integral 01. Disponible en: https://www.zonanegativa.com/thorgal-integral-01/ (Consultado 27/07/2020)

- Cepriá, F. (2008) Hans Georg Kresse. Disponible en: https://www.tebeosfera.com/autores/kresse_hans_georg.html: (Consultado 26/08/2020)

- Chabannes, J-S. (2018) Jean-Yves Mitton ("Vae Victis / Chroniques Barbares / Alwida"): " Dessiner est à chaque fois une récréation et une recréation ». Disponible en: https://www.actuabd.com/Jean-Yves-Mitton-Vae-Victis-Chroniques-Barbares-AlwidaDessiner-est-a-chaque (Consultado 07/08/2020)

- Cruz, I. (2014) 'Vikings', basada en hechos ¿reales? Disponible en: https://serielizados.com/vikings-basada-en-hechos-reales-serie-vikingos-canal-historyserielizados/ (Consultado 19/08/2020)

- Don Lawrence (2005). Disponible en: https://www.lambiek.net/artists/l/lawrence.htm (Consultado 27/07/2020)

- Galonce, J (2017) Crítica: 'The Last Kingdom', el nacimiento de una nación. Disponible en: https://fueradeseries.com/hola-me-llamo-uhtred-de-bebbanburg-t\%C3\%BA-mataste-ami-padre-prep\%C3\%A1rate-a-morir-10d9a31aa407 (Consultado 21/08/2020)

- Galonce, J (2017) Crítica: 'Norsemen', una parodia de vikingos entre los Monty Python y Astérix. Disponible en: https://fueradeseries.com/critica-norsemen-una-parodia-devikingos-entre-los-monty-python-y-asterix-7d33f3a1750f (Consultado 30/08/2020)

- García, J. (2016) El Hit de Ayer: The Lost Vikings. Disponible en: https://es.ign.com/thelost-vikings-pc/103137/feature/el-hit-de-ayer-the-lost-vikings (Consultado 22/08/2020)

- García, A. (2018) La historia del legendario Ragnar Lodbrok. Disponible en: https://archivoshistoria.com/la-historia-de-ragnar-lodbrok/ (Consultado 19/08/2020) 
- Govea, A. (2020) La travesía de la heroína en Hellblade: Senua's Sacrifice (2017). Disponible en: https://inexistente.org/2020/05/08/la-travesia-de-la-heroina-en-hellbladesenuas-sacrifice-2017/ (Consultado 27/08/2020)

- Knudde, K. (2006) Hans G. Kresse. Disponible en:

https://web.archive.org/web/20200724115014/https://www.lambiek.net/artists/k/kresse.ht $\underline{m}$ (Consultado 27/07/2020)

- Larrinaga, M. (2019) Análisis histórico de la serie Vikingos I: Reinos Escandinavos y la dinastía de Ragnar Lodbrok. Disponible en: https://www.revistalainterferencia.com/2019/03/28/analisis-historico-de-la-serie-vikingosp1-reinos-escandinavos-y-la-dinastia-de-ragnar-lodbrok-mikel-larrinaga/ (Consultado $19 / 08 / 2020)$

- Martínez-Pinna, E. (2003) Hal Foster y El Príncipe Valiente. Comentarios apasionados. Primera época (11) Disponible en: www.tebeosfera.com/1/Documento/Articulo/Clasicos/Foster/PrincipeValiente.htm. (Consultado 27/07/2020)

- Martínez, A. (2016) Reseñas desde Star City: Crónicas Bárbaras La furia de los vikingos. Disponible en: http://www.eslahoradelastortas.com/resenas-desde-star-city-cronicasbarbaras-la-furia-los-vikingos/ (Consultado 07/08/2020)

- Mejino, L y Cascajosa (2018) Norsemen. Disponible en: https://serielistas.lasexta.com/norsemen/ (Consultado 30/08/2020)

- Mendryk, H. (2007) The Early Sandman. Disponible en: https://kirbymuseum.org/blogs/simonandkirby/archives/1089 (Consultado 13/08/2020)

- Molina, J. R. (2015) ¿Otra de Vikingos? Sí: «The Last Kingdom». Disponible en: https://www.rirca.es/otra-de-vikingos-si-the-last-kingdom/ (Consultado 21/08/2020)

- Montes, J (2016) Al infierno con los vikingos. Disponible en: https://www.alfabetajuega.com/avance/hellblade-senuas-sacrifice-al-infierno-con-losvikingos-n-2601 (Consultado 27/08/2020) 
- Morillo, V (2018) 'Ragnarok', la nueva serie del creador de 'Borgen', se verá a nivel mundial en Netflix. Disponible en: https://fueradeseries.com/ragnarok-nueva-seriecreador-borgen-adam-price-netflix-3ece8b545c01 (Consultado 22/08/2020)

- Olivera, A. (2010) Thorgal, un héroe diferente. Disponible en: https://www.tebeosfera.com/documentos/thorgal_un_heroe_diferente.html (Consultado $7 / 08 / 2020)$

- Pardo, J. (2012) Vinland Saga. Disponible en: https://www.zonanegativa.com/vinlandsaga/ (Consultado 09/08/2020)

- Penélope, E. (2015) ¿Te acuerdas de Vickie el Vikingo? Disponible en: http://www.minigranada.com/te-acuerdas-de-vickie-el-vikingo/\#comments (Consultado $13 / 08 / 2020)$

- Pérez, C. (2020) God of War: Os contamos la historia de Kratos, una leyenda de los videojuegos. Disponible en: https://vandal.elespanol.com/noticia/1350732261/god-of-waros-contamos-la-historia-de-kratos-una-leyenda-de-los-videojuegos/ (Consultado $25 / 08 / 2020)$

- Personal de Gamespot (2006). Rune Q\&A: We sit down and talk with lead designer Tim Gerritsen about this high fantasy action game. Disponible en: https://www.gamespot.com/articles/rune-qanda/1100-2638613/ (Consultado 27/08/2020)

- Pozo, D. (2020) Del Thor de Marvel a la serie 'Ragnarök' de Netflix: la reinvención de la mitología nórdica. Disponible en: https://hipertextual.com/2020/04/thor-marvel-serieragnarok-netflix-reinvencion-mitologia-nordica (Consultado 22/08/2020)

- Robles, M. (2018) Vikings: ¿Cómo eran las mujeres guerreras en la sociedad vikinga real? Disponible en: https://www.filo.news/actualidad/Vikings-Como-eran-las-mujeresguerreras-en-la-sociedad-vikinga-real-20181128-0061.html (Consultado 19/08/2020)

- Rodríguez Humanes, J. M. y Barrero, M. (2008) Erik el hombre del norte. Disponible en: https://www.tebeosfera.com/colecciones/erik. el hombre del norte 1952 hispano ameri cana.html (Consultado 26/08/2020) 
- Rosa, O. (2001) 89. Journey into Mystery \#97. Disponible en: https://excelsior.universomarvel.com/era marvel/era jim1097.html (Consultado $13 / 08 / 2020)$

- Rouse, R. (2000) Rune: If ale gives you health it has to be a good game, right? Disponible en: https://www.ign.com/articles/2000/10/05/rune-2 (Consultado 27/08/2020)

- Rubio, J. (2018) Desentrañando God of War y el próximo viaje de Kratos. Disponible en: https://vandal.elespanol.com/reportaje/desentranando-god-of-war-y-el-proximo-viaje-dekratos (Consultado 25/08/2020)

- Sedano, J. (2013) Beowulf, de Santiago García y David Rubín. Disponible en: https://www.lacasadeel.net/2013/12/beowulf-de-santiago-garcia-y-david-rubin.html (Consultado 06/09/2020)

- Serrano, J.A. (2012) David Rubín. Disponible en: http://www.guiadelcomic.es/r/davidrubin.htm (Consultado 06/09/2020)

- Serrano, J.A. (2013) Santiago García (guionista). Disponible en: http://www.guiadelcomic.es/g/santiago-garcia.htm (Consultado 06/09/2020)

- Serrano, D. (2014) BEOWULF, de Santiago García y David Rubín. Disponible en https://www.zonazhero.es/beowulf-de-santiago-garcia-y-david-rubin/ IConsultado 06/09/2020)

- Such, M. (2017) 'Vikingos' es más fiel a la historia de lo que pensamos. Disponible en: https://fueradeseries.com/vikings-es-m\%C3\%A1s-fiel-a-la-historia-de-lo-que-pensamosf8a47f8f4a6e (Consultado 19/08/2020)

- Torralba, J. y Martín, R. (2009) Northlanders: El regreso de Sven. Disponible en: https://www.zonanegativa.com/northlanders-el-regreso-de-sven/ (Consultado 15/08/2020)

- Ugartondo, A. (2015) Siegfried. Disponible en: https://www.zonanegativa.com/siegfried/ (Consultado 09/08/2020)

- Zondergeld, G.R. (2013) Kresse, Hans Georg (1921-1992). Disponible en: https://web.archive.org/web/20160817062747/http://resources.huygens.knaw.nl/bwn18802000/lemmata/bwn5/kresse (Consultado 27/07/2020) 